\title{
Stroop Color-Word Interference Test: Normative data for the Latin American Spanish speaking adult population
}

\author{
D. Rivera ${ }^{\mathrm{a}}$, P.B. Perrin ${ }^{\mathrm{b}}$, L.F. Stevens ${ }^{\mathrm{c}}$, M.T. Garza ${ }^{\mathrm{d}}$, C. Weil ${ }^{\mathrm{e}}$, C.P. Saracho ${ }^{\mathrm{f}}$, W. Rodríguez ${ }^{\mathrm{g}}$, \\ Y. Rodríguez-Agudelo ${ }^{\mathrm{h}}$, B. Rábago ${ }^{\mathrm{i}}, \mathrm{G}$. Weiler ${ }^{\mathrm{j}}$, C. García de la Cadena ${ }^{\mathrm{k}}$, M. Longoni ${ }^{\mathrm{l}}$, \\ C. Martínez ${ }^{\mathrm{m}}$, N. Ocampo-Barba ${ }^{\mathrm{n}}$, A. Aliaga ${ }^{\mathrm{o}}$, J. Galarza-del-Angel $^{\mathrm{p}}$, A. Guerra $^{\mathrm{q}}$, \\ L. Esenarro ${ }^{\mathrm{r}}$ and J.C. Arango-Lasprilla ${ }^{\mathrm{s}, \mathrm{a}, *}$ \\ ${ }^{a}$ Faculty of Psychology and Education, University of Deusto, Bilbao, Spain \\ ${ }^{\mathrm{b}}$ Department of Psychology, Virginia Commonwealth University, Richmond, USA \\ ${ }^{\mathrm{c}}$ Hunter Holmes McGuire Department of Veterans Affairs Medical Center, Richmond, VA, USA \\ ${ }^{\mathrm{d}}$ Facultad de Psicología Universidad Autónoma de Nuevo León, Monterrey, Mexico \\ ${ }^{\mathrm{e}}$ Universidad Dr. José Matías Delgado, San Salvador, El Salvador \\ ${ }^{\mathrm{f}}$ CETYS Universidad, Mexicali, Mexico \\ ${ }^{\mathrm{g}}$ Ponce Health Sciences University, Ponce, Puerto Rico \\ ${ }^{\mathrm{h}}$ Instituto Nacional de Neurología y Neurocirugía MVS, Mexico City, Mexico \\ i Instituto Vocacional Enrique Díaz de León, Guadalajara, Mexico \\ $\mathrm{j}$ Instituto de Prevención Social, Asuncion, Paraguay \\ ${ }^{\mathrm{k}}$ Departamento de Psicología, Universidad del Valle de Guatemala, Guatemala City, Guatemala \\ ${ }^{1}$ Clínica de rehabilitación Las Araucarias, Buenos Aires, Argentina \\ ${ }^{\mathrm{m}}$ Departamento de Medicina de Rehabilitación, Universidad Nacional Autónoma de Honduras, \\ Tegucigalpa, Honduras \\ ${ }^{\mathrm{n}}$ Fundación Horizontes, Santa Cruz de la Sierra, Bolivia \\ ${ }^{\circ}$ Servicio Médico Legal, Ministerio de Justicia, Santiago, Chile \\ ${ }^{\mathrm{p}}$ Universidad Autónoma de Baja California, Mexicali, Mexico \\ ${ }^{\mathrm{q}}$ Departamento de Psicología, Universidad de Camagüey Ignacio Agramonte Loynaz, Camaguey, Cuba \\ ${ }^{\mathrm{r}}$ Instituto de Neuropsicología y Demencias, Lima, Peru \\ ${ }^{\mathrm{s}}$ IKERBASQUE, Basque Foundation for Science, Bilbao, Spain
}

\begin{abstract}
.
OBJECTIVE: To generate normative data on the Stroop Test across 11 countries in Latin America, with country-specific adjustments for gender, age, and education, where appropriate.

METHOD: The sample consisted of 3,977 healthy adults who were recruited from Argentina, Bolivia, Chile, Cuba, El Salvador, Guatemala, Honduras, Mexico, Paraguay, Peru, and, Puerto Rico. Each subject was administered the Stroop Test, as part of a larger neuropsychological battery. A standardized five-step statistical procedure was used to generate the norms.
\end{abstract}

*Address for correspondence: Juan Carlos Arango-Lasprilla, Ph.D., IKERBASQUE Research Professor, Department of Psychology, University of Deusto, IKERBASQUE, Basque Foundation for
Science, Bilbao, Spain. Tel.: +34 804859 4329; E-mail: jcarango@ deusto.es. 
RESULTS: The final multiple linear regression models explained $14-36 \%$ of the variance in Stroop Word scores, $12-41 \%$ of the variance in the Stoop Color, 14-36\% of the variance in the Stroop Word-Color scores, and 4-15\% of the variance in Stroop Interference scores. Although $t$-tests showed significant differences between men and women on the Stroop test, none of the countries had an effect size larger than 0.3. As a result, gender-adjusted norms were not generated.

CONCLUSIONS: This is the first normative multicenter study conducted in Latin America to create norms for the Stoop Test in a Spanish-Speaking sample. This study will therefore have important implications for the future of neuropsychology research and practice throughout the region.

Keywords: Normative data, Stroop Color-Word Interference Test, reference values, Latin America, selective attention, executive function

\section{Introduction}

The Stroop Test is an executive functioning measure of selective attention, cognitive flexibility, cognitive inhibition, and information processing speed (Bryan \& Luszcz, 2000; Rosselli et al., 2002; Strauss, Sherman, \& Spreen, 2006; Van der Elst, Van Boxtel, Van Breukelen, \& Jolles, 2006). The test was originally developed by John Ridley Stoop in 1935, and since then several versions of the Stroop Test have been created and are commercially available (Strauss et al., 2006), including the Victoria version (Regard, 1981), the Comalli version (Comalli, Wapner, \& Werner, 1962), and the Golden version (Golden, 1978; Golden \& Freshwater, 2002). Stroop tasks are also included in the Delis-Kaplan Executive Function System (Delis, Kaplan, \& Kramer, 2001) and the Cognitive Assessment System (Naglieri \& Das, 1997) batteries (Strauss et al., 2006). These different versions tend to vary on number of items, number of colors used, and use of colored patches/dots vs. colored X's (Strauss et al., 2006).

Various psychological mechanisms have been found to underlie the Stroop task, including information processing speed, working memory, semantic activation, and the ability to strengthen one response characteristic (Strauss et al., 2006). Areas of the brain involved in this task include the inferior frontal, dorsolateral prefrontal, and anterior cingulated cortices (Egner \& Hirsch, 2005; Harrison et al., 2005; Peterson et al., 1999). Increased Stroop interference has been observed in a variety of patient illness groups believed to have executive dysfunction (for full review see Strauss et al., 2006), including schizophrenia (Moritz, Birkner, \& Kloss, 2002), Parkinson's disease (Hanes, Andrewes, Smith, \& Pantelis, 1996), Huntington's disease (Snowden, Craufurd, Griffiths, Thompson, \& Neary, 2001), Friedreich's ataxia (White, Lalonde, \& Boetz-Marquard, 2000), prenatal exposure to alcohol (Connor, Sampson, Bookstein, Barr, \& Streissguth, 2000), chronic alcoholism (Dao-Castellana et al., 1998), Human Immunodeficiency Virus (HIV) infection (Castellon, Hinkin, \&
Myers, 2000), benign focal childhood epilepsy (Chevalier, Metz-Lutz, \& Segalowitz, 2000), Attention Deficit Hyperactivity Disorder (ADHD; Homack \& Riccio, 2004), and Alzheimer disease (Bondi et al., 2002). Increased interference can be observed among individuals with head injury when utilizing a more challenging version of the Stroop task (Bohnen, Jolles, Twijnstra, 1992).

Several demographic variables have also been shown to be associated with Stroop scores (see Strauss et al., 2006; Peña-Casanova et al., 2009 for reviews). Generally, studies indicate that aging is associated with slower speed of color naming and increased interference (e.g., Moering, Schinka, Mortimer, \& Graves, 2004); women tend to do better on color-naming but gender differences are equivocal for interference (Strauss et al., 2006); education has a modest relation to interference (e.g., Steinberg, Bieliauskas, Smith, \& Ivnik, 2005), and members of minority race/ethnicity perform more poorly than Caucasians (Moering et al., 2004; Rosselli et al., 2002).

Many studies provide normative data for the Golden version of the Stroop. The standardization sample was originally based on individuals aged 15-90 years, but sample characteristics were not clearly described (Strauss et al., 2006). Normative data also exist from a sample of 356 community-dwelling, independentlyfunctioning Caucasian individuals over the age of 55 (Ivnik, Malec, Smith, \& Tangalos, 1996) and a sample of 303 community-dwelling African American individuals aged 56-94 years (Lucas et al., 2005). Tables for both of these normative samples are provided by Strauss and colleagues as well (2006). Moering and colleagues (2004) also provide normative data for 236 African Americans aged 60-84 years. Metanorms based on a compilation of six datasets are also provided for the interference condition only, by Mitrushina, Boone, Razani and D'Elia, (2005).

Several studies also provide normative data for the different languages in which the Stroop has been translated, such as for the Italian (Barbarotto et al., 
1998), Hebrew (Ingraham, Chard, Wood, \& Mirsky, 1988), Korean (Seol et al., 2008), and Greek (Zalonis et al., 2009) versions. Normative data also exist for the Spanish version of the Stroop for residents of the Madrid region of Spain and Spanish-speakers from the US-Mexico border (Artiola, Hermosillo, Heaton, \& Pardee, 1999); older Catalan adults in Spain (LlinásReglá, Vilalta-Franch, López-Pousa, Calvó-Perxas, \& Garre-Olmo, 2013); a group of English monolinguals, Spanish-English bilinguals, and Spanish monolinguals in Florida (Rosselli et al., 2002); and monolingual Latino men (Lopez, Salazar, Villaseñor, Saucedo, \& Peña, 2003). Peña-Casanova and colleagues (2009) also published age and education adjusted Stroop norms on community-dwelling Spaniards, aged 50-90 years.

Although there are many normative studies for the Stroop test that focus on various European and Asian countries, there are no normative data for Latin American countries. Therefore, the purpose of the current study was to provide normative data on the Stroop Test across 11 countries in Latin America, with countryspecific adjustments for gender, age, and education, where appropriate.

\section{Method}

\subsection{Participants}

The sample consisted of 3,977 healthy individuals who were recruited from Argentina, Bolivia, Chile, Cuba, El Salvador, Guatemala, Honduras, Mexico, Paraguay, Peru, and, Puerto Rico. The participants were selected according to the following criteria: a) were between 18 to 95 years of age, b) were born and currently lived in the country where the protocol was conducted, c) spoke Spanish as their native language, d) had completed at least one year of formal education, e) were able to read and write at the time of evaluation, f) scored $\geq 23$ on the Mini-Mental State Examination (MMSE, Folstein, Folstein, \& McHugh, 1975), g) scored $\leq 4$ on the Patient Health Questionnaire-9 (PHQ-9, Kroenke, Spitzer, \& Williams, 2001), and h) scored $\geq 90$ on the Barthel Index (Mahoney \& Barthel, 1965).

Participants with self-reported neurologic or psychiatric disorders were excluded due to a potential effect on cognitive performance. Participants were volunteers from the community and signed an informed consent. 62 participants were excluded from the analyses, with a final sample of 3915 participants.
Socio-demographic and participant characteristics for each of the countries' samples have been reported elsewhere (Guàrdia-Olmos, Peró-Cebollero, Rivera, \& Arango-Lasprilla, 2015). The multi-center study was approved by the Ethics Committee of the coordinating site, the University of Deusto, Spain.

\subsection{Instrument administration}

The Stroop Color and Word test consists of three pages, each with 100 components randomly organized into five columns. The subject has 45 seconds to read aloud, as quickly as possible, the columns from left to right. The sheet on words is formed by the words "Red," "Green," and "Blue" in black ink, and the score is the number of words read correctly. For the sheet on colors, there are groups of four X's ("XXXX") printed in blue, green, and red. The score is the number of elements properly named. Finally, the last list consists of the three words of the first printed page in the colors of the second, with words being incongruent with the color of the ink. The task is to name the ink color, inhibiting the reading of the word, and the score is the number of correctly named elements. Finally, an Interference Index is calculated with the formula: $\mathrm{WC}-[(\mathrm{WxC}) /$ $(P+\mathrm{W})]$, and indicates the degree to which the person has control over interference (Golden, 2007).

\subsection{Statistical analyses}

The detailed statistical analyses used to generate the normative data for this test are described in GuàrdiaOlmos et al. (2015). In summary, the data manipulation process for each country-specific dataset involved fivesteps: a) $t$ - tests for independent samples and effect sizes $(r)$ were conducted to determine gender effects. If the effect size was larger than 0.3 , gender was included in the model with gender dummy coded and female as the reference group $($ male $=1$ and female $=0)$. b) A multivariate regression model was used to specify the predictive model including gender (if effect size was larger than 0.3), age as a continuous variable, and education as a dummy coded variable with 1 if the participants had $>12$ years of education and 0 if participants had 1-12 years of education. If gender, age and/or education was not statistically significant in this multivariate model with an alpha of 0.05 , the non-significant variables were removed and the model was re-run. Then a final regression model was conducted that included age (if statistically significant in the multivariate model), dichotomized 
Table 1

Effect of gender in the Stroop-Word

\begin{tabular}{|c|c|c|c|c|c|c|}
\hline Country & Gender & Mean (SD) & $t$ & df & Sig. (2-tailed) & $r$ \\
\hline \multirow[t]{2}{*}{ Argentina $^{\mathrm{a}}$} & Male & $94.5(18.1)$ & -0.93 & 145.1 & 0.355 & 0.077 \\
\hline & Female & $96.5(14.2)$ & & & & \\
\hline \multirow[t]{2}{*}{ Bolivia } & Male & $69.6(26.4)$ & -0.24 & 264 & 0.813 & 0.015 \\
\hline & Female & $70.4(27.7)$ & & & & \\
\hline \multirow[t]{2}{*}{ Chile } & Male & $79.1(24.4)$ & 0.09 & 313 & 0.931 & 0.005 \\
\hline & Female & $78.9(23.5)$ & & & & \\
\hline \multirow[t]{2}{*}{ Cuba } & Male & $83.5(24.4)$ & -1.12 & 297 & 0.264 & 0.065 \\
\hline & Female & $86.6(23.8)$ & & & & \\
\hline \multirow[t]{2}{*}{ El Salvador ${ }^{\mathrm{a}}$} & Male & $70.8(26.7)$ & 0.61 & 169.4 & 0.540 & 0.047 \\
\hline & Female & $68.8(22.0)$ & & & & \\
\hline \multirow[t]{2}{*}{ Guatemala } & Male & $81.9(22.9)$ & -0.88 & 206 & 0.382 & 0.061 \\
\hline & Female & $84.6(21.3)$ & & & & \\
\hline \multirow[t]{2}{*}{ Honduras } & Male & $73.3(25.4)$ & 3.27 & 181 & $0.001^{* *}$ & 0.236 \\
\hline & Female & $60.9(24.4)$ & & & & \\
\hline \multirow[t]{2}{*}{ Mexico $^{\mathrm{a}}$} & Male & $84.9(22.9)$ & 1.35 & 796.1 & 0.178 & 0.048 \\
\hline & Female & $83.1(21.3)$ & & & & \\
\hline \multirow[t]{2}{*}{ Paraguay } & Male & $78.1(15.6)$ & 1.69 & 261 & 0.092 & 0.104 \\
\hline & Female & $75.2(12.4)$ & & & & \\
\hline \multirow[t]{2}{*}{ Peru } & Male & 96.7 (18.2) & 2.25 & 239 & $0.025^{*}$ & 0.144 \\
\hline & Female & $90.6(21.2)$ & & & & \\
\hline \multirow[t]{2}{*}{ Puerto Rico } & Male & 86.5 (20.6) & -0.63 & 291 & 0.532 & 0.037 \\
\hline & Female & $88.1(21.1)$ & & & & \\
\hline
\end{tabular}

${ }^{a}$ Value of the $t$-test for independent groups from the different variances with the corresponding correction of Yuen-Welch of degrees of freedom. ${ }^{*} p<0.05,{ }^{* *} p<0.01$.

education (if statistically significant in the multivariate model), and/or gender (if effect size was greater than 0.3) $\left[\hat{y}_{i}=\beta_{0}+\left(\beta_{\text {Age }}\right.\right.$. Age $\left._{i}\right)+\left(\beta_{E d u c} . E d u c_{i}\right)+$ $\left(\beta_{\text {Gender }}\right.$. Gender $\left.\left.r_{i}\right)\right]$; c) residual scores were calculated based on this final model $\left(e_{i}=y_{i}-\hat{y}_{i}\right)$; d) using the SD (residual) value provided by the regression model, residuals were standardized: $z=e_{i} / S D_{e}$, with $S D_{e}$, with $S D_{e}($ residual $)=$ the standard deviation of the residuals in the normative sample; and e) standardized residuals were converted to percentile values (Strauss et al., 2006). Using each country's dataset, these steps were applied to Stroop Word, Color, Word-Color, and Interference scores. In certain countries, there was no effect of gender, nor age, nor education on the scores. In these cases, the normative data were generated directly using the raw scores.

\section{Results}

\subsection{Stroop Word}

Regarding the effect of gender on Stroop Word, the $t$-tests showed significant differences between men and women in Guatemala, and Peru; however, none of these two countries had an effect size larger than 0.3. Table 1 shows the results of the gender analyses by country on Stroop Word. As shown in Table 1, the effect sizes for all countries were less than 0.3 , and therefore gender was not taken into account to generate Stroop Word normative data for any of the countries in the study.

The final eleven Stroop Word multivariate linear regression models for each country are shown in Table 2. In all countries the Stroop Word score increased for those with more than 12 years of education (see Table 2) and, in all countries Stroop Word score decreased in a linear fashion as a function of age. The amount of variance explained in Stroop Word scores ranged from 14\% (in Argentina) to 36\% (in Chile).

\subsection{Stroop Color}

Regarding the effect of gender on Stroop Color, the $t$-tests showed significant differences between men and women in the countries of Guatemala, Honduras, and Mexico; however, none of these three countries had an effect size larger than 0.3. Table 3 shows the results of the gender analysis by country on Stroop Color. As shown in Table 1, the effect sizes for all countries were less than 0.3 , and therefore gender was not taken into account to generate Stroop Color normative data for any of the countries in the study.

The final eleven Stroop Color multivariate linear regression models for each country are shown in Table 4. In all countries, except Peru, the Stroop Color 
Table 2

Final multiple linear regression models for Stroop-Word

\begin{tabular}{|c|c|c|c|c|c|c|c|}
\hline Country & & $\mathrm{B}$ & Std. Error & $t$ & Sig. & $\mathrm{R}^{2}$ & $S D e$ (residual) \\
\hline \multirow[t]{3}{*}{ Argentina } & (Constant) & 103.486 & 2.342 & 44.183 & $<0.001$ & 0.140 & 14.344 \\
\hline & Age & -0.235 & 0.042 & -5.642 & $<0.001$ & & \\
\hline & Education & 5.908 & 1.630 & 3.626 & $<0.001$ & & \\
\hline \multirow[t]{3}{*}{ Bolivia } & (Constant) & 104.713 & 3.876 & 27.018 & $<0.001$ & 0.338 & 22.115 \\
\hline & Age & -0.662 & 0.063 & -10.530 & $<0.001$ & & \\
\hline & Education & 12.184 & 3.634 & 3.353 & $<0.001$ & & \\
\hline \multirow[t]{3}{*}{ Chile } & (Constant) & 105.001 & 3.563 & 29.466 & $<0.001$ & 0.359 & 19.091 \\
\hline & Age & -0.544 & 0.057 & -9.481 & $<0.001$ & & \\
\hline & Education & 16.139 & 2.617 & 6.168 & $<0.001$ & & \\
\hline \multirow[t]{3}{*}{ Cuba } & (Constant) & 114.730 & 3.404 & 33.703 & $<0.001$ & 0.326 & 19.770 \\
\hline & Age & -0.616 & 0.058 & -10.547 & $<0.001$ & & \\
\hline & Education & 13.756 & 2.727 & 5.044 & $<0.001$ & & \\
\hline \multirow[t]{3}{*}{ El Salvador } & (Constant) & 76.632 & 3.961 & 19.346 & $<0.001$ & 0.229 & 20.976 \\
\hline & Age & -0.220 & 0.065 & -3.386 & $<0.001$ & & \\
\hline & Education & 24.956 & 3.322 & 7.511 & $<0.001$ & & \\
\hline \multirow[t]{3}{*}{ Guatemala } & (Constant) & 99.526 & 4.526 & 21.990 & $<0.001$ & 0.203 & 19.642 \\
\hline & Age & -0.408 & 0.079 & -5.164 & $<0.001$ & & \\
\hline & Education & 14.069 & 2.820 & 4.989 & $<0.001$ & & \\
\hline \multirow[t]{3}{*}{ Honduras } & (Constant) & 88.953 & 4.637 & 19.181 & $<0.001$ & 0.324 & 20.887 \\
\hline & Age & -0.573 & 0.084 & -6.796 & $<0.001$ & & \\
\hline & Education & 17.728 & 3.714 & 4.773 & $<0.001$ & & \\
\hline \multirow[t]{3}{*}{ Mexico } & (Constant) & 107.696 & 1.535 & 70.155 & $<0.001$ & 0.267 & 18.723 \\
\hline & Age & -0.494 & 0.026 & -18.994 & $<0.001$ & & \\
\hline & Education & 9.063 & 1.269 & 7.140 & $<0.001$ & & \\
\hline \multirow[t]{3}{*}{ Paraguay } & (Constant) & 86.433 & 2.968 & 29.120 & $<0.001$ & 0.330 & 11.248 \\
\hline & Age & -0.242 & 0.051 & -4.698 & $<0.001$ & & \\
\hline & Education & 14.975 & 1.984 & 7.547 & $<0.001$ & & \\
\hline \multirow[t]{3}{*}{ Peru } & (Constant) & 104.045 & 3.333 & 31.215 & $<0.001$ & 0.266 & 17.447 \\
\hline & Age & -0.409 & 0.056 & -7.320 & $<0.001$ & & \\
\hline & Education & 10.152 & 2.406 & 4.219 & $<0.001$ & & \\
\hline \multirow[t]{3}{*}{ Puerto Rico } & (Constant) & 107.949 & 3.581 & 30.142 & $<0.001$ & 0.248 & 18.083 \\
\hline & Age & -0.473 & 0.060 & -7.945 & $<0.001$ & & \\
\hline & Education & 7.654 & 2.200 & 3.479 & $<0.001$ & & \\
\hline
\end{tabular}

score increased for those with more than 12 years of education (see Table 4) in all countries Stroop Color score decreased in a linear fashion as a function of age. The amount of variance explained in Stroop Color scores ranged from $14 \%$ (in Guatemala) to $42 \%$ (in Chile).

\subsection{Stroop Word-Color}

Regarding the effect of gender on Stroop WordColor, the $t$-tests showed significant differences between men and women in the countries of Chile, Honduras, and Mexico, however, none of these countries had an effect size larger than 0.3. Table 5 shows the results of the gender analysis by country on Stroop Word-Color. As shown in Table 5, the effect sizes for all countries were less than 0.3 , and therefore gender was not taken into account to generate Stroop Word-Color normative data for any of the countries in the study.
The final eleven Stroop Word-Color multivariate linear regression models for each country are shown in Table 6. In all countries the Stroop Word-Color score increased for those with more than 12 years of education (see Table 6) and decreased in a linear fashion as a function of age. The amount of variance explained in Stroop Word-Color scores ranged from $16 \%$ (in Guatemala) to $43 \%$ (in Chile).

\subsection{Stroop Interference}

Regarding the effect of gender on Stroop Interference, the $t$-tests showed significant differences between men and women in Chile, Cuba, Mexico, and Puerto Rico, however, none of these four countries had an effect size larger than 0.3 . Table 7 shows the results of the gender analysis by country on Stroop Interference. As shown in Table 7, the effect sizes for all countries were less than 0.3 , and therefore gender was not taken into account to generate Stroop Interference normative data for any of the countries in the study. 
Table 3

Effect of gender in the Stroop-Color

\begin{tabular}{|c|c|c|c|c|c|c|}
\hline Country & Gender & Mean (SD) & $t$ & df & Sig. (2-tailed) & $r$ \\
\hline \multirow[t]{2}{*}{ Argentina } & Male & $66.3(13.8)$ & -0.68 & 317 & 0.449 & 0.038 \\
\hline & Female & $67.5(14.6)$ & & & & \\
\hline \multirow[t]{2}{*}{ Bolivia } & Male & $52.3(21.6)$ & -0.89 & 265 & 0.373 & 0.055 \\
\hline & Female & $54.8(22.5)$ & & & & \\
\hline \multirow[t]{2}{*}{ Chile } & Male & $58.3(18.2)$ & 1.55 & 314 & 0.123 & 0.087 \\
\hline & Female & $55.2(16.5)$ & & & & \\
\hline \multirow[t]{2}{*}{ Cuba } & Male & $59.8(19.0)$ & -0.56 & 298 & 0.573 & 0.033 \\
\hline & Female & $61.1(20.3)$ & & & & \\
\hline \multirow[t]{2}{*}{ El Salvador } & Male & $52.9(20.9)$ & 1.57 & 243 & 0.119 & 0.100 \\
\hline & Female & $49.1(17.0)$ & & & & \\
\hline \multirow[t]{2}{*}{ Guatemala } & Male & $55.4(17.3)$ & -2.30 & 206 & $0.023^{*}$ & 0.158 \\
\hline & Female & $60.7(16.1)$ & & & & \\
\hline \multirow[t]{2}{*}{ Honduras } & Male & $54.6(18.2)$ & 2.72 & 181 & $0.007^{* *}$ & 0.198 \\
\hline & Female & $47.3(17.0)$ & & & & \\
\hline \multirow[t]{2}{*}{ Mexico $^{\mathrm{a}}$} & Male & $63.5(19.2)$ & 2.83 & 743.1 & $0.005^{* *}$ & 0.103 \\
\hline & Female & $60.4(16.5)$ & & & & \\
\hline \multirow[t]{2}{*}{ Paraguay } & Male & $62.6(13.7)$ & 0.60 & 261 & 0.548 & 0.037 \\
\hline & Female & $61.7(12.1)$ & & & & \\
\hline \multirow[t]{2}{*}{ Peru } & Male & $71.3(15.5)$ & 1.40 & 239 & 0.164 & 0.090 \\
\hline & Female & $68.3(15.9)$ & & & & \\
\hline \multirow[t]{2}{*}{ Puerto Rico } & Male & $61.5(15.4)$ & -1.35 & 291 & 0.179 & 0.079 \\
\hline & Female & $63.9(15.4)$ & & & & \\
\hline
\end{tabular}

${ }^{a}$ Value of the $t$-test for independent groups from the different variances with the corresponding correction of Yuen-Welch of degrees of freedom. ${ }^{*} p<0.05,{ }^{* *} p<0.01$.

The final seven Stroop Interference multivariate linear regression models for each country are shown in Table 8. El Salvador, Peru, and Puerto Rico, the Stroop Interference score increased for those with more than 12 years of education (see Table 8), and Argentina, Chile, Mexico, and Paraguay decreased in a linear fashion as a function of age. Cuba, Bolivia, Guatemala, and Honduras did not show effect to age, and education level. The amount of variance explained in Stroop Interference scores ranged from $4 \%$ (El Salvador) to $15 \%$ (in Puerto Rico).

\subsection{Normative procedure}

Norms (e.g., a percentile score) for the Stroop Word-Color test different scores were established using the five-step procedure described above. To facilitate the understanding of the procedure to obtain the percentile associated with a score on this test, an example will be given. Suppose you need to find the percentile score for a Peruvian man, who is 50 years old and has 14 years of education. He has a score of 80 on Stroop Word. The steps to obtain the percentile for this score are: a) Check Table 1 to determine if the effect size of gender in the country of interest (Peru) on this test and time point (Stroop Word) is greater than 0.3 by country. The column labelled $r$ in Table 1 indicates the effect size. In this example, the effect size is 0.144 , which is not greater than 0.3 . For Peruvian on this test, gender does not influence scores to a sufficient degree to take it into account when determining the percentile. b) Find Peru in Table 2, which provides the final regression models by country for Stroop Word scores. Use the B weights to create an equation that will allow you to obtain the predicted Stroop Word score. The corresponding B weights are multiplied by the actual age and dichotomized education scores and added to a constant in order to calculate the predicted value. In this case, the predicted Stroop Word score would be calculated using the equation $\left[\hat{y}_{i}=104.045+(-0.409\right.$. Age $\left._{i}\right)+\left(10.152 \cdot{\left.\left.\text { Dichotomized Educational } \text { Level }_{i}\right)\right]}\right.$ (the values have been rounded for presentation in the formula). The subscript notation $i$ indicate the person of interest. The person's age is 50, but the education variable is not continuous in the model. Years of education is split into either 1 to 12 years (and assigned a 0 ) or more than 12 years (and assigned a 1) in the model. Since our hypothetical person in the example has 14 years of education, his educational level value is 1 . Thus the predicted value is $\quad \hat{y}_{i}=104.045+(-0.409 \cdot 50)+(10.152 \cdot 1)=$ $104.045-20.463+10.152=93.733$. c) In order to calculate the residual value (indicated with an $e$ in the equation), we subtract the actual value from the 
Table 4

Final multiple linear regression models for Stroop-Color

\begin{tabular}{|c|c|c|c|c|c|c|c|}
\hline Country & & $\mathrm{B}$ & Std. Error & $t$ & Sig. & $\mathrm{R}^{2}$ & SDe (residual) \\
\hline \multirow[t]{3}{*}{ Argentina } & (Constant) & 74.954 & 2.094 & 35.802 & $<0.001$ & 0.202 & 12.821 \\
\hline & Age & -0.254 & 0.037 & -6.817 & $<0.001$ & & \\
\hline & Education & 7.082 & 1.457 & 4.862 & $<0.001$ & & \\
\hline \multirow[t]{3}{*}{ Bolivia } & (Constant) & 85.904 & 2.986 & 28.766 & $<0.001$ & 0.409 & 17.046 \\
\hline & Age & -0.606 & 0.048 & -12.507 & $<0.001$ & & \\
\hline & Education & 9.302 & 2.775 & 3.352 & 0.001 & & \\
\hline \multirow[t]{3}{*}{ Chile } & (Constant) & 77.268 & 2.463 & 31.372 & $<0.001$ & 0.415 & 13.195 \\
\hline & Age & -0.431 & 0.040 & -10.880 & $<0.001$ & & \\
\hline & Education & 12.053 & 1.801 & 6.693 & $<0.001$ & & \\
\hline \multirow[t]{3}{*}{ Cuba } & (Constant) & 84.940 & 2.862 & 29.676 & $<0.001$ & 0.284 & 16.655 \\
\hline & Age & -0.495 & 0.049 & -10.070 & $<0.001$ & & \\
\hline & Education & 7.793 & 2.286 & 3.409 & 0.001 & & \\
\hline \multirow[t]{3}{*}{ El Salvador } & (Constant) & 62.283 & 3.259 & 19.108 & $<0.001$ & 0.144 & 17.260 \\
\hline & Age & -0.251 & 0.054 & -4.695 & $<0.001$ & & \\
\hline & Education & 10.865 & 2.734 & 3.974 & $<0.001$ & & \\
\hline \multirow{3}{*}{ Guatemala } & (Constant) & 73.428 & 3.549 & 20.690 & $<0.001$ & 0.161 & 15.402 \\
\hline & Age & -0.335 & 0.062 & -5.413 & $<0.001$ & & \\
\hline & Education & 6.781 & 2.211 & 3.066 & 0.002 & & \\
\hline \multirow[t]{3}{*}{ Honduras } & (Constant) & 72.485 & 3.130 & 23.162 & $<0.001$ & 0.371 & 14.095 \\
\hline & Age & -0.504 & 0.057 & -8.863 & $<0.001$ & & \\
\hline & Education & 8.223 & 2.507 & 3.280 & 0.001 & & \\
\hline \multirow[t]{3}{*}{ Mexico } & (Constant) & 83.657 & 1.192 & 70.158 & $<0.001$ & 0.306 & 14.574 \\
\hline & Age & -0.444 & 0.020 & -21.997 & $<0.001$ & & \\
\hline & Education & 5.360 & 0.987 & 5.432 & $<0.001$ & & \\
\hline \multirow[t]{3}{*}{ Paraguay } & (Constant) & 70.177 & 2.892 & 24.270 & $<0.001$ & 0.254 & 10.957 \\
\hline & Age & -0.195 & 0.050 & -3.889 & $<0.001$ & & \\
\hline & Education & 12.156 & 1.933 & 6.289 & $<0.001$ & & \\
\hline \multirow[t]{2}{*}{ Peru } & (Constant) & 83.744 & 2.162 & 38.730 & $<0.001$ & 0.184 & 14.265 \\
\hline & Age & -0.329 & 0.045 & -7.350 & $<0.001$ & & \\
\hline \multirow[t]{3}{*}{ Puerto Rico } & (Constant) & 83.497 & 2.465 & 33.879 & $<0.001$ & 0.347 & 12.444 \\
\hline & Age & -0.446 & 0.041 & -10.899 & $<0.001$ & & \\
\hline & Education & 4.501 & 1.514 & 2.973 & 0.003 & & \\
\hline
\end{tabular}

predicted value we just calculated $\left(e_{i}=y_{i}-\hat{y}_{i}\right)$. In this case, it would be $e_{i}=80-93.201=-13.733$. d) Next, consult the $S D_{e}$ column in Table 2 to obtain the country-specific $S D_{e}$ (residual) value. For Mexico it is 17.477. Using this value, we can transform the residual value to a standardized $z$ score using the equation $\left(e_{i} / S D_{e}\right.$. In this case, we have $(-13.733) / 1+17.447=-0.787$. This is the standardized $z$ score for a Peruvian man aged 50 and 14 years of education and a score of 80 on Stroop Word. e) The last step is to look-up the tables in the statistical reference books (e.g. Strauss et al., 2006) or use a trusted online calculator like the one available at http://www.measuringu.com/pcalcz.php. In the online calculator, you would enter the $z$ score and choose a one-sided test and note the percent of area after hitting the submit button. In this case, the probability of -0.787 corresponds to the 22 th percentile. Please remember to use the appropriate tables that correspond to each test (Stroop Word, Color, Word-Color, and
Interference) when performing these calculations. If the percentile for the Stroop Color, Word-Color, and Interference scores is desired, Tables 3-8 must be used.

\subsection{User-friendly normative data}

The five-step normative procedures explained above can provide more individualized norms. However, this method can be prone to human error due to the number of required computations. To enhance user-friendliness, the authors have completed these steps for a range of raw scores based on small age range groupings (see Guàrdia-Olmos et al., 2015) and created tables that clinicians can more easily use to obtain a percentile range associated with a given raw score on this test. These tables are available by country and type of test in the Appendix. In order to obtain an approximate percentile for the above example (converting a raw score of 80 for a Peruvian man who is 50 years old and has 14 years of education using the simplified normative 
Table 5

Effect of gender in the Stroop Word-Color

\begin{tabular}{|c|c|c|c|c|c|c|}
\hline Country & Gender & Mean (SD) & $t$ & $\mathrm{df}$ & Sig. (2-tailed) & $r$ \\
\hline \multirow[t]{2}{*}{ Argentina } & Male & $39.4(10.3)$ & 0.27 & 317 & 0.790 & 0.015 \\
\hline & Female & $39.1(11.2)$ & & & & \\
\hline \multirow{2}{*}{ Bolivia } & Male & $31.0(15.3)$ & -1.23 & 265 & 0.220 & 0.075 \\
\hline & Female & $33.6(17.2)$ & & & & \\
\hline \multirow[t]{2}{*}{ Chile $^{\mathrm{a}}$} & Male & $35.3(16.6)$ & 2.09 & 247.83 & $0.037^{*}$ & 0.132 \\
\hline & Female & $31.6(13.7)$ & & & & \\
\hline \multirow[t]{2}{*}{ Cuba } & Male & $36.2(14.6)$ & 0.84 & 298 & 0.399 & 0.049 \\
\hline & Female & $34.7(14.7)$ & & & & \\
\hline \multirow[t]{2}{*}{ El Salvador } & Male & $30.8(13.4)$ & 1.79 & 243 & 0.075 & 0.114 \\
\hline & Female & $27.9(11.4)$ & & & & \\
\hline \multirow[t]{2}{*}{ Guatemala } & Male & $32.5(13.8)$ & -0.62 & 206 & 0.534 & 0.043 \\
\hline & Female & $33.6(11.8)$ & & & & \\
\hline \multirow[t]{2}{*}{ Honduras } & Male & $33.5(10.9)$ & 3.13 & 181 & $0.002^{* *}$ & 0.227 \\
\hline & Female & $28.4(10.3)$ & & & & \\
\hline \multirow[t]{2}{*}{ Mexico $^{\mathrm{a}}$} & Male & $39.7(16.5)$ & 4.96 & 707.15 & $<0.001^{* * *}$ & 0.183 \\
\hline & Female & $35.2(13.3)$ & & & & \\
\hline \multirow[t]{2}{*}{ Paraguay } & Male & $32.2(10.8)$ & 1.73 & 261 & 0.084 & 0.107 \\
\hline & Female & $29.9(9.9)$ & & & & \\
\hline \multirow[t]{2}{*}{ Peru } & Male & $41.4(14.1)$ & 1.35 & 239 & 0.177 & 0.087 \\
\hline & Female & $38.9(13.7)$ & & & & \\
\hline \multirow[t]{2}{*}{ Puerto Rico } & Male & $39.0(15.2)$ & 0.89 & 291 & 0.372 & 0.052 \\
\hline & Female & $37.5(13.4)$ & & & & \\
\hline
\end{tabular}

${ }^{a}$ Value of the $t$-test for independent groups from the different variances with the corresponding correction of Yuen-Welch of degrees of freedom. ${ }^{*} p<0.05,{ }^{* *} p<0.01,{ }^{* * *} p<0.001$.

tables provided, the following steps are recommended. (1) First, identify the appropriate table ensuring the specific country and test. In this case, the table for Stroop Word scores for Peru can be found in Table A10. (2) Note if the title of the table indicates that it is only to be used for one specific gender. In this case, gender is not specified. Thus Table A10 is used for both males and females. (3) Next, the table is divided based on educational level (1 to 12 vs. $>12$ years of education). Since this man has 14 years of education, he falls into the ">12 years of education" category. These data can be found in the top section of the table. (4) Determine the age range most appropriate for the individual. In this case, 50 fall into the column $48-52$ years of age. (5) Read down the age range column to find the approximate location of the raw score the person obtained on the test. Reading down the 48-52 column, the score of 80 obtained by this Peruvian man corresponds to an approximate percentile of 20 .

The percentile obtained via this user-friendly table method (20th) is slightly different than the more exact one (22nd) obtained following the individual conversion steps above because the table method is based on an age range (e.g., individuals aged 48-52) instead of the exact age (individuals aged 50). If the exact score is not listed in the column, you must estimate the percentile value from the listed raw scores.

\section{Discussion}

The purpose of the current study was to generate normative data on the Stroop across 11 countries in Latin America, with country-specific adjustments for gender, age, and education, where appropriate. The final multiple linear regression models explained between $14-36 \%$ of the variance in Stroop Word scores, 12-41\% of the variance Stroop Color scores, $14-36 \%$ of the variance in Stroop Word-Color scores, and $4-15 \%$ of the variance in Stroop Interference scores. Although several gender differences emerged on different Stroop scores in several countries, all of the effect sizes were small, so gender-adjusted norms were not generated. The only previous research on gender differences in Stroop performance found that women performed better on color-naming but that gender differences were equivocal for interference (Strauss et al., 2006). In the current study, gender differences flipped flopped in different countries for the Stroop Color, and generally gender differences were equivocal in the current study as well. When considering the prior literature, the current study suggests that gender-adjustments should not be made in calculating percentiles for the Stroop in Latin America.

All four Stroop scores increased linearly as a function of education in the vast majority of countries. How- 
Table 6

Final multiple linear regression models for Stroop Word-Color

\begin{tabular}{|c|c|c|c|c|c|c|c|}
\hline Country & & $\mathrm{B}$ & Std. Error & $t$ & Sig. & $\mathrm{R}^{2}$ & $S D e$ (residual) \\
\hline \multirow[t]{3}{*}{ Argentina } & (Constant) & 47.375 & 1.485 & 31.904 & $<0.001$ & 0.309 & 9.094 \\
\hline & Age & -0.250 & 0.026 & -9.466 & $<0.001$ & & \\
\hline & Education & 6.079 & 1.033 & 5.883 & $<0.001$ & & \\
\hline \multirow[t]{3}{*}{ Bolivia } & (Constant) & 50.566 & 2.547 & 19.851 & $<0.001$ & 0.227 & 14.540 \\
\hline & Age & -0.338 & 0.041 & -8.179 & $<0.001$ & & \\
\hline & Education & 4.958 & 2.367 & 2.095 & 0.037 & & \\
\hline \multirow[t]{3}{*}{ Chile } & (Constant) & 49.782 & 2.133 & 23.335 & $<0.001$ & 0.426 & 11.430 \\
\hline & Age & -0.357 & 0.034 & -10.401 & $<0.001$ & & \\
\hline & Education & 12.098 & 1.560 & 7.756 & $<0.001$ & & \\
\hline \multirow[t]{3}{*}{ Cuba } & (Constant) & 50.088 & 2.289 & 21.882 & $<0.001$ & 0.173 & 13.320 \\
\hline & Age & -0.293 & 0.039 & -7.465 & $<0.001$ & & \\
\hline & Education & 3.753 & 1.828 & 2.053 & 0.041 & & \\
\hline \multirow[t]{3}{*}{ El Salvador } & (Constant) & 38.050 & 2.010 & 18.935 & $<0.001$ & 0.246 & 10.641 \\
\hline & Age & -0.200 & 0.033 & -6.072 & $<0.001$ & & \\
\hline & Education & 10.197 & 1.686 & 6.050 & $<0.001$ & & \\
\hline \multirow[t]{3}{*}{ Guatemala } & (Constant) & 43.348 & 2.676 & 16.201 & $<0.001$ & 0.163 & 11.612 \\
\hline & Age & -0.239 & 0.047 & -5.111 & $<0.001$ & & \\
\hline & Education & 6.041 & 1.667 & 3.623 & $<0.001$ & & \\
\hline \multirow[t]{3}{*}{ Honduras } & (Constant) & 39.063 & 2.094 & 18.655 & $<0.001$ & 0.231 & 9.431 \\
\hline & Age & -0.212 & 0.038 & -5.559 & $<0.001$ & & \\
\hline & Education & 5.969 & 1.677 & 3.559 & $<0.001$ & & \\
\hline \multirow[t]{3}{*}{ Mexico } & (Constant) & 54.458 & 0.995 & 54.732 & $<0.001$ & 0.306 & 12.144 \\
\hline & Age & -0.361 & 0.017 & -21.438 & $<0.001$ & & \\
\hline & Education & 5.489 & 0.822 & 6.675 & $<0.001$ & & \\
\hline \multirow[t]{3}{*}{ Paraguay } & (Constant) & 37.968 & 2.094 & 18.129 & $<0.001$ & 0.405 & 7.936 \\
\hline & Age & -0.179 & 0.036 & -4.936 & $<0.001$ & & \\
\hline & Education & 13.052 & 1.400 & 9.322 & $<0.001$ & & \\
\hline \multirow[t]{3}{*}{ Peru } & (Constant) & 52.222 & 2.219 & 23.534 & $<0.001$ & 0.296 & 11.615 \\
\hline & Age & -0.339 & 0.037 & -9.105 & $<0.001$ & & \\
\hline & Education & 3.700 & 1.602 & 2.310 & 0.022 & & \\
\hline \multirow[t]{3}{*}{ Puerto Rico } & (Constant) & 59.779 & 2.167 & 27.581 & $<0.001$ & 0.408 & 10.944 \\
\hline & Age & -0.459 & 0.036 & -12.735 & $<0.001$ & & \\
\hline & Education & 3.580 & 1.332 & 2.688 & 0.008 & & \\
\hline
\end{tabular}

ever, there was no effect of education for Stroop Color in Guatemala or for Stroop Interference in Peru, Honduras, Puerto Rico, or El Salvador. These general effects of education are in line with previous research showing that education is positively associated with Stroop performance (Steinberg et al., 2005). It is therefore important that neuropsychologists in Latin America use the education-adjusted norms for each country on the Stroop, except in Guatemala for the Stroop Color or in Peru, Honduras, Puerto Rico, and El Salvador for the Stroop Interference. There are likely substantial differences in education quality across countries in Latin America, and therefore the current study's Stroop education adjustments are important to use in the appropriate Latin American countries.

Stroop scores consistently decreased with increasing age in all countries in the current study. This finding is in line with previous research documenting aging to be associated with slower speed of Stroop color naming and increased interference (Moering et al., 2004). In light of the prior findings, the current study suggests that Stroop corrections for age in Latin America be made consistently, given the robust age effect identified.

\subsection{Limitations and future directions}

This study has several limitations and directions for future research. First, neuropsychologists need to exercise caution in using the Stroop norms from the current study when performing assessments in countries other than those in which data were collected. An extremely important direction for future research involves creating Stroop norms in other countries in Latin America that were not included in the current study, such as Ecuador, Uruguay, Venezuela, and Panama. Although this is an important limitation, the Stroop norms from this study may be more accurate in other Latin American countries than the norms that neuropsychologists in those countries are currently using. This generalizability is extremely important to examine in future research. 
Table 7

Effect of gender in the Stroop-Interference

\begin{tabular}{|c|c|c|c|c|c|c|}
\hline Country & Gender & Mean (SD) & $t$ & df & Sig. (2-tailed) & $r$ \\
\hline \multirow[t]{2}{*}{ Argentina } & Male & $0.7(8.6)$ & 1.11 & 317 & 0.270 & 0.062 \\
\hline & Female & $-0.4(7.4)$ & & & & \\
\hline \multirow[t]{2}{*}{ Bolivia } & Male & $1.8(12.4)$ & -0.91 & 265 & 0.363 & 0.056 \\
\hline & Female & 3.1 (11.6) & & & & \\
\hline \multirow[t]{2}{*}{ Chile $^{\mathrm{a}}$} & Male & $2.0(10.2)$ & 2.48 & 251.0 & $0.014^{*}$ & 0.155 \\
\hline & Female & $-0.7(8.6)$ & & & & \\
\hline \multirow[t]{2}{*}{ Cuba } & Male & $1.7(9.9)$ & 2.10 & 298 & 0.036 & 0.121 \\
\hline & Female & $-0.8(10.6)$ & & & & \\
\hline \multirow[t]{2}{*}{ El Salvador } & Male & $1.0(8.3)$ & 1.12 & 243 & 0.264 & 0.072 \\
\hline & Female & $-0.3(9.0)$ & & & & \\
\hline \multirow[t]{2}{*}{ Guatemala } & Male & $-0.1(9.5)$ & 1.04 & 206 & 0.299 & 0.072 \\
\hline & Female & $-1.5(9.1)$ & & & & \\
\hline \multirow[t]{2}{*}{ Honduras } & Male & $2.5(6.0)$ & 0.44 & 181 & 0.663 & 0.032 \\
\hline & Female & $2.1(7.2)$ & & & & \\
\hline \multirow[t]{2}{*}{ Mexico } & Male & 3.7 (11.1) & 5.08 & 1,279 & $<0.001^{* * *}$ & 0.141 \\
\hline & Female & $0.5(10.0)$ & & & & \\
\hline \multirow[t]{2}{*}{ Paraguay } & Male & $-2.4(7.9)$ & 1.40 & 261 & 0.162 & 0.086 \\
\hline & Female & $-3.8(7.9)$ & & & & \\
\hline \multirow[t]{2}{*}{ Peru } & Male & $0.8(10.9)$ & 0.30 & 239 & 0.761 & 0.020 \\
\hline & Female & $0.4(9.5)$ & & & & \\
\hline \multirow[t]{2}{*}{ Puerto Rico } & Male & $3.3(11.3)$ & 2.03 & 291 & $0.043^{*}$ & 0.118 \\
\hline & Female & $0.8(10.4)$ & & & & \\
\hline
\end{tabular}

a Value of the $t$-test for independent groups from the different variances with the corresponding correction of Yuen-Welch of degrees of freedom. ${ }^{*} p<0.05,{ }^{* *} p<0.01,{ }^{* * *} p<0.001$.

Table 8

Final multiple linear regression models for Stroop-Interference

\begin{tabular}{|c|c|c|c|c|c|c|c|}
\hline Country & & $\mathrm{B}$ & Std. Error & $t$ & Sig. & $\mathrm{R}^{2}$ & $S D e$ (residual) \\
\hline \multirow[t]{3}{*}{ Argentina } & (Constant) & 4.053 & 1.174 & 3.451 & 0.001 & 0.137 & 7.192 \\
\hline & Age & -0.121 & 0.021 & -5.801 & $<0.001$ & & \\
\hline & Education & 2.686 & 0.817 & 3.288 & 0.001 & & \\
\hline \multirow[t]{3}{*}{ Chile } & (Constant) & 5.355 & 1.618 & 3.310 & 0.001 & 0.145 & 8.666 \\
\hline & Age & -0.112 & 0.026 & -4.320 & $<0.001$ & & \\
\hline & Education & 5.191 & 1.183 & 4.389 & $<0.001$ & & \\
\hline \multirow[t]{2}{*}{ El Salvador } & (Constant) & 4.509 & 1.569 & 2.874 & 0.004 & 0.043 & 8.571 \\
\hline & Age & -0.078 & 0.026 & -2.928 & 0.004 & & \\
\hline \multirow[t]{3}{*}{ Mexico } & (Constant) & 7.736 & 0.826 & 9.366 & $<0.001$ & 0.072 & 10.095 \\
\hline & Age & -0.125 & 0.014 & -8.955 & $<0.001$ & & \\
\hline & Education & 2.021 & 0.683 & 2.957 & 0.003 & & \\
\hline \multirow[t]{3}{*}{ Paraguay } & (Constant) & -0.570 & 1.921 & -0.296 & 0.767 & 0.150 & 7.280 \\
\hline & Age & -0.073 & 0.033 & -2.196 & 0.029 & & \\
\hline & Education & 6.412 & 1.284 & 4.993 & $<0.001$ & & \\
\hline \multirow[t]{2}{*}{ Peru } & (Constant) & 7.622 & 1.434 & 5.314 & $<0.001$ & 0.116 & 9.463 \\
\hline & Age & -0.162 & 0.030 & -5.465 & $<0.001$ & & \\
\hline \multirow[t]{2}{*}{ Puerto Rico } & (Constant) & 13.414 & 1.717 & 7.813 & $<0.001$ & 0.151 & 9.990 \\
\hline & Age & -0.227 & 0.032 & -7.154 & $<0.001$ & & \\
\hline
\end{tabular}

Second, participants in this study spoke Spanish as their primary language, but it is unknown whether they spoke additional secondary languages. Stroop performance could differ in bilingual individuals from Latin America, and future research should study potential effects of bilingualism on performance. Participants were recruited from specific cities or regions of countries as opposed to nationally within those countries. This study is the largest neuropsychological normative study conducted to date in Latin America for the Stroop, or in any global region, so it should be considered a first step in the direction of larger, nationally representative normative studies. The sample was limited also in that although a good number of participants had fewer than 12 years of education, those who were unable to read were excluded, and as a result, these norms may not apply to illiterate adults. Similarly, participants with a history of neurological conditions and children did not 
participate in the study; future studies should collect data from these distinct populations.

Third, administration of the Stroop is extremely common in Latin America for neuropsychological assessment, but other common instruments need to be normed in the same manner to improve their use in this region as well. In the same vein, future research should examine the ecological validity and psychometric properties of the Stroop and other common neuropsychological instruments in Latin America. Researchers need to create instruments within Latin American cultures that have high ecological validity, as the Stroop was created in a Western culture that potentially differs in important ways from the diverse cultures in Latin America. Future studies would benefit from developing assessments within local cultures, instead of simply translating and norming instruments developed in other cultural contexts.

Although these limitations are present, only limited studies have produced Stroop norms in Spanishspeaking populations such as Spanish-speakers from the US-Mexico border (Artiola et al., 1999), Spain (Llinás-Reglá et al., 2013; Peña-Casanova et al., 2009), or Florida (Rosselli et al., 2002). As a result, this study was the first to create Stroop norms across 11 countries in Latin America with nearly 4,000 participants. It was the largest, most comprehensive Stroop normative study in any global region conducted to date, and its norms have the potential to have lasting effects on the standard of neuropsychological assessment with the Stroop in Latin America unlike any study before it.

\section{References}

Artiola, L., Hermosillo, D., Heaton, R., \& Pardee, R. E. (1999). Manual de normas y procedimientos para la batería neuropsicológica en espaǹol. Tucson, AZ: mPress.

Barbarotto, R., Laiacona, M., Frosio, R., Vecchio, M., Farinato, A. \& Capitani, E. (1998). A normative study on visual reaction times and two Stroop color-word tests. Italian Journal of Neurological Sciences, 19(3), 161-170.

Bohnen, N., Jolles, J., \& Twijnstra, A. (1992). Modification of the Stroop Color Word Test improves differentiation between patients with mild head injury and matched controls. The Clinical Neuropsychologist, 6(2), 178-188.

Bondi, M. W., Serody, A. B., Chan, A. S., Eberson-Schumate, S. C., Delis, D. C., Hansen, L. A., \& Salmon, D. P. (2002). Cognitive and neuropathologic correlates of Stroop Color-Word Test performance in Alzheimer's disease. Neuropsychology, 16(3), 335-343.

Bryan, J., \& Luszcz, M. A. (2000). Measurement of executive function: Considerations for detecting adult age differences. Journal of Clinical and Experimental Neuropsychology, 22(1), 40-55.
Castellon, S. A., Hinkin, C. H., \& Myers, H. F. (2000). Neuropsychiatric disturbance is associated with executive dysfunction in HIV-1 infection. Journal of the International Neuropsychological Society, 6(03), 336-347.

Chevalier, H., Metz-Lutz, M.-N., \& Segalowitz, S. J. (2000). Impulsivity and control of inhibition in benign focal childhood epilepsy. Brain and Cognition, 43(1-3), 86-90.

Comalli Jr., P. E., Wapner, S., \& Werner, H. (1962). Interference effects of Stroop Color-Word Test in childhood, adulthood, and aging. Journal of Genetic Psychology, 100(1), 47-53.

Connor, P. D., Sampson, P. D., Bookstein, F. L., Barr, H. M., \& Streissguth, A. P. (2000). Direct and indirect effects of parental alcohol damage on executive function. Developmental Neuropsychology, 18(3), 331-354.

Dao-Castellana, M. H., Samson, Y., Legaugt, F., Martinot, J. L., Aubin, H. J., Crouzel, C., Feldman, L., Barrucand, D., Rancurel, G., Feline, A., \& Syrota, A. (1998). Frontal dysfunction in neurologically normal chronic alcoholic subjects: Metabolic and neuropsychological findings. Psychological Medicine, 28(05), 1039-1048.

Delis, D. C., Kaplan, E., \& Kramer, J. H. (2001). Delis-Kaplan Executive Function System. San Antonio, TX: The Psychological Corporation.

Egner, T., \& Hirsch, J. (2005). The neural correlates and functional integration of cognitive control in a Stroop task. Neuroimage, 24(2), 539-547.

Folstein, M. F., Folstein, S. E., \& McHugh, P. R. (1975). "Minimental state": A practical method for grading the cognitive state of patients for the clinician. Journal of Psychiatric Research, 12(3), 189-198.

Golden, C. J. (2007). Stroop, Test de Colores y Palabras: Manual (5 ${ }^{\circ}$ Edicición). Madrid: Tea Ediciones, S.A.

Golden, C. J., \& Freshwater, S. M. (2002). Stroop Color and Word Test: Revised examiner's manual. Wood Dale, IL: Stoelting Co.

Guàrdia-Olmos, J., Peró-Cebollero, M., Rivera, D., \& ArangoLasprilla, J.C. (2015). Methodology for the development of normative data for ten Spanish-language neuropsychological tests in eleven Latin American countries. NeuroRehabilitation, 37, 493-499.

Hanes, K. R., Andrewes, D. G., Smith, D. J., \& Pantelis, C. (1996). A brief assessment of executive control dysfunction: Discriminant validity and homogeneity of planning, set shift, and fluency measures. Archives of Clinical Neuropsychology, 11(3), 185-191.

Hanninen, T., Hallikainen, M., Koivisto, K., Partanen, K., Laakso, M. P., Riekkinen, P. J., \& Soininen, H. (1997). Decline of frontal lobe functions in subjects with age-associated memory impairment. Neurology, 48(1), 148-153.

Harrison, B. J., Shaw, M., Yücel, M., Purcell, R., Brewer, W. J., Strother, S. C., et al., (2005). Functional connectivity during Stroop task performance. Neuroimage, 24(1), 181-191.

Homack, S., \& Riccio, C. A. (2004). A meta-analysis of the sensitivity and specificity of the Stroop Color and Word Test with children. Archives of Clinical Neuropsychology, 19(6), 725743.

Ingraham, L. J., Chard, F., Wood, M., \& Mirsky, A. F. (1988). An Hebrew language version of the Stroop test. Perceptual and Motor Skills, 67(1), 187-192.

Ivnik, R. J., Malec, J. F., Smith, G. E., \& Tangalos, E. G. (1996). Neuropsychological test norms above age 55: COWAT, BNT, MAE token, WRAT-R reading, AMNART, Stroop, TMT, and JLO. The Clinical Neuropsychologist, 10(3), 262-278. 
Kroenke, K., Spitzer, R. L., \& Williams, J. B. (2001). The PHQ-9. Journal of General Internal Medicine, 16(9), 606-613.

Llinás-Reglá, J., Vilalta-Franch, J., López-Pousa, S., Calvó-Perxas, L., \& Garre-Olmo, J. (2013). Demographically adjusted norms for Catalan older adults on the Stroop Color and Word Test. Archives of Clinical Neuropsychology, 28(3), 282-296.

Lopez, E., Salazar, X. F., Villaseñor, T., Saucedo, C., \& Peña, R. (2003). Validez y datos normativos de las pruebas de nominación en personas con educación limitada. In Poster presented at The Congress of the "Sociedad Lationoamericana de Neuropsicologia", Montreal, Canada.

Lucas, J. A., Ivnik, R. J., Smith, G. E., Ferman, T. J., Willis, F. B., Petersen, R. C., \& Graff-Radford, N. R. (2005). Mayo's Older African Americans Normative Studies: Norms for Boston Naming test, Controlled Oral Word Association, Category Fluency, Animal Naming, Token Test, WRAT-3 Reading, Trail Making Test, Stroop Test, and Judgment of Line Orientation. The Clinical Neuropsychologist, 19(2), 243-269.

Mahoney, F. I., \& Barthel, D. (1965). Functional evaluation: The Barthel Index. Maryland State Medical Journal, 14, 56-61.

Mitrushina, M. M., Boone, K. B., Razani, J., \& D'Elia, L. F. (2005). Handbook of normative data for neuropsychological assessment (2nd ed.). New York: Oxford University Press.

Moering, R. G., Schinka, J. A., Mortimer, J. A., \& Graves, A. B. (2004). Normative data for elderly African Americans for the Stroop Color and Word Test. Archives of Clinical Neuropsychology, 19(1), 61-71.

Moritz, S., Birkner, C., \& Kloss, M. (2002). Executive functioning in obsessive-compulsive disorder, unipolar depression, and schizophrenia. Archives of Clinical Neuropsychology, 17(5), 477-783.

Naglieri, J. A., \& Das, J. P. (1997). Cognitive assessment systems interpretive handbook. Itaska, IL: Riverside.

Peña-Casanova, J., Quiñones-Úbeda, S., Gramunt-Fombuena, N., Quintana, M., Aguilar, M., Molinunevo, J. L., Serradell, M., et al. (2009). Spanish multicenter normative studies (NEURONORMA Project): Norms for the Stroop Color-Word Interference Test and the Tower of London-Drexel. Archives of Clinical Neuropsychology, 24(4), 413-429.

Peterson, B. S., Skudlarksi, P., Gatenby, J. C., Zhang, H., Anderson, A. W., \& Gore, J. C. (1999). An fMRI study of Stroop colorword interference: Evidence for cingulated subregions subserving multiple distributed attentional systems. Biological Psychiatry, 45(10), 1237-1258.

Regard, M. (1981). Cognitive rigidity and flexibility: A neuropsychological study. Unpublished Ph.D. dissertation, University of Victoria.
Rosselli, M., Ardila, A., Santisi, M. N., del Rosario Arecco, M., Salvatierra, J., Conde, A., et al. (2002). Stroop effect in Spanish-English bilinguals. Journal of the International Neuropsychological Society, 8(06), 819-827.

Seol, E. H., Lee, D. Y., Choo, I. H., Kim, S. G., Kim, K. W., Youn, J. C., Jhoo, J. H., \& Woo, J. I. (2008). Normative study of the Stroop Color and Word Test in an educationally diverse elderly population. International Journal of Geriatric Psychiatry, 23(10), 1020-1027.

Snowden, J., Craufurd, D., Griffiths, H., Thompson, J., \& Neary, D. (2001). Longitudinal evaluation of cognitive disorder in Huntington's disease. Journal of the International Neuropsychological Society, 7(01), 33-44.

Steinberg, B. A., Bieliauskas, L. A., Smith, G. E., \& Ivnik, R. J. (2005). Mayo's Older Americans Normative Studies: Age- and IQ- adjusted norms for the Trail Making Test, the Stroop Test, and MAE Controlled Oral Word Association Test. The Clinical Neuropsychologist, 19(3-4), 329-377.

Strauss, E., Sherman, E., \& Spreen, O. (2006) A Compendium of Neuropsychological Tests: Administration, Norms, and Commentary (3rd ed.). New York: Oxford University Press.

Van Breukelen, G. J. P., \& Vlaeyen, J. W. S. (2005). Norming clinical questionnaires with multiple regression: The Pain Cognition List. Psychological Assessment, 17(3), 336-344.

Van der Elst, W., Van Boxtel, M. P. J., Van Breukelen, G. J. P., \& Jolles, J. (2007). Assessment of information processing in working memory in applied settings: The paper \& pencil memory scanning test. Psychological Medicine, 37(09), 1335-1344.

Van der Elst, W., Van Boxtel, M. P., Van Breukelen, G. J., \& Jolles, J. (2006). The stroop color-word test: Influence of age, sex, and education; and normative data for a large sample across the adult age range. Assessment, 13(1), 62-79.

White, M., Lalonde, R., \& Boetz-Marquard, T. (2000). Neuropsychologic and neuropsychiatric characteristics of patients with Friedreich's ataxia. Acta Neurologica Scandinavica, 102(4), 222226.

Zalonis, I., Christidi, F., Bonakis, A., Kararizou, E., Triantafyllou, N. I., Paraskevas, G., Kapaki, E., \& Vasilopoulos, D. (2009). The Stroop effect in Greek healthy population: Normative data for the Stroop Neuropsychological Screening Test. Archives of Clinical Neuropsychology, 24(1), 81-88. 


\section{Appendix}

Table A1

Normative data for the Stroop-Word stratified by age and education levels for ARGENTINA

\begin{tabular}{|c|c|c|c|c|c|c|c|c|c|c|c|c|c|c|}
\hline & \multirow[b]{2}{*}{ Percentile } & \multicolumn{13}{|c|}{ Age (Years) } \\
\hline & & $18-22$ & $23-27$ & $28-32$ & $33-37$ & $38-42$ & $43-47$ & $48-52$ & $53-57$ & $58-62$ & $63-67$ & $68-72$ & $73-77$ & $>77$ \\
\hline \multirow{13}{*}{ 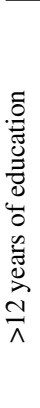 } & 95 & 128.2 & 127.0 & 125.9 & 124.7 & 123.5 & 122.3 & 121.2 & 120.0 & 118.8 & 117.6 & 116.4 & 115.3 & $\overline{114.1}$ \\
\hline & 90 & 123.0 & 121.9 & 120.7 & 119.5 & 118.3 & 117.2 & 116.0 & 114.8 & 113.6 & 112.5 & 111.3 & 110.1 & 108.9 \\
\hline & 85 & 119.6 & 118.4 & 117.3 & 116.1 & 114.9 & 113.7 & 112.5 & 111.4 & 110.2 & 109.0 & 107.8 & 106.7 & 105.5 \\
\hline & 80 & 116.7 & 115.6 & 114.4 & 113.2 & 112.0 & 110.9 & 109.7 & 108.5 & 107.3 & 106.1 & 105.0 & 103.8 & 102.6 \\
\hline & 70 & 112.1 & 111.0 & 109.8 & 108.6 & 107.4 & 106.3 & 105.1 & 103.9 & 102.7 & 101.6 & 100.4 & 99.2 & 98.0 \\
\hline & 60 & 108.3 & 107.1 & 105.9 & 104.7 & 103.6 & 102.4 & 101.2 & 100.0 & 98.9 & 97.7 & 96.5 & 95.3 & 94.2 \\
\hline & 50 & 104.7 & 103.5 & 102.3 & 101.2 & 100.0 & 98.8 & 97.6 & 96.5 & 95.3 & 94.1 & 92.9 & 91.7 & 90.6 \\
\hline & 40 & 101.1 & 99.9 & 98.7 & 97.6 & 96.4 & 95.2 & 94.0 & 92.9 & 91.7 & 90.5 & 89.3 & 88.2 & 87.0 \\
\hline & 30 & 97.2 & 96.1 & 94.9 & 93.7 & 92.5 & 91.3 & 90.2 & 89.0 & 87.8 & 86.6 & 85.5 & 84.3 & 83.1 \\
\hline & 20 & 92.6 & 91.5 & 90.3 & 89.1 & 87.9 & 86.8 & 85.6 & 84.4 & 83.2 & 82.1 & 80.9 & 79.7 & 78.5 \\
\hline & 15 & 89.8 & 88.6 & 87.4 & 86.2 & 85.1 & 83.9 & 82.7 & 81.5 & 80.4 & 79.2 & 78.0 & 76.8 & 75.7 \\
\hline & 10 & 86.3 & 85.2 & 84.0 & 82.8 & 81.6 & 80.4 & 79.3 & 78.1 & 76.9 & 75.7 & 74.6 & 73.4 & 72.2 \\
\hline & 5 & 81.2 & 80.0 & 78.8 & 77.6 & 76.5 & 75.3 & 74.1 & 72.9 & 71.8 & 70.6 & 69.4 & 68.2 & 67.0 \\
\hline \multirow{13}{*}{ 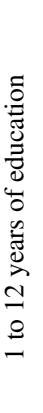 } & 95 & 122.3 & 121.1 & 120.0 & 118.8 & 117.6 & 116.4 & 115.2 & 114.1 & 112.9 & 111.7 & 110.5 & 109.4 & 108.2 \\
\hline & 90 & 117.1 & 116.0 & 114.8 & 113.6 & 112.4 & 111.3 & 110.1 & 108.9 & 107.7 & 106.6 & 105.4 & 104.2 & 103.0 \\
\hline & 85 & 113.7 & 112.5 & 111.3 & 110.2 & 109.0 & 107.8 & 106.6 & 105.5 & 104.3 & 103.1 & 101.9 & 100.8 & 99.6 \\
\hline & 80 & 110.8 & 109.7 & 108.5 & 107.3 & 106.1 & 104.9 & 103.8 & 102.6 & 101.4 & 100.2 & 99.1 & 97.9 & 96.7 \\
\hline & 70 & 106.2 & 105.1 & 103.9 & 102.7 & 101.5 & 100.4 & 99.2 & 98.0 & 96.8 & 95.7 & 94.5 & 93.3 & 92.1 \\
\hline & 60 & 102.4 & 101.2 & 100.0 & 98.8 & 97.7 & 96.5 & 95.3 & 94.1 & 93.0 & 91.8 & 90.6 & 89.4 & 88.2 \\
\hline & 50 & 98.8 & 97.6 & 96.4 & 95.3 & 94.1 & 92.9 & 91.7 & 90.5 & 89.4 & 88.2 & 87.0 & 85.8 & 84.7 \\
\hline & 40 & 95.2 & 94.0 & 92.8 & 91.7 & 90.5 & 89.3 & 88.1 & 87.0 & 85.8 & 84.6 & 83.4 & 82.3 & 81.1 \\
\hline & 30 & 91.3 & 90.1 & 89.0 & 87.8 & 86.6 & 85.4 & 84.3 & 83.1 & 81.9 & 80.7 & 79.6 & 78.4 & 77.2 \\
\hline & 20 & 86.7 & 85.6 & 84.4 & 83.2 & 82.0 & 80.8 & 79.7 & 78.5 & 77.3 & 76.1 & 75.0 & 73.8 & 72.6 \\
\hline & 15 & 83.9 & 82.7 & 81.5 & 80.3 & 79.2 & 78.0 & 76.8 & 75.6 & 74.5 & 73.3 & 72.1 & 70.9 & 69.7 \\
\hline & 10 & 80.4 & 79.2 & 78.1 & 76.9 & 75.7 & 74.5 & 73.4 & 72.2 & 71.0 & 69.8 & 68.7 & 67.5 & 66.3 \\
\hline & 5 & 75.3 & 74.1 & 72.9 & 71.7 & 70.6 & 69.4 & 68.2 & 67.0 & 65.8 & 64.7 & 63.5 & 62.3 & 61.1 \\
\hline
\end{tabular}

Table A2

Normative data for the Stroop-Word stratified by age and education levels for BOLIVIA

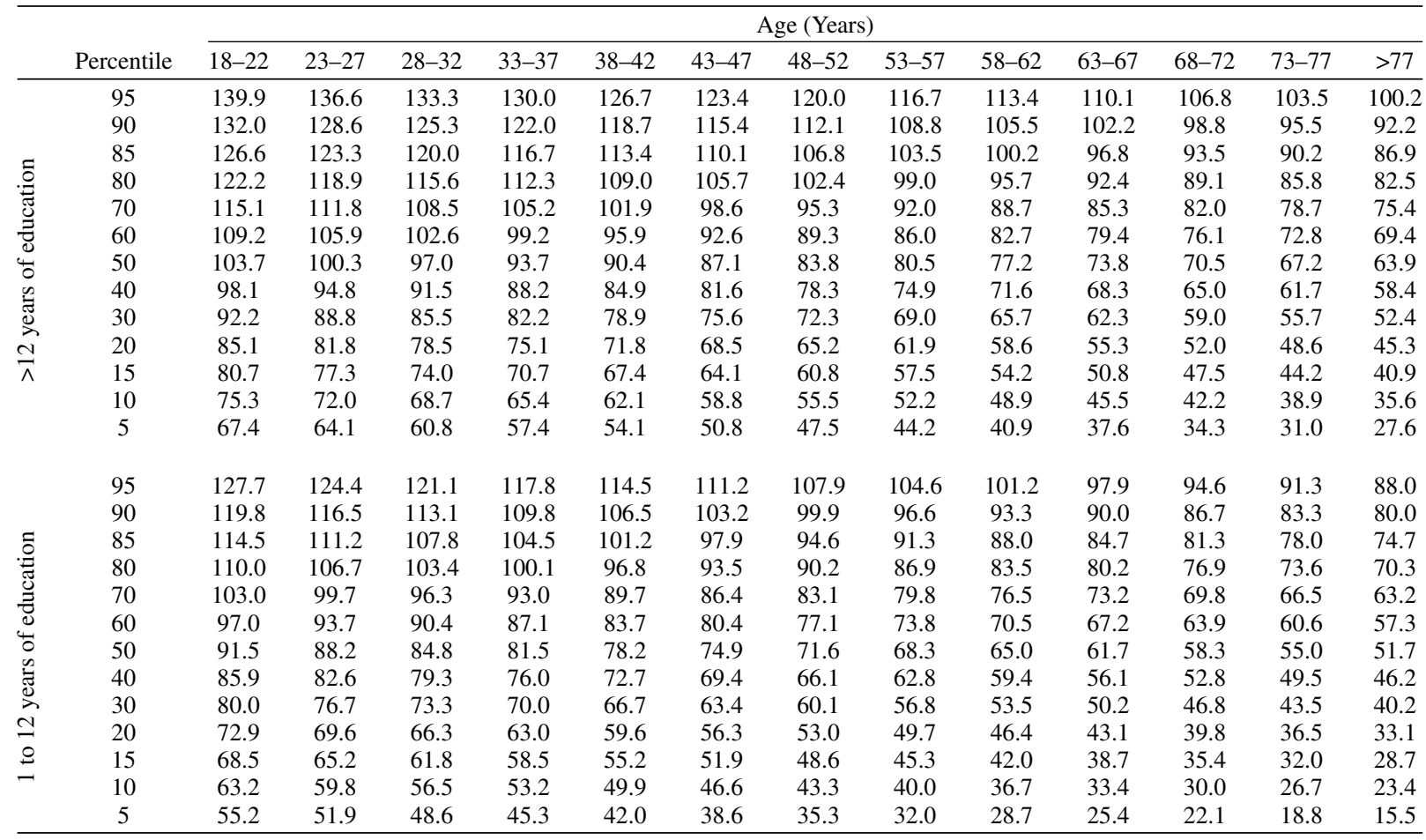


Table A3

Normative data for the Stroop-Word stratified by age and education levels for CHILE

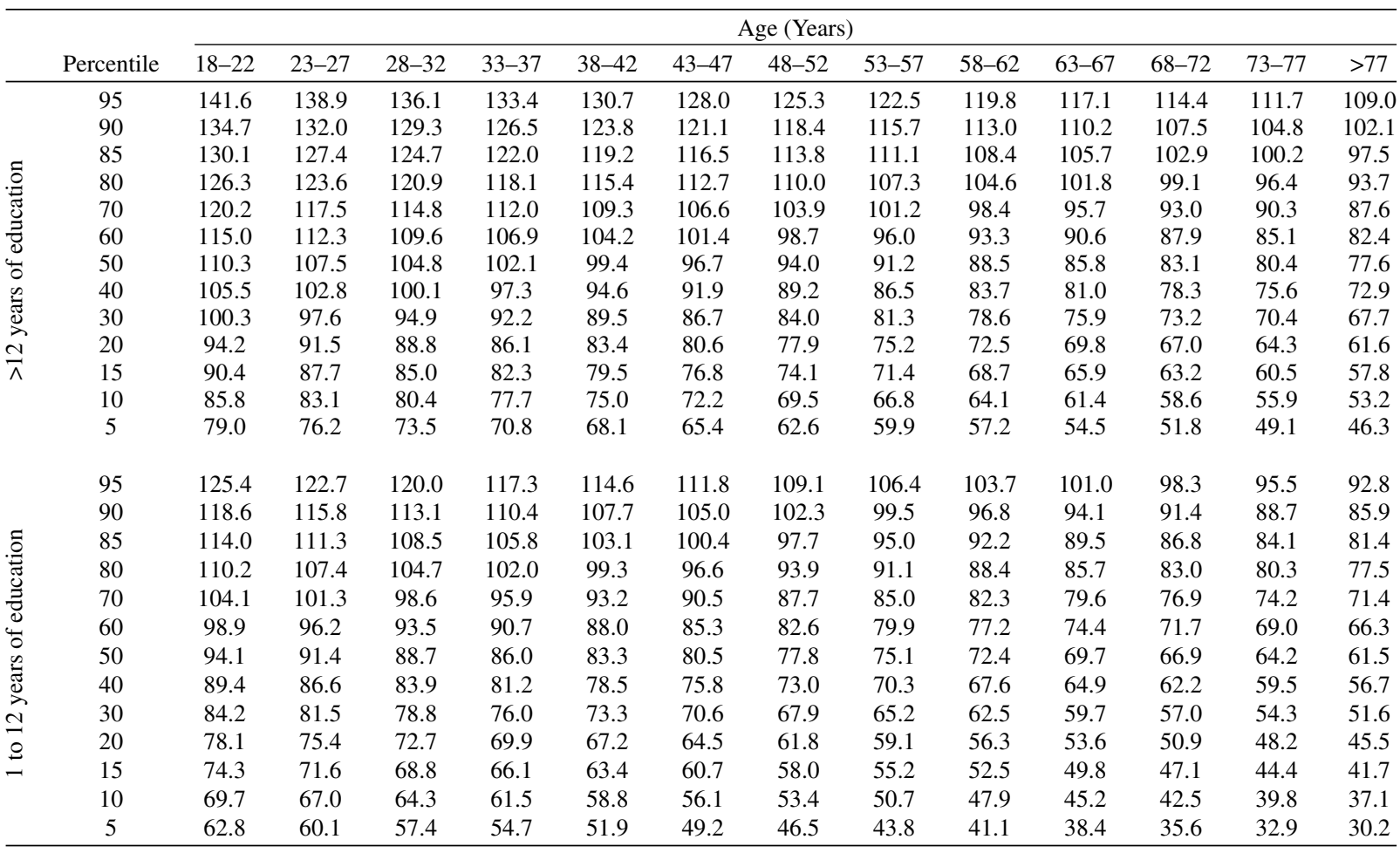

Table A4

Normative data for the Stroop-Word stratified by age and education levels for CUBA

\begin{tabular}{|c|c|c|c|c|c|c|c|c|c|c|c|c|c|c|}
\hline \multirow{2}{*}{\multicolumn{2}{|c|}{ rcentile }} & \multicolumn{13}{|c|}{ Age (Years) } \\
\hline & & $18-22$ & $23-27$ & $28-32$ & $33-37$ & $38-42$ & $43-47$ & $48-52$ & $53-57$ & $58-62$ & $63-67$ & $68-72$ & $73-77$ & $>77$ \\
\hline \multirow{13}{*}{ 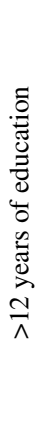 } & 95 & 148.6 & 145.5 & 142.4 & 139.3 & 136.3 & 133.2 & 130.1 & 127.0 & 123.9 & 120.8 & 117.8 & 114.7 & 111.6 \\
\hline & 90 & 141.5 & 138.4 & 135.3 & 132.2 & 129.1 & 126.1 & 123.0 & 119.9 & 116.8 & 113.7 & 110.6 & 107.6 & 104.5 \\
\hline & 85 & 136.7 & 133.6 & 130.6 & 127.5 & 124.4 & 121.3 & 118.2 & 115.1 & 112.1 & 109.0 & 105.9 & 102.8 & 99.7 \\
\hline & 80 & 132.8 & 129.7 & 126.6 & 123.5 & 120.4 & 117.4 & 114.3 & 111.2 & 108.1 & 105.0 & 102.0 & 98.9 & 95.8 \\
\hline & 70 & 126.4 & 123.4 & 120.3 & 117.2 & 114.1 & 111.0 & 108.0 & 104.9 & 101.8 & 98.7 & 95.6 & 92.5 & 89.5 \\
\hline & 60 & 121.1 & 118.0 & 114.9 & 111.9 & 108.8 & 105.7 & 102.6 & 99.5 & 96.4 & 93.4 & 90.3 & 87.2 & 84.1 \\
\hline & 50 & 116.2 & 113.1 & 110.0 & 106.9 & 103.8 & 100.8 & 97.7 & 94.6 & 91.5 & 88.4 & 85.3 & 82.3 & 79.2 \\
\hline & 40 & 111.2 & 108.1 & 105.1 & 102.0 & 98.9 & 95.8 & 92.7 & 89.6 & 86.6 & 83.5 & 80.4 & 77.3 & 74.2 \\
\hline & 30 & 105.9 & 102.8 & 99.7 & 96.6 & 93.6 & 90.5 & 87.4 & 84.3 & 81.2 & 78.1 & 75.1 & 72.0 & 68.9 \\
\hline & 20 & 99.6 & 96.5 & 93.4 & 90.3 & 87.2 & 84.1 & 81.1 & 78.0 & 74.9 & 71.8 & 68.7 & 65.7 & 62.6 \\
\hline & 15 & 95.6 & 92.5 & 89.4 & 86.4 & 83.3 & 80.2 & 77.1 & 74.0 & 70.9 & 67.9 & 64.8 & 61.7 & 58.6 \\
\hline & 10 & 90.9 & 87.8 & 84.7 & 81.6 & 78.5 & 75.4 & 72.4 & 69.3 & 66.2 & 63.1 & 60.0 & 57.0 & 53.9 \\
\hline & 5 & 83.7 & 80.7 & 77.6 & 74.5 & 71.4 & 68.3 & 65.2 & 62.2 & 59.1 & 56.0 & 52.9 & 49.8 & 46.8 \\
\hline \multirow{13}{*}{ 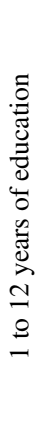 } & 95 & 134.8 & 131.7 & 128.7 & 125.6 & 122.5 & 119.4 & 116.3 & 113.3 & 110.2 & 107.1 & 104.0 & 100.9 & 97.8 \\
\hline & 90 & 127.7 & 124.6 & 121.5 & 118.5 & 115.4 & 112.3 & 109.2 & 106.1 & 103.1 & 100.0 & 96.9 & 93.8 & 90.7 \\
\hline & 85 & 123.0 & 119.9 & 116.8 & 113.7 & 110.6 & 107.6 & 104.5 & 101.4 & 98.3 & 95.2 & 92.1 & 89.1 & 86.0 \\
\hline & 80 & 119.0 & 115.9 & 112.8 & 109.8 & 106.7 & 103.6 & 100.5 & 97.4 & 94.4 & 91.3 & 88.2 & 85.1 & 82.0 \\
\hline & 70 & 112.7 & 109.6 & 106.5 & 103.4 & 100.4 & 97.3 & 94.2 & 91.1 & 88.0 & 84.9 & 81.9 & 78.8 & 75.7 \\
\hline & 60 & 107.3 & 104.3 & 101.2 & 98.1 & 95.0 & 91.9 & 88.9 & 85.8 & 82.7 & 79.6 & 76.5 & 73.4 & 70.4 \\
\hline & 50 & 102.4 & 99.3 & 96.2 & 93.2 & 90.1 & 87.0 & 83.9 & 80.8 & 77.8 & 74.7 & 71.6 & 68.5 & 65.4 \\
\hline & 40 & 97.5 & 94.4 & 91.3 & 88.2 & 85.1 & 82.1 & 79.0 & 75.9 & 72.8 & 69.7 & 66.6 & 63.6 & 60.5 \\
\hline & 30 & 92.1 & 89.0 & 86.0 & 82.9 & 79.8 & 76.7 & 73.6 & 70.6 & 67.5 & 64.4 & 61.3 & 58.2 & 55.1 \\
\hline & 20 & 85.8 & 82.7 & 79.6 & 76.6 & 73.5 & 70.4 & 67.3 & 64.2 & 61.1 & 58.1 & 55.0 & 51.9 & 48.8 \\
\hline & 15 & 81.8 & 78.8 & 75.7 & 72.6 & 69.5 & 66.4 & 63.4 & 60.3 & 57.2 & 54.1 & 51.0 & 47.9 & 44.9 \\
\hline & 10 & 77.1 & 74.0 & 70.9 & 67.9 & 64.8 & 61.7 & 58.6 & 55.5 & 52.4 & 49.4 & 46.3 & 43.2 & 40.1 \\
\hline & 5 & 70.0 & 66.9 & 63.8 & 60.7 & 57.7 & 54.6 & 51.5 & 48.4 & 45.3 & 42.2 & 39.2 & 36.1 & 33.0 \\
\hline
\end{tabular}


Table A5

Normative data for the Stroop-Word stratified by age and education levels for El SALVADOR

\begin{tabular}{|c|c|c|c|c|c|c|c|c|c|c|c|c|c|c|}
\hline & \multirow[b]{2}{*}{ Percentile } & \multicolumn{13}{|c|}{ Age (Years) } \\
\hline & & $18-22$ & $23-27$ & $28-32$ & $33-37$ & $38-42$ & $43-47$ & $48-52$ & $53-57$ & $58-62$ & $63-67$ & $68-72$ & $73-77$ & $>77$ \\
\hline \multirow{13}{*}{ 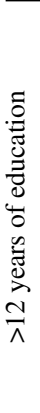 } & 95 & 131.6 & 130.5 & 129.4 & 128.3 & 127.2 & 126.1 & 125.0 & 123.9 & 122.8 & 121.7 & 120.6 & 119.5 & 118.4 \\
\hline & 90 & 124.0 & 122.9 & 121.8 & 120.7 & 119.6 & 118.5 & 117.4 & 116.3 & 115.2 & 114.1 & 113.0 & 111.9 & 110.8 \\
\hline & 85 & 119.0 & 117.9 & 116.8 & 115.7 & 114.6 & 113.5 & 112.4 & 111.3 & 110.2 & 109.1 & 108.0 & 106.9 & 105.8 \\
\hline & 80 & 114.8 & 113.7 & 112.6 & 111.5 & 110.4 & 109.3 & 108.2 & 107.1 & 106.0 & 104.9 & 103.8 & 102.7 & 101.6 \\
\hline & 70 & 108.1 & 107.0 & 105.9 & 104.8 & 103.7 & 102.6 & 101.5 & 100.4 & 99.3 & 98.2 & 97.1 & 96.0 & 94.9 \\
\hline & 60 & 102.4 & 101.3 & 100.2 & 99.1 & 98.0 & 96.9 & 95.8 & 94.7 & 93.6 & 92.5 & 91.4 & 90.3 & 89.2 \\
\hline & 50 & 97.2 & 96.1 & 95.0 & 93.9 & 92.8 & 91.7 & 90.6 & 89.5 & 88.4 & 87.3 & 86.2 & 85.1 & 84.0 \\
\hline & 40 & 91.9 & 90.8 & 89.7 & 88.6 & 87.5 & 86.4 & 85.3 & 84.2 & 83.1 & 82.0 & 80.9 & 79.8 & 78.7 \\
\hline & 30 & 86.3 & 85.2 & 84.1 & 83.0 & 81.9 & 80.8 & 79.7 & 78.6 & 77.5 & 76.4 & 75.3 & 74.2 & 73.1 \\
\hline & 20 & 79.6 & 78.5 & 77.4 & 76.3 & 75.2 & 74.1 & 73.0 & 71.9 & 70.7 & 69.6 & 68.5 & 67.4 & 66.3 \\
\hline & 15 & 75.4 & 74.3 & 73.2 & 72.1 & 71.0 & 69.9 & 68.8 & 67.7 & 66.6 & 65.5 & 64.4 & 63.2 & 62.1 \\
\hline & 10 & 70.3 & 69.2 & 68.1 & 67.0 & 65.9 & 64.8 & 63.7 & 62.6 & 61.5 & 60.4 & 59.3 & 58.2 & 57.1 \\
\hline & 5 & 62.8 & 61.7 & 60.6 & 59.5 & 58.4 & 57.3 & 56.2 & 55.1 & 54.0 & 52.9 & 51.8 & 50.7 & 49.6 \\
\hline \multirow{13}{*}{ 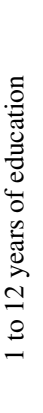 } & 95 & 106.6 & 105.5 & 104.4 & 103.3 & 102.2 & 101.1 & 100.0 & 98.9 & 97.8 & 96.7 & 95.6 & 94.5 & 93.4 \\
\hline & 90 & 99.1 & 98.0 & 96.9 & 95.8 & 94.7 & 93.6 & 92.5 & 91.4 & 90.3 & 89.2 & 88.1 & 87.0 & 85.9 \\
\hline & 85 & 94.0 & 92.9 & 91.8 & 90.7 & 89.6 & 88.5 & 87.4 & 86.3 & 85.2 & 84.1 & 83.0 & 81.9 & 80.8 \\
\hline & 80 & 89.8 & 88.7 & 87.6 & 86.5 & 85.4 & 84.3 & 83.2 & 82.1 & 81.0 & 79.9 & 78.8 & 77.7 & 76.6 \\
\hline & 70 & 83.1 & 82.0 & 80.9 & 79.8 & 78.7 & 77.6 & 76.5 & 75.4 & 74.3 & 73.2 & 72.1 & 71.0 & 69.9 \\
\hline & 60 & 77.5 & 76.4 & 75.3 & 74.2 & 73.1 & 72.0 & 70.9 & 69.8 & 68.7 & 67.6 & 66.5 & 65.4 & 64.2 \\
\hline & 50 & 72.2 & 71.1 & 70.0 & 68.9 & 67.8 & 66.7 & 65.6 & 64.5 & 63.4 & 62.3 & 61.2 & 60.1 & 59.0 \\
\hline & 40 & 67.0 & 65.9 & 64.8 & 63.7 & 62.6 & 61.5 & 60.4 & 59.3 & 58.2 & 57.1 & 56.0 & 54.9 & 53.8 \\
\hline & 30 & 61.3 & 60.2 & 59.1 & 58.0 & 56.9 & 55.8 & 54.7 & 53.6 & 52.5 & 51.4 & 50.3 & 49.2 & 48.1 \\
\hline & 20 & 54.6 & 53.5 & 52.4 & 51.3 & 50.2 & 49.1 & 48.0 & 46.9 & 45.8 & 44.7 & 43.6 & 42.5 & 41.4 \\
\hline & 15 & 50.4 & 49.3 & 48.2 & 47.1 & 46.0 & 44.9 & 43.8 & 42.7 & 41.6 & 40.5 & 39.4 & 38.3 & 37.2 \\
\hline & 10 & 45.4 & 44.3 & 43.2 & 42.1 & 41.0 & 39.9 & 38.8 & 37.7 & 36.6 & 35.5 & 34.4 & 33.3 & 32.2 \\
\hline & 5 & 37.8 & 36.7 & 35.6 & 34.5 & 33.4 & 32.3 & 31.2 & 30.1 & 29.0 & 27.9 & 26.8 & 25.7 & 24.6 \\
\hline
\end{tabular}

Table A6

Normative data for the Stroop-Word stratified by age and education levels for GUATEMALA

\begin{tabular}{|c|c|c|c|c|c|c|c|c|c|c|c|c|c|c|}
\hline & \multirow[b]{2}{*}{ Percentile } & \multicolumn{13}{|c|}{ Age (Years) } \\
\hline & & $18-22$ & $23-27$ & $28-32$ & $33-37$ & $38-42$ & $43-47$ & $48-52$ & $53-57$ & $58-62$ & $63-67$ & $68-72$ & $73-77$ & $>77$ \\
\hline \multirow{13}{*}{ 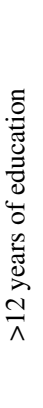 } & 95 & 137.7 & 135.6 & 133.6 & 131.5 & 129.5 & 127.5 & 125.4 & 123.4 & 121.3 & 119.3 & 117.3 & 115.2 & 113.2 \\
\hline & 90 & 130.6 & 128.5 & 126.5 & 124.5 & 122.4 & 120.4 & 118.3 & 116.3 & 114.3 & 112.2 & 110.2 & 108.1 & 106.1 \\
\hline & 85 & 125.9 & 123.8 & 121.8 & 119.7 & 117.7 & 115.7 & 113.6 & 111.6 & 109.6 & 107.5 & 105.5 & 103.4 & 101.4 \\
\hline & 80 & 121.9 & 119.9 & 117.9 & 115.8 & 113.8 & 111.7 & 109.7 & 107.7 & 105.6 & 103.6 & 101.5 & 99.5 & 97.5 \\
\hline & 70 & 115.7 & 113.6 & 111.6 & 109.5 & 107.5 & 105.5 & 103.4 & 101.4 & 99.3 & 97.3 & 95.3 & 93.2 & 91.2 \\
\hline & 60 & 110.3 & 108.3 & 106.3 & 104.2 & 102.2 & 100.2 & 98.1 & 96.1 & 94.0 & 92.0 & 90.0 & 87.9 & 85.9 \\
\hline & 50 & 105.4 & 103.4 & 101.4 & 99.3 & 97.3 & 95.2 & 93.2 & 91.2 & 89.1 & 87.1 & 85.0 & 83.0 & 81.0 \\
\hline & 40 & 100.5 & 98.5 & 96.4 & 94.4 & 92.4 & 90.3 & 88.3 & 86.3 & 84.2 & 82.2 & 80.1 & 78.1 & 76.1 \\
\hline & 30 & 95.2 & 93.2 & 91.1 & 89.1 & 87.1 & 85.0 & 83.0 & 81.0 & 78.9 & 76.9 & 74.8 & 72.8 & 70.8 \\
\hline & 20 & 88.9 & 86.9 & 84.9 & 82.8 & 80.8 & 78.7 & 76.7 & 74.7 & 72.6 & 70.6 & 68.5 & 66.5 & 64.5 \\
\hline & 15 & 85.0 & 83.0 & 80.9 & 78.9 & 76.9 & 74.8 & 72.8 & 70.7 & 68.7 & 66.7 & 64.6 & 62.6 & 60.5 \\
\hline & 10 & 80.3 & 78.3 & 76.2 & 74.2 & 72.1 & 70.1 & 68.1 & 66.0 & 64.0 & 61.9 & 59.9 & 57.9 & 55.8 \\
\hline & 5 & 73.2 & 71.2 & 69.1 & 67.1 & 65.1 & 63.0 & 61.0 & 59.0 & 56.9 & 54.9 & 52.8 & 50.8 & 48.8 \\
\hline \multirow{13}{*}{ 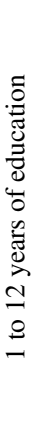 } & 95 & 123.6 & 121.5 & 119.5 & 117.5 & 115.4 & 113.4 & 111.3 & 109.3 & 107.3 & 105.2 & 103.2 & 101.2 & 99.1 \\
\hline & 90 & 116.5 & 114.5 & 112.4 & 110.4 & 108.4 & 106.3 & 104.3 & 102.2 & 100.2 & 98.2 & 96.1 & 94.1 & 92.0 \\
\hline & 85 & 111.8 & 109.8 & 107.7 & 105.7 & 103.6 & 101.6 & 99.6 & 97.5 & 95.5 & 93.4 & 91.4 & 89.4 & 87.3 \\
\hline & 80 & 107.9 & 105.8 & 103.8 & 101.8 & 99.7 & 97.7 & 95.6 & 93.6 & 91.6 & 89.5 & 87.5 & 85.4 & 83.4 \\
\hline & 70 & 101.6 & 99.5 & 97.5 & 95.5 & 93.4 & 91.4 & 89.3 & 87.3 & 85.3 & 83.2 & 81.2 & 79.2 & 77.1 \\
\hline & 60 & 96.3 & 94.2 & 92.2 & 90.2 & 88.1 & 86.1 & 84.0 & 82.0 & 80.0 & 77.9 & 75.9 & 73.8 & 71.8 \\
\hline & 50 & 91.4 & 89.3 & 87.3 & 85.3 & 83.2 & 81.2 & 79.1 & 77.1 & 75.1 & 73.0 & 71.0 & 68.9 & 66.9 \\
\hline & 40 & 86.5 & 84.4 & 82.4 & 80.3 & 78.3 & 76.3 & 74.2 & 72.2 & 70.1 & 68.1 & 66.1 & 64.0 & 62.0 \\
\hline & 30 & 81.2 & 79.1 & 77.1 & 75.0 & 73.0 & 71.0 & 68.9 & 66.9 & 64.8 & 62.8 & 60.8 & 58.7 & 56.7 \\
\hline & 20 & 74.9 & 72.8 & 70.8 & 68.8 & 66.7 & 64.7 & 62.6 & 60.6 & 58.6 & 56.5 & 54.5 & 52.4 & 50.4 \\
\hline & 15 & 70.9 & 68.9 & 66.9 & 64.8 & 62.8 & 60.7 & 58.7 & 56.7 & 54.6 & 52.6 & 50.6 & 48.5 & 46.5 \\
\hline & 10 & 66.2 & 64.2 & 62.1 & 60.1 & 58.1 & 56.0 & 54.0 & 52.0 & 49.9 & 47.9 & 45.8 & 43.8 & 41.8 \\
\hline & 5 & 59.2 & 57.1 & 55.1 & 53.0 & 51.0 & 49.0 & 46.9 & 44.9 & 42.8 & 40.8 & 38.8 & 36.7 & 34.7 \\
\hline
\end{tabular}


Table A7

Normative data for the Stroop-Word stratified by age and education levels for HONDURAS

\begin{tabular}{|c|c|c|c|c|c|c|c|c|c|c|c|c|c|c|}
\hline & \multirow[b]{2}{*}{ Percentile } & \multicolumn{13}{|c|}{ Age (Years) } \\
\hline & & $18-22$ & $23-27$ & $28-32$ & $33-37$ & $38-42$ & $43-47$ & $48-52$ & $53-57$ & $58-62$ & $63-67$ & $68-72$ & $73-77$ & $>77$ \\
\hline \multirow{13}{*}{ 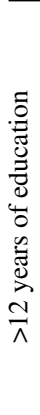 } & 95 & 129.5 & 126.6 & 123.7 & 120.9 & 118.0 & 115.1 & 112.3 & 109.4 & 106.5 & 103.7 & 100.8 & 97.9 & 95.1 \\
\hline & 90 & 122.0 & 119.1 & 116.2 & 113.4 & 110.5 & 107.6 & 104.8 & 101.9 & 99.0 & 96.2 & 93.3 & 90.4 & 87.6 \\
\hline & 85 & 116.9 & 114.1 & 111.2 & 108.3 & 105.5 & 102.6 & 99.7 & 96.9 & 94.0 & 91.1 & 88.3 & 85.4 & 82.5 \\
\hline & 80 & 112.8 & 109.9 & 107.0 & 104.2 & 101.3 & 98.4 & 95.6 & 92.7 & 89.8 & 87.0 & 84.1 & 81.2 & 78.4 \\
\hline & 70 & 106.1 & 103.2 & 100.3 & 97.5 & 94.6 & 91.7 & 88.9 & 86.0 & 83.1 & 80.3 & 77.4 & 74.6 & 71.7 \\
\hline & 60 & 100.4 & 97.6 & 94.7 & 91.8 & 89.0 & 86.1 & 83.2 & 80.4 & 77.5 & 74.6 & 71.8 & 68.9 & 66.0 \\
\hline & 50 & 95.2 & 92.4 & 89.5 & 86.6 & 83.8 & 80.9 & 78.0 & 75.2 & 72.3 & 69.4 & 66.6 & 63.7 & 60.8 \\
\hline & 40 & 90.0 & 87.1 & 84.3 & 81.4 & 78.5 & 75.7 & 72.8 & 69.9 & 67.1 & 64.2 & 61.3 & 58.5 & 55.6 \\
\hline & 30 & 84.4 & 81.5 & 78.6 & 75.8 & 72.9 & 70.0 & 67.2 & 64.3 & 61.4 & 58.6 & 55.7 & 52.8 & 50.0 \\
\hline & 20 & 77.7 & 74.8 & 71.9 & 69.1 & 66.2 & 63.3 & 60.5 & 57.6 & 54.7 & 51.9 & 49.0 & 46.1 & 43.3 \\
\hline & 15 & 73.5 & 70.6 & 67.8 & 64.9 & 62.0 & 59.2 & 56.3 & 53.4 & 50.6 & 47.7 & 44.8 & 42.0 & 39.1 \\
\hline & 10 & 68.5 & 65.6 & 62.7 & 59.9 & 57.0 & 54.2 & 51.3 & 48.4 & 45.6 & 42.7 & 39.8 & 37.0 & 34.1 \\
\hline & 5 & 61.0 & 58.1 & 55.2 & 52.4 & 49.5 & 46.6 & 43.8 & 40.9 & 38.0 & 35.2 & 32.3 & 29.4 & 26.6 \\
\hline \multirow{13}{*}{ 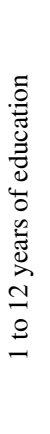 } & 95 & 111.7 & 108.9 & 106.0 & 103.1 & 100.3 & 97.4 & 94.5 & 91.7 & 88.8 & 85.9 & 83.1 & 80.2 & 77.4 \\
\hline & 90 & 104.2 & 101.4 & 98.5 & 95.6 & 92.8 & 89.9 & 87.0 & 84.2 & 81.3 & 78.4 & 75.6 & 72.7 & 69.8 \\
\hline & 85 & 99.2 & 96.3 & 93.5 & 90.6 & 87.7 & 84.9 & 82.0 & 79.1 & 76.3 & 73.4 & 70.6 & 67.7 & 64.8 \\
\hline & 80 & 95.0 & 92.2 & 89.3 & 86.4 & 83.6 & 80.7 & 77.8 & 75.0 & 72.1 & 69.2 & 66.4 & 63.5 & 60.6 \\
\hline & 70 & 88.4 & 85.5 & 82.6 & 79.8 & 76.9 & 74.0 & 71.2 & 68.3 & 65.4 & 62.6 & 59.7 & 56.8 & 54.0 \\
\hline & 60 & 82.7 & 79.8 & 77.0 & 74.1 & 71.2 & 68.4 & 65.5 & 62.6 & 59.8 & 56.9 & 54.1 & 51.2 & 48.3 \\
\hline & 50 & 77.5 & 74.6 & 71.8 & 68.9 & 66.0 & 63.2 & 60.3 & 57.4 & 54.6 & 51.7 & 48.8 & 46.0 & 43.1 \\
\hline & 40 & 72.3 & 69.4 & 66.5 & 63.7 & 60.8 & 57.9 & 55.1 & 52.2 & 49.3 & 46.5 & 43.6 & 40.7 & 37.9 \\
\hline & 30 & 66.6 & 63.8 & 60.9 & 58.0 & 55.2 & 52.3 & 49.4 & 46.6 & 43.7 & 40.8 & 38.0 & 35.1 & 32.2 \\
\hline & 20 & 59.9 & 57.1 & 54.2 & 51.3 & 48.5 & 45.6 & 42.7 & 39.9 & 37.0 & 34.2 & 31.3 & 28.4 & 25.6 \\
\hline & 15 & 55.8 & 52.9 & 50.0 & 47.2 & 44.3 & 41.4 & 38.6 & 35.7 & 32.8 & 30.0 & 27.1 & 24.2 & 21.4 \\
\hline & 10 & 50.8 & 47.9 & 45.0 & 42.2 & 39.3 & 36.4 & 33.6 & 30.7 & 27.8 & 25.0 & 22.1 & 19.2 & 16.4 \\
\hline & 5 & 43.2 & 40.4 & 37.5 & 34.6 & 31.8 & 28.9 & 26.0 & 23.2 & 20.3 & 17.4 & 14.6 & 11.7 & 8.8 \\
\hline
\end{tabular}

Table A8

Normative data for the Stroop-Word stratified by age and education levels for MEXICO

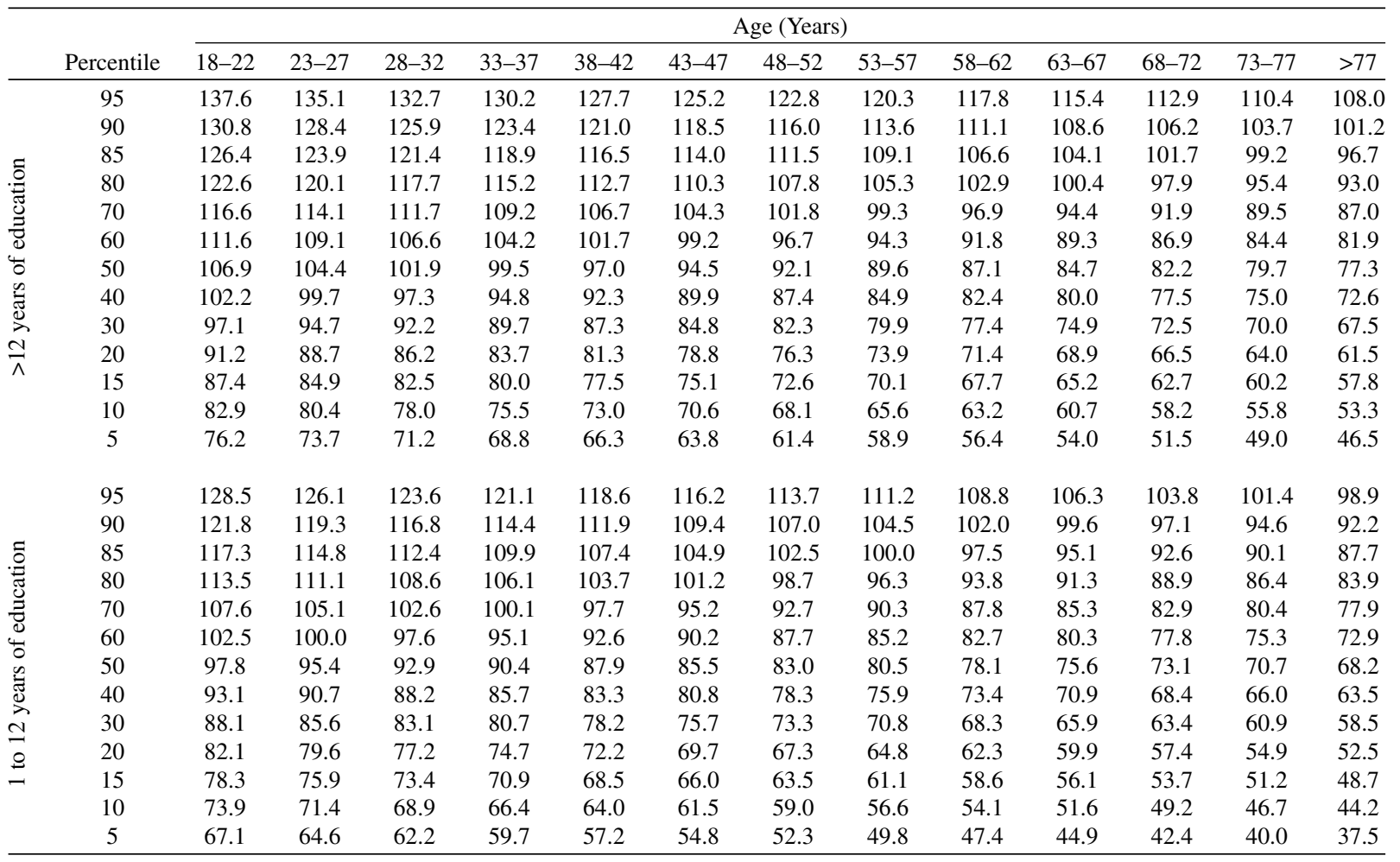


Table A9

Normative data for the Stroop-Word stratified by age and education levels for PARAGUAY

\begin{tabular}{|c|c|c|c|c|c|c|c|c|c|c|c|c|c|c|}
\hline & \multirow[b]{2}{*}{ Percentile } & \multicolumn{13}{|c|}{ Age (Years) } \\
\hline & & $18-22$ & $23-27$ & $28-32$ & $33-37$ & $38-42$ & $43-47$ & $48-52$ & $53-57$ & $58-62$ & $63-67$ & $68-72$ & $73-77$ & $>77$ \\
\hline \multirow{13}{*}{ 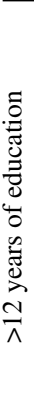 } & 95 & 115.0 & 113.8 & 112.6 & 111.4 & 110.2 & 109.0 & 107.8 & 106.6 & 105.4 & 104.1 & 102.9 & 101.7 & 100.5 \\
\hline & 90 & 111.0 & 109.8 & 108.6 & 107.3 & 106.1 & 104.9 & 103.7 & 102.5 & 101.3 & 100.1 & 98.9 & 97.7 & 96.5 \\
\hline & 85 & 108.3 & 107.1 & 105.9 & 104.6 & 103.4 & 102.2 & 101.0 & 99.8 & 98.6 & 97.4 & 96.2 & 95.0 & 93.8 \\
\hline & 80 & 106.0 & 104.8 & 103.6 & 102.4 & 101.2 & 100.0 & 98.8 & 97.6 & 96.4 & 95.1 & 93.9 & 92.7 & 91.5 \\
\hline & 70 & 102.4 & 101.2 & 100.0 & 98.8 & 97.6 & 96.4 & 95.2 & 94.0 & 92.8 & 91.6 & 90.3 & 89.1 & 87.9 \\
\hline & 60 & 99.4 & 98.2 & 97.0 & 95.8 & 94.6 & 93.3 & 92.1 & 90.9 & 89.7 & 88.5 & 87.3 & 86.1 & 84.9 \\
\hline & 50 & 96.6 & 95.4 & 94.2 & 93.0 & 91.7 & 90.5 & 89.3 & 88.1 & 86.9 & 85.7 & 84.5 & 83.3 & 82.1 \\
\hline & 40 & 93.8 & 92.6 & 91.3 & 90.1 & 88.9 & 87.7 & 86.5 & 85.3 & 84.1 & 82.9 & 81.7 & 80.5 & 79.3 \\
\hline & 30 & 90.7 & 89.5 & 88.3 & 87.1 & 85.9 & 84.7 & 83.5 & 82.3 & 81.1 & 79.9 & 78.6 & 77.4 & 76.2 \\
\hline & 20 & 87.1 & 85.9 & 84.7 & 83.5 & 82.3 & 81.1 & 79.9 & 78.7 & 77.5 & 76.3 & 75.0 & 73.8 & 72.6 \\
\hline & 15 & 84.9 & 83.7 & 82.5 & 81.3 & 80.0 & 78.8 & 77.6 & 76.4 & 75.2 & 74.0 & 72.8 & 71.6 & 70.4 \\
\hline & 10 & 82.2 & 81.0 & 79.8 & 78.6 & 77.3 & 76.1 & 74.9 & 73.7 & 72.5 & 71.3 & 70.1 & 68.9 & 67.7 \\
\hline & 5 & 78.1 & 76.9 & 75.7 & 74.5 & 73.3 & 72.1 & 70.9 & 69.7 & 68.5 & 67.3 & 66.0 & 64.8 & 63.6 \\
\hline \multirow{13}{*}{ 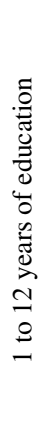 } & 95 & 100.0 & 98.8 & 97.6 & 96.4 & 95.2 & 94.0 & 92.8 & 91.6 & 90.4 & 89.2 & 88.0 & 86.8 & 85.5 \\
\hline & 90 & 96.0 & 94.8 & 93.6 & 92.4 & 91.2 & 90.0 & 88.7 & 87.5 & 86.3 & 85.1 & 83.9 & 82.7 & 81.5 \\
\hline & 85 & 93.3 & 92.1 & 90.9 & 89.7 & 88.5 & 87.3 & 86.0 & 84.8 & 83.6 & 82.4 & 81.2 & 80.0 & 78.8 \\
\hline & 80 & 91.0 & 89.8 & 88.6 & 87.4 & 86.2 & 85.0 & 83.8 & 82.6 & 81.4 & 80.2 & 79.0 & 77.8 & 76.6 \\
\hline & 70 & 87.4 & 86.2 & 85.0 & 83.8 & 82.6 & 81.4 & 80.2 & 79.0 & 77.8 & 76.6 & 75.4 & 74.2 & 73.0 \\
\hline & 60 & 84.4 & 83.2 & 82.0 & 80.8 & 79.6 & 78.4 & 77.2 & 76.0 & 74.7 & 73.5 & 72.3 & 71.1 & 69.9 \\
\hline & 50 & 81.6 & 80.4 & 79.2 & 78.0 & 76.8 & 75.6 & 74.4 & 73.1 & 71.9 & 70.7 & 69.5 & 68.3 & 67.1 \\
\hline & 40 & 78.8 & 77.6 & 76.4 & 75.2 & 74.0 & 72.7 & 71.5 & 70.3 & 69.1 & 67.9 & 66.7 & 65.5 & 64.3 \\
\hline & 30 & 75.8 & 74.5 & 73.3 & 72.1 & 70.9 & 69.7 & 68.5 & 67.3 & 66.1 & 64.9 & 63.7 & 62.5 & 61.3 \\
\hline & 20 & 72.2 & 70.9 & 69.7 & 68.5 & 67.3 & 66.1 & 64.9 & 63.7 & 62.5 & 61.3 & 60.1 & 58.9 & 57.7 \\
\hline & 15 & 69.9 & 68.7 & 67.5 & 66.3 & 65.1 & 63.9 & 62.7 & 61.4 & 60.2 & 59.0 & 57.8 & 56.6 & 55.4 \\
\hline & 10 & 67.2 & 66.0 & 64.8 & 63.6 & 62.4 & 61.2 & 60.0 & 58.7 & 57.5 & 56.3 & 55.1 & 53.9 & 52.7 \\
\hline & 5 & 63.2 & 61.9 & 60.7 & 59.5 & 58.3 & 57.1 & 55.9 & 54.7 & 53.5 & 52.3 & 51.1 & 49.9 & 48.7 \\
\hline
\end{tabular}

Table A10

Normative data for the Stroop-Word stratified by age and education levels for PERU

\begin{tabular}{|c|c|c|c|c|c|c|c|c|c|c|c|c|c|c|}
\hline & \multirow[b]{2}{*}{ Percentile } & \multicolumn{13}{|c|}{ Age (Years) } \\
\hline & & $18-22$ & $23-27$ & $28-32$ & $33-37$ & $38-42$ & $43-47$ & $48-52$ & $53-57$ & $58-62$ & $63-67$ & $68-72$ & $73-77$ & $>77$ \\
\hline \multirow{13}{*}{ 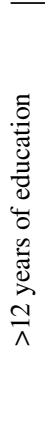 } & 95 & 134.6 & 132.6 & 130.5 & 128.5 & 126.4 & 124.4 & 122.3 & 120.3 & 118.3 & 116.2 & 114.2 & 112.1 & 110.1 \\
\hline & 90 & 128.3 & 126.3 & 124.3 & 122.2 & 120.2 & 118.1 & 116.1 & 114.0 & 112.0 & 109.9 & 107.9 & 105.8 & 103.8 \\
\hline & 85 & 124.2 & 122.1 & 120.1 & 118.0 & 116.0 & 113.9 & 111.9 & 109.8 & 107.8 & 105.7 & 103.7 & 101.6 & 99.6 \\
\hline & 80 & 120.7 & 118.6 & 116.6 & 114.5 & 112.5 & 110.4 & 108.4 & 106.3 & 104.3 & 102.2 & 100.2 & 98.2 & 96.1 \\
\hline & 70 & 115.1 & 113.0 & 111.0 & 108.9 & 106.9 & 104.9 & 102.8 & 100.8 & 98.7 & 96.7 & 94.6 & 92.6 & 90.5 \\
\hline & 60 & 110.4 & 108.3 & 106.3 & 104.2 & 102.2 & 100.1 & 98.1 & 96.0 & 94.0 & 92.0 & 89.9 & 87.9 & 85.8 \\
\hline & 50 & 106.0 & 104.0 & 101.9 & 99.9 & 97.8 & 95.8 & 93.7 & 91.7 & 89.6 & 87.6 & 85.5 & 83.5 & 81.5 \\
\hline & 40 & 101.6 & 99.6 & 97.6 & 95.5 & 93.5 & 91.4 & 89.4 & 87.3 & 85.3 & 83.2 & 81.2 & 79.1 & 77.1 \\
\hline & 30 & 96.9 & 94.9 & 92.8 & 90.8 & 88.8 & 86.7 & 84.7 & 82.6 & 80.6 & 78.5 & 76.5 & 74.4 & 72.4 \\
\hline & 20 & 91.4 & 89.3 & 87.3 & 85.2 & 83.2 & 81.1 & 79.1 & 77.0 & 75.0 & 72.9 & 70.9 & 68.8 & 66.8 \\
\hline & 15 & 87.9 & 85.8 & 83.8 & 81.7 & 79.7 & 77.6 & 75.6 & 73.5 & 71.5 & 69.4 & 67.4 & 65.4 & 63.3 \\
\hline & 10 & 83.7 & 81.6 & 79.6 & 77.5 & 75.5 & 73.4 & 71.4 & 69.4 & 67.3 & 65.3 & 63.2 & 61.2 & 59.1 \\
\hline & 5 & 77.4 & 75.4 & 73.3 & 71.3 & 69.2 & 67.2 & 65.1 & 63.1 & 61.0 & 59.0 & 56.9 & 54.9 & 52.8 \\
\hline \multirow{13}{*}{ 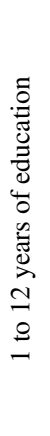 } & 95 & 124.5 & 122.4 & 120.4 & 118.3 & 116.3 & 114.2 & 112.2 & 110.1 & 108.1 & 106.1 & 104.0 & 102.0 & 99.9 \\
\hline & 90 & 118.2 & 116.1 & 114.1 & 112.1 & 110.0 & 108.0 & 105.9 & 103.9 & 101.8 & 99.8 & 97.7 & 95.7 & 93.6 \\
\hline & 85 & 114.0 & 112.0 & 109.9 & 107.9 & 105.8 & 103.8 & 101.7 & 99.7 & 97.6 & 95.6 & 93.5 & 91.5 & 89.4 \\
\hline & 80 & 110.5 & 108.5 & 106.4 & 104.4 & 102.3 & 100.3 & 98.2 & 96.2 & 94.1 & 92.1 & 90.1 & 88.0 & 86.0 \\
\hline & 70 & 104.9 & 102.9 & 100.8 & 98.8 & 96.7 & 94.7 & 92.7 & 90.6 & 88.6 & 86.5 & 84.5 & 82.4 & 80.4 \\
\hline & 60 & 100.2 & 98.2 & 96.1 & 94.1 & 92.0 & 90.0 & 87.9 & 85.9 & 83.9 & 81.8 & 79.8 & 77.7 & 75.7 \\
\hline & 50 & 95.9 & 93.8 & 91.8 & 89.7 & 87.7 & 85.6 & 83.6 & 81.5 & 79.5 & 77.4 & 75.4 & 73.3 & 71.3 \\
\hline & 40 & 91.5 & 89.5 & 87.4 & 85.4 & 83.3 & 81.3 & 79.2 & 77.2 & 75.1 & 73.1 & 71.0 & 69.0 & 66.9 \\
\hline & 30 & 86.8 & 84.7 & 82.7 & 80.6 & 78.6 & 76.6 & 74.5 & 72.5 & 70.4 & 68.4 & 66.3 & 64.3 & 62.2 \\
\hline & 20 & 81.2 & 79.2 & 77.1 & 75.1 & 73.0 & 71.0 & 68.9 & 66.9 & 64.8 & 62.8 & 60.7 & 58.7 & 56.6 \\
\hline & 15 & 77.7 & 75.7 & 73.6 & 71.6 & 69.5 & 67.5 & 65.4 & 63.4 & 61.3 & 59.3 & 57.3 & 55.2 & 53.2 \\
\hline & 10 & 73.5 & 71.5 & 69.4 & 67.4 & 65.3 & 63.3 & 61.2 & 59.2 & 57.2 & 55.1 & 53.1 & 51.0 & 49.0 \\
\hline & 5 & 67.2 & 65.2 & 63.2 & 61.1 & 59.1 & 57.0 & 55.0 & 52.9 & 50.9 & 48.8 & 46.8 & 44.7 & 42.7 \\
\hline
\end{tabular}


Table A11

Normative data for the Stroop-Word stratified by age and education levels for PUERTO RICO

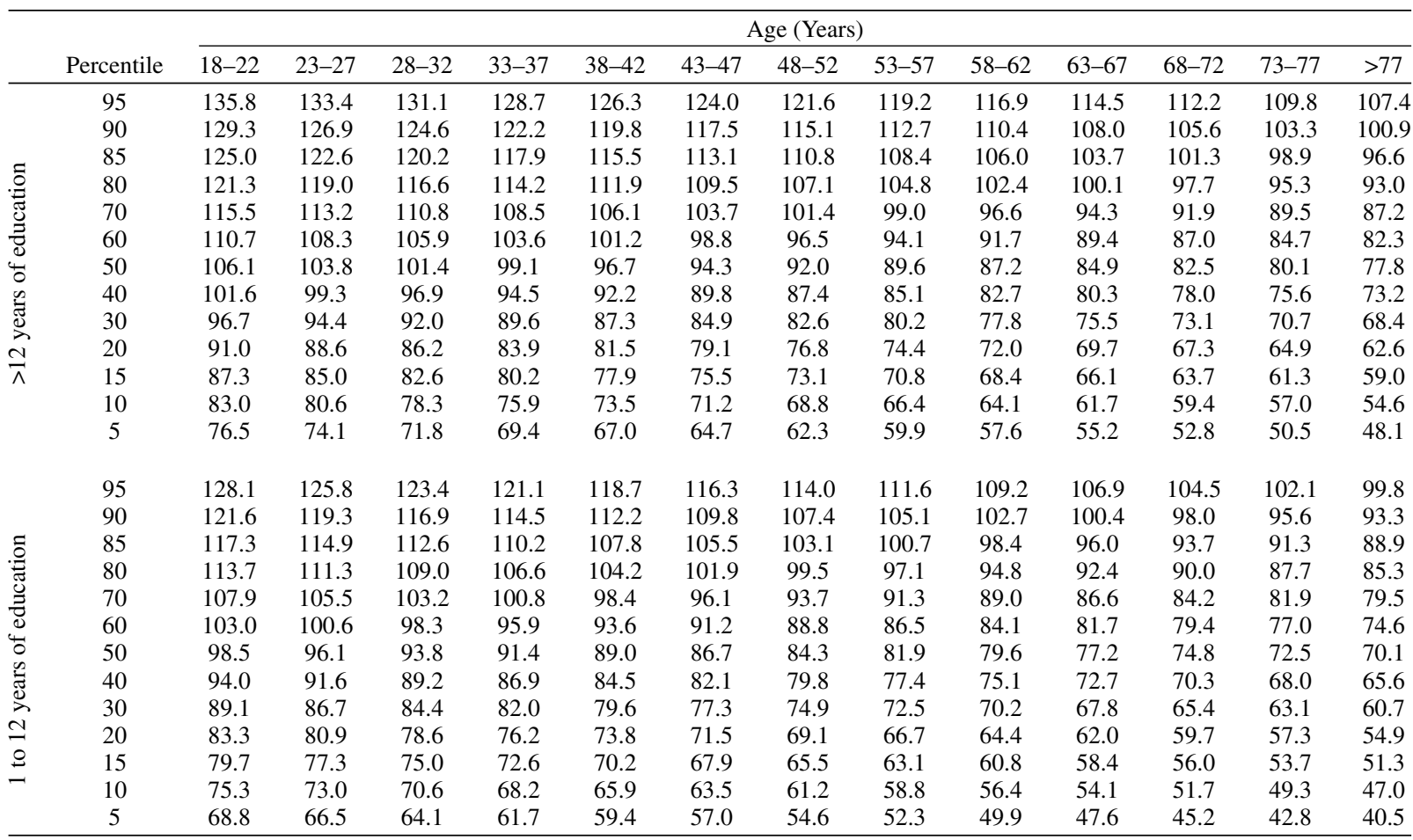

Table A12

Normative data for the Stroop-Color stratified by age and education levels for ARGENTINA

\begin{tabular}{|c|c|c|c|c|c|c|c|c|c|c|c|c|c|c|}
\hline \multirow{2}{*}{\multicolumn{2}{|c|}{ rcentile }} & \multicolumn{13}{|c|}{ Age (Years) } \\
\hline & & $18-22$ & $23-27$ & $28-32$ & $33-37$ & $38-42$ & $43-47$ & $48-52$ & $53-57$ & $58-62$ & $63-67$ & $68-72$ & $73-77$ & $>77$ \\
\hline \multirow{13}{*}{ 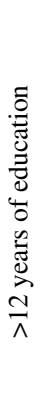 } & 95 & 98.0 & 96.7 & 95.4 & 94.2 & 92.9 & 91.6 & 90.4 & 89.1 & 87.8 & 86.5 & 85.3 & 84.0 & 82.7 \\
\hline & 90 & 93.4 & 92.1 & 90.8 & 89.6 & 88.3 & 87.0 & 85.7 & 84.5 & 83.2 & 81.9 & 80.7 & 79.4 & 78.1 \\
\hline & 85 & 90.3 & 89.0 & 87.7 & 86.5 & 85.2 & 83.9 & 82.7 & 81.4 & 80.1 & 78.9 & 77.6 & 76.3 & 75.0 \\
\hline & 80 & 87.7 & 86.5 & 85.2 & 83.9 & 82.6 & 81.4 & 80.1 & 78.8 & 77.6 & 76.3 & 75.0 & 73.7 & 72.5 \\
\hline & 70 & 83.6 & 82.3 & 81.1 & 79.8 & 78.5 & 77.3 & 76.0 & 74.7 & 73.5 & 72.2 & 70.9 & 69.6 & 68.4 \\
\hline & 60 & 80.2 & 78.9 & 77.6 & 76.3 & 75.1 & 73.8 & 72.5 & 71.3 & 70.0 & 68.7 & 67.5 & 66.2 & 64.9 \\
\hline & 50 & 77.0 & 75.7 & 74.4 & 73.1 & 71.9 & 70.6 & 69.3 & 68.1 & 66.8 & 65.5 & 64.2 & 63.0 & 61.7 \\
\hline & 40 & 73.7 & 72.5 & 71.2 & 69.9 & 68.7 & 67.4 & 66.1 & 64.9 & 63.6 & 62.3 & 61.0 & 59.8 & 58.5 \\
\hline & 30 & 70.3 & 69.0 & 67.7 & 66.5 & 65.2 & 63.9 & 62.7 & 61.4 & 60.1 & 58.9 & 57.6 & 56.3 & 55.0 \\
\hline & 20 & 66.2 & 64.9 & 63.6 & 62.4 & 61.1 & 59.8 & 58.6 & 57.3 & 56.0 & 54.7 & 53.5 & 52.2 & 50.9 \\
\hline & 15 & 63.6 & 62.3 & 61.1 & 59.8 & 58.5 & 57.3 & 56.0 & 54.7 & 53.5 & 52.2 & 50.9 & 49.6 & 48.4 \\
\hline & 10 & 60.5 & 59.3 & 58.0 & 56.7 & 55.5 & 54.2 & 52.9 & 51.6 & 50.4 & 49.1 & 47.8 & 46.6 & 45.3 \\
\hline & 5 & 55.9 & 54.7 & 53.4 & 52.1 & 50.8 & 49.6 & 48.3 & 47.0 & 45.8 & 44.5 & 43.2 & 41.9 & 40.7 \\
\hline \multirow{13}{*}{ 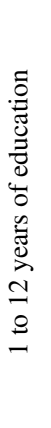 } & 95 & 90.9 & 89.6 & 88.4 & 87.1 & 85.8 & 84.5 & 83.3 & 82.0 & 80.7 & 79.5 & 78.2 & 76.9 & 75.6 \\
\hline & 90 & 86.3 & 85.0 & 83.7 & 82.5 & 81.2 & 79.9 & 78.7 & 77.4 & 76.1 & 74.8 & 73.6 & 72.3 & 71.0 \\
\hline & 85 & 83.2 & 81.9 & 80.7 & 79.4 & 78.1 & 76.9 & 75.6 & 74.3 & 73.0 & 71.8 & 70.5 & 69.2 & 68.0 \\
\hline & 80 & 80.6 & 79.4 & 78.1 & 76.8 & 75.6 & 74.3 & 73.0 & 71.7 & 70.5 & 69.2 & 67.9 & 66.7 & 65.4 \\
\hline & 70 & 76.5 & 75.3 & 74.0 & 72.7 & 71.5 & 70.2 & 68.9 & 67.6 & 66.4 & 65.1 & 63.8 & 62.6 & 61.3 \\
\hline & 60 & 73.1 & 71.8 & 70.5 & 69.3 & 68.0 & 66.7 & 65.5 & 64.2 & 62.9 & 61.6 & 60.4 & 59.1 & 57.8 \\
\hline & 50 & 69.9 & 68.6 & 67.3 & 66.1 & 64.8 & 63.5 & 62.2 & 61.0 & 59.7 & 58.4 & 57.2 & 55.9 & 54.6 \\
\hline & 40 & 66.7 & 65.4 & 64.1 & 62.9 & 61.6 & 60.3 & 59.0 & 57.8 & 56.5 & 55.2 & 54.0 & 52.7 & 51.4 \\
\hline & 30 & 63.2 & 61.9 & 60.7 & 59.4 & 58.1 & 56.9 & 55.6 & 54.3 & 53.0 & 51.8 & 50.5 & 49.2 & 48.0 \\
\hline & 20 & 59.1 & 57.8 & 56.6 & 55.3 & 54.0 & 52.7 & 51.5 & 50.2 & 48.9 & 47.7 & 46.4 & 45.1 & 43.9 \\
\hline & 15 & 56.5 & 55.3 & 54.0 & 52.7 & 51.5 & 50.2 & 48.9 & 47.6 & 46.4 & 45.1 & 43.8 & 42.6 & 41.3 \\
\hline & 10 & 53.5 & 52.2 & 50.9 & 49.6 & 48.4 & 47.1 & 45.8 & 44.6 & 43.3 & 42.0 & 40.8 & 39.5 & 38.2 \\
\hline & 5 & 48.8 & 47.6 & 46.3 & 45.0 & 43.8 & 42.5 & 41.2 & 39.9 & 38.7 & 37.4 & 36.1 & 34.9 & 33.6 \\
\hline
\end{tabular}


Table A13

Normative data for the Stroop-Color stratified by age and education levels for BOLIVIA

\begin{tabular}{|c|c|c|c|c|c|c|c|c|c|c|c|c|c|c|}
\hline & \multirow[b]{2}{*}{ Percentile } & \multicolumn{13}{|c|}{ Age (Years) } \\
\hline & & $18-22$ & $23-27$ & $28-32$ & $33-37$ & $38-42$ & $43-47$ & $48-52$ & $53-57$ & $58-62$ & $63-67$ & $68-72$ & $73-77$ & $>77$ \\
\hline \multirow{13}{*}{ 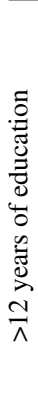 } & 95 & 111.0 & 108.0 & 105.0 & 101.9 & 98.9 & 95.9 & 92.9 & 89.8 & 86.8 & 83.8 & 80.7 & 77.7 & 74.7 \\
\hline & 90 & 104.9 & 101.9 & 98.8 & 95.8 & 92.8 & 89.8 & 86.7 & 83.7 & 80.7 & 77.6 & 74.6 & 71.6 & 68.5 \\
\hline & 85 & 100.8 & 97.8 & 94.8 & 91.7 & 88.7 & 85.7 & 82.6 & 79.6 & 76.6 & 73.5 & 70.5 & 67.5 & 64.4 \\
\hline & 80 & 97.4 & 94.4 & 91.3 & 88.3 & 85.3 & 82.2 & 79.2 & 76.2 & 73.2 & 70.1 & 67.1 & 64.1 & 61.0 \\
\hline & 70 & 91.9 & 88.9 & 85.9 & 82.9 & 79.8 & 76.8 & 73.8 & 70.7 & 67.7 & 64.7 & 61.6 & 58.6 & 55.6 \\
\hline & 60 & 87.3 & 84.3 & 81.3 & 78.3 & 75.2 & 72.2 & 69.2 & 66.1 & 63.1 & 60.1 & 57.0 & 54.0 & 51.0 \\
\hline & 50 & 83.1 & 80.1 & 77.0 & 74.0 & 71.0 & 67.9 & 64.9 & 61.9 & 58.8 & 55.8 & 52.8 & 49.7 & 46.7 \\
\hline & 40 & 78.8 & 75.8 & 72.8 & 69.7 & 66.7 & 63.7 & 60.6 & 57.6 & 54.6 & 51.5 & 48.5 & 45.5 & 42.5 \\
\hline & 30 & 74.2 & 71.2 & 68.2 & 65.1 & 62.1 & 59.1 & 56.0 & 53.0 & 50.0 & 46.9 & 43.9 & 40.9 & 37.9 \\
\hline & 20 & 68.8 & 65.7 & 62.7 & 59.7 & 56.6 & 53.6 & 50.6 & 47.6 & 44.5 & 41.5 & 38.5 & 35.4 & 32.4 \\
\hline & 15 & 65.4 & 62.3 & 59.3 & 56.3 & 53.2 & 50.2 & 47.2 & 44.1 & 41.1 & 38.1 & 35.1 & 32.0 & 29.0 \\
\hline & 10 & 61.3 & 58.2 & 55.2 & 52.2 & 49.1 & 46.1 & 43.1 & 40.1 & 37.0 & 34.0 & 31.0 & 27.9 & 24.9 \\
\hline & 5 & 55.1 & 52.1 & 49.1 & 46.0 & 43.0 & 40.0 & 36.9 & 33.9 & 30.9 & 27.9 & 24.8 & 21.8 & 18.8 \\
\hline \multirow{13}{*}{ 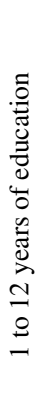 } & 95 & 101.7 & 98.7 & 95.7 & 92.6 & 89.6 & 86.6 & 83.6 & 80.5 & 77.5 & 74.5 & 71.4 & 68.4 & 65.4 \\
\hline & 90 & 95.6 & 92.6 & 89.5 & 86.5 & 83.5 & 80.4 & 77.4 & 74.4 & 71.4 & 68.3 & 65.3 & 62.3 & 59.2 \\
\hline & 85 & 91.5 & 88.5 & 85.4 & 82.4 & 79.4 & 76.4 & 73.3 & 70.3 & 67.3 & 64.2 & 61.2 & 58.2 & 55.1 \\
\hline & 80 & 88.1 & 85.1 & 82.0 & 79.0 & 76.0 & 72.9 & 69.9 & 66.9 & 63.9 & 60.8 & 57.8 & 54.8 & 51.7 \\
\hline & 70 & 82.6 & 79.6 & 76.6 & 73.6 & 70.5 & 67.5 & 64.5 & 61.4 & 58.4 & 55.4 & 52.3 & 49.3 & 46.3 \\
\hline & 60 & 78.0 & 75.0 & 72.0 & 69.0 & 65.9 & 62.9 & 59.9 & 56.8 & 53.8 & 50.8 & 47.7 & 44.7 & 41.7 \\
\hline & 50 & 73.8 & 70.8 & 67.7 & 64.7 & 61.7 & 58.6 & 55.6 & 52.6 & 49.5 & 46.5 & 43.5 & 40.4 & 37.4 \\
\hline & 40 & 69.5 & 66.5 & 63.5 & 60.4 & 57.4 & 54.4 & 51.3 & 48.3 & 45.3 & 42.2 & 39.2 & 36.2 & 33.2 \\
\hline & 30 & 64.9 & 61.9 & 58.9 & 55.8 & 52.8 & 49.8 & 46.7 & 43.7 & 40.7 & 37.6 & 34.6 & 31.6 & 28.6 \\
\hline & 20 & 59.5 & 56.4 & 53.4 & 50.4 & 47.3 & 44.3 & 41.3 & 38.2 & 35.2 & 32.2 & 29.2 & 26.1 & 23.1 \\
\hline & 15 & 56.1 & 53.0 & 50.0 & 47.0 & 43.9 & 40.9 & 37.9 & 34.8 & 31.8 & 28.8 & 25.7 & 22.7 & 19.7 \\
\hline & 10 & 52.0 & 48.9 & 45.9 & 42.9 & 39.8 & 36.8 & 33.8 & 30.7 & 27.7 & 24.7 & 21.7 & 18.6 & 15.6 \\
\hline & 5 & 45.8 & 42.8 & 39.8 & 36.7 & 33.7 & 30.7 & 27.6 & 24.6 & 21.6 & 18.6 & 15.5 & 12.5 & 9.5 \\
\hline
\end{tabular}

Table A14

Normative data for the Stroop-Color stratified by age and education levels for CHILE

\begin{tabular}{|c|c|c|c|c|c|c|c|c|c|c|c|c|c|c|}
\hline & \multirow[b]{2}{*}{ Percentile } & \multicolumn{13}{|c|}{ Age (Years) } \\
\hline & & $\overline{18-22}$ & $23-27$ & $28-32$ & $33-37$ & $38-42$ & $43-47$ & $48-52$ & $53-57$ & $58-62$ & $63-67$ & $68-72$ & $73-77$ & $>77$ \\
\hline \multirow{13}{*}{ 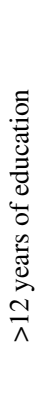 } & 95 & 102.3 & 100.2 & 98.0 & 95.9 & 93.7 & 91.6 & 89.4 & 87.2 & 85.1 & 82.9 & 80.8 & 78.6 & 76.5 \\
\hline & 90 & 97.6 & 95.4 & 93.3 & 91.1 & 89.0 & 86.8 & 84.7 & 82.5 & 80.3 & 78.2 & 76.0 & 73.9 & 71.7 \\
\hline & 85 & 94.4 & 92.3 & 90.1 & 88.0 & 85.8 & 83.6 & 81.5 & 79.3 & 77.2 & 75.0 & 72.9 & 70.7 & 68.5 \\
\hline & 80 & 91.8 & 89.6 & 87.5 & 85.3 & 83.2 & 81.0 & 78.8 & 76.7 & 74.5 & 72.4 & 70.2 & 68.1 & 65.9 \\
\hline & 70 & 87.6 & 85.4 & 83.2 & 81.1 & 78.9 & 76.8 & 74.6 & 72.5 & 70.3 & 68.2 & 66.0 & 63.8 & 61.7 \\
\hline & 60 & 84.0 & 81.8 & 79.7 & 77.5 & 75.4 & 73.2 & 71.1 & 68.9 & 66.7 & 64.6 & 62.4 & 60.3 & 58.1 \\
\hline & 50 & 80.7 & 78.5 & 76.4 & 74.2 & 72.1 & 69.9 & 67.8 & 65.6 & 63.4 & 61.3 & 59.1 & 57.0 & 54.8 \\
\hline & 40 & 77.4 & 75.2 & 73.1 & 70.9 & 68.8 & 66.6 & 64.5 & 62.3 & 60.1 & 58.0 & 55.8 & 53.7 & 51.5 \\
\hline & 30 & 73.8 & 71.7 & 69.5 & 67.4 & 65.2 & 63.1 & 60.9 & 58.7 & 56.6 & 54.4 & 52.3 & 50.1 & 48.0 \\
\hline & 20 & 69.6 & 67.5 & 65.3 & 63.1 & 61.0 & 58.8 & 56.7 & 54.5 & 52.4 & 50.2 & 48.1 & 45.9 & 43.7 \\
\hline & 15 & 67.0 & 64.8 & 62.7 & 60.5 & 58.3 & 56.2 & 54.0 & 51.9 & 49.7 & 47.6 & 45.4 & 43.3 & 41.1 \\
\hline & 10 & 63.8 & 61.7 & 59.5 & 57.3 & 55.2 & 53.0 & 50.9 & 48.7 & 46.6 & 44.4 & 42.2 & 40.1 & 37.9 \\
\hline & 5 & 59.1 & 56.9 & 54.7 & 52.6 & 50.4 & 48.3 & 46.1 & 44.0 & 41.8 & 39.7 & 37.5 & 35.3 & 33.2 \\
\hline \multirow{13}{*}{ 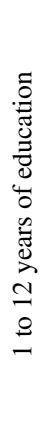 } & 95 & 90.3 & 88.1 & 86.0 & 83.8 & 81.7 & 79.5 & 77.3 & 75.2 & 73.0 & 70.9 & 68.7 & 66.6 & 64.4 \\
\hline & 90 & 85.5 & 83.4 & 81.2 & 79.1 & 76.9 & 74.8 & 72.6 & 70.4 & 68.3 & 66.1 & 64.0 & 61.8 & 59.7 \\
\hline & 85 & 82.4 & 80.2 & 78.1 & 75.9 & 73.7 & 71.6 & 69.4 & 67.3 & 65.1 & 63.0 & 60.8 & 58.7 & 56.5 \\
\hline & 80 & 79.7 & 77.6 & 75.4 & 73.3 & 71.1 & 68.9 & 66.8 & 64.6 & 62.5 & 60.3 & 58.2 & 56.0 & 53.9 \\
\hline & 70 & 75.5 & 73.3 & 71.2 & 69.0 & 66.9 & 64.7 & 62.6 & 60.4 & 58.3 & 56.1 & 53.9 & 51.8 & 49.6 \\
\hline & 60 & 71.9 & 69.8 & 67.6 & 65.5 & 63.3 & 61.2 & 59.0 & 56.9 & 54.7 & 52.5 & 50.4 & 48.2 & 46.1 \\
\hline & 50 & 68.6 & 66.5 & 64.3 & 62.2 & 60.0 & 57.9 & 55.7 & 53.6 & 51.4 & 49.2 & 47.1 & 44.9 & 42.8 \\
\hline & 40 & 65.3 & 63.2 & 61.0 & 58.9 & 56.7 & 54.6 & 52.4 & 50.3 & 48.1 & 45.9 & 43.8 & 41.6 & 39.5 \\
\hline & 30 & 61.8 & 59.6 & 57.5 & 55.3 & 53.2 & 51.0 & 48.8 & 46.7 & 44.5 & 42.4 & 40.2 & 38.1 & 35.9 \\
\hline & 20 & 57.6 & 55.4 & 53.2 & 51.1 & 48.9 & 46.8 & 44.6 & 42.5 & 40.3 & 38.2 & 36.0 & 33.8 & 31.7 \\
\hline & 15 & 54.9 & 52.8 & 50.6 & 48.5 & 46.3 & 44.1 & 42.0 & 39.8 & 37.7 & 35.5 & 33.4 & 31.2 & 29.0 \\
\hline & 10 & 51.8 & 49.6 & 47.4 & 45.3 & 43.1 & 41.0 & 38.8 & 36.7 & 34.5 & 32.3 & 30.2 & 28.0 & 25.9 \\
\hline & 5 & 47.0 & 44.8 & 42.7 & 40.5 & 38.4 & 36.2 & 34.1 & 31.9 & 29.8 & 27.6 & 25.4 & 23.3 & 21.1 \\
\hline
\end{tabular}


Table A15

Normative data for the Stroop-Color stratified by age and education levels for CUBA

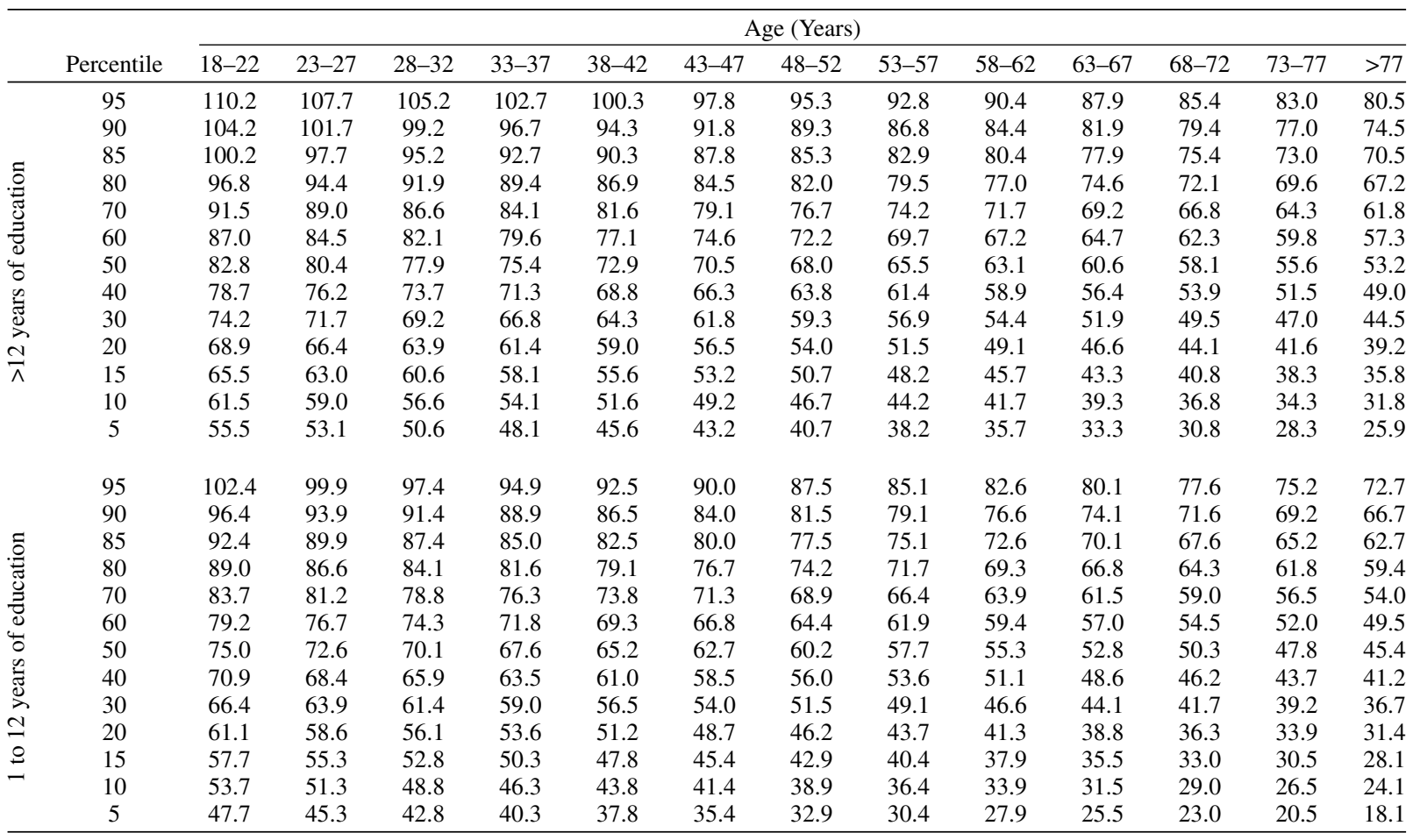

Table A16

Normative data for the Stroop-Color stratified by age and education levels for EL SALVADOR

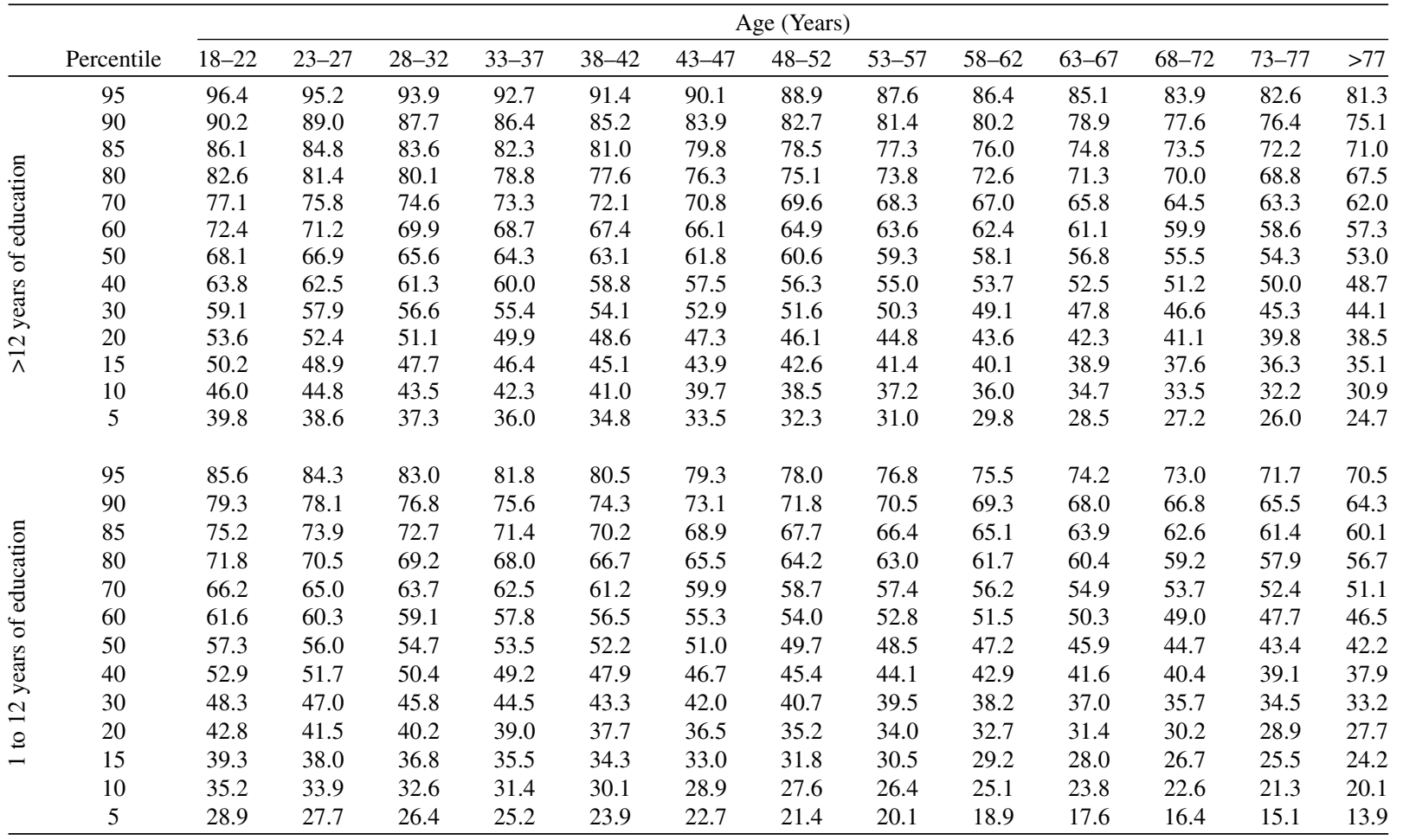


Table A17

Normative data for the Stroop-Color stratified by age and education levels for GUATEMALA

\begin{tabular}{|c|c|c|c|c|c|c|c|c|c|c|c|c|c|c|}
\hline & \multirow[b]{2}{*}{ Percentile } & \multicolumn{13}{|c|}{ Age (Years) } \\
\hline & & $18-22$ & $23-27$ & $28-32$ & $33-37$ & $38-42$ & $43-47$ & $48-52$ & $53-57$ & $58-62$ & $63-67$ & $68-72$ & $73-77$ & $>77$ \\
\hline \multirow{13}{*}{ 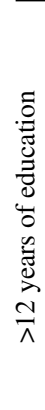 } & 95 & 98.8 & 97.1 & 95.4 & 93.7 & 92.1 & 90.4 & 88.7 & 87.0 & 85.4 & 83.7 & 82.0 & 80.3 & 78.7 \\
\hline & 90 & 93.2 & 91.5 & 89.9 & 88.2 & 86.5 & 84.8 & 83.2 & 81.5 & 79.8 & 78.1 & 76.5 & 74.8 & 73.1 \\
\hline & 85 & 89.5 & 87.8 & 86.2 & 84.5 & 82.8 & 81.1 & 79.5 & 77.8 & 76.1 & 74.4 & 72.8 & 71.1 & 69.4 \\
\hline & 80 & 86.4 & 84.8 & 83.1 & 81.4 & 79.7 & 78.1 & 76.4 & 74.7 & 73.0 & 71.4 & 69.7 & 68.0 & 66.3 \\
\hline & 70 & 81.5 & 79.8 & 78.2 & 76.5 & 74.8 & 73.1 & 71.5 & 69.8 & 68.1 & 66.4 & 64.8 & 63.1 & 61.4 \\
\hline & 60 & 77.4 & 75.7 & 74.0 & 72.3 & 70.7 & 69.0 & 67.3 & 65.6 & 63.9 & 62.3 & 60.6 & 58.9 & 57.2 \\
\hline & 50 & 73.5 & 71.8 & 70.2 & 68.5 & 66.8 & 65.1 & 63.4 & 61.8 & 60.1 & 58.4 & 56.7 & 55.1 & 53.4 \\
\hline & 40 & 69.7 & 68.0 & 66.3 & 64.6 & 62.9 & 61.3 & 59.6 & 57.9 & 56.2 & 54.6 & 52.9 & 51.2 & 49.5 \\
\hline & 30 & 65.5 & 63.8 & 62.1 & 60.5 & 58.8 & 57.1 & 55.4 & 53.8 & 52.1 & 50.4 & 48.7 & 47.1 & 45.4 \\
\hline & 20 & 60.6 & 58.9 & 57.2 & 55.5 & 53.9 & 52.2 & 50.5 & 48.8 & 47.2 & 45.5 & 43.8 & 42.1 & 40.5 \\
\hline & 15 & 57.5 & 55.8 & 54.1 & 52.5 & 50.8 & 49.1 & 47.4 & 45.8 & 44.1 & 42.4 & 40.7 & 39.0 & 37.4 \\
\hline & 10 & 53.8 & 52.1 & 50.4 & 48.8 & 47.1 & 45.4 & 43.7 & 42.1 & 40.4 & 38.7 & 37.0 & 35.4 & 33.7 \\
\hline & 5 & 48.2 & 46.6 & 44.9 & 43.2 & 41.5 & 39.9 & 38.2 & 36.5 & 34.8 & 33.2 & 31.5 & 29.8 & 28.1 \\
\hline \multirow{13}{*}{ 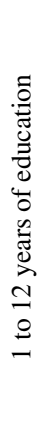 } & 95 & 92.0 & 90.3 & 88.6 & 87.0 & 85.3 & 83.6 & 81.9 & 80.3 & 78.6 & 76.9 & 75.2 & 73.5 & 71.9 \\
\hline & 90 & 86.4 & 84.8 & 83.1 & 81.4 & 79.7 & 78.1 & 76.4 & 74.7 & 73.0 & 71.4 & 69.7 & 68.0 & 66.3 \\
\hline & 85 & 82.7 & 81.1 & 79.4 & 77.7 & 76.0 & 74.4 & 72.7 & 71.0 & 69.3 & 67.7 & 66.0 & 64.3 & 62.6 \\
\hline & 80 & 79.7 & 78.0 & 76.3 & 74.6 & 73.0 & 71.3 & 69.6 & 67.9 & 66.3 & 64.6 & 62.9 & 61.2 & 59.5 \\
\hline & 70 & 74.7 & 73.1 & 71.4 & 69.7 & 68.0 & 66.4 & 64.7 & 63.0 & 61.3 & 59.6 & 58.0 & 56.3 & 54.6 \\
\hline & 60 & 70.6 & 68.9 & 67.2 & 65.5 & 63.9 & 62.2 & 60.5 & 58.8 & 57.2 & 55.5 & 53.8 & 52.1 & 50.5 \\
\hline & 50 & 66.7 & 65.0 & 63.4 & 61.7 & 60.0 & 58.3 & 56.7 & 55.0 & 53.3 & 51.6 & 50.0 & 48.3 & 46.6 \\
\hline & 40 & 62.9 & 61.2 & 59.5 & 57.8 & 56.2 & 54.5 & 52.8 & 51.1 & 49.5 & 47.8 & 46.1 & 44.4 & 42.8 \\
\hline & 30 & 58.7 & 57.0 & 55.4 & 53.7 & 52.0 & 50.3 & 48.7 & 47.0 & 45.3 & 43.6 & 42.0 & 40.3 & 38.6 \\
\hline & 20 & 53.8 & 52.1 & 50.4 & 48.8 & 47.1 & 45.4 & 43.7 & 42.1 & 40.4 & 38.7 & 37.0 & 35.3 & 33.7 \\
\hline & 15 & 50.7 & 49.0 & 47.4 & 45.7 & 44.0 & 42.3 & 40.6 & 39.0 & 37.3 & 35.6 & 33.9 & 32.3 & 30.6 \\
\hline & 10 & 47.0 & 45.3 & 43.7 & 42.0 & 40.3 & 38.6 & 37.0 & 35.3 & 33.6 & 31.9 & 30.2 & 28.6 & 26.9 \\
\hline & 5 & 41.5 & 39.8 & 38.1 & 36.4 & 34.8 & 33.1 & 31.4 & 29.7 & 28.1 & 26.4 & 24.7 & 23.0 & 21.4 \\
\hline
\end{tabular}

Table A18

Normative data for the Stroop-Color stratified by age and education levels for HONDURAS

\begin{tabular}{|c|c|c|c|c|c|c|c|c|c|c|c|c|c|c|}
\hline & \multirow[b]{2}{*}{ Percentile } & \multicolumn{13}{|c|}{ Age (Years) } \\
\hline & & $18-22$ & $23-27$ & $28-32$ & $33-37$ & $38-42$ & $43-47$ & $48-52$ & $53-57$ & $58-62$ & $63-67$ & $68-72$ & $73-77$ & $>77$ \\
\hline \multirow{13}{*}{ 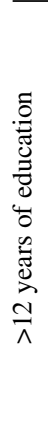 } & 95 & 93.7 & 91.2 & 88.7 & 86.2 & 83.6 & 81.1 & 78.6 & 76.1 & 73.6 & 71.0 & 68.5 & 66.0 & 63.5 \\
\hline & 90 & 88.7 & 86.1 & 83.6 & 81.1 & 78.6 & 76.0 & 73.5 & 71.0 & 68.5 & 66.0 & 63.4 & 60.9 & 58.4 \\
\hline & 85 & 85.3 & 82.8 & 80.2 & 77.7 & 75.2 & 72.7 & 70.1 & 67.6 & 65.1 & 62.6 & 60.1 & 57.5 & 55.0 \\
\hline & 80 & 82.5 & 79.9 & 77.4 & 74.9 & 72.4 & 69.8 & 67.3 & 64.8 & 62.3 & 59.8 & 57.2 & 54.7 & 52.2 \\
\hline & 70 & 77.9 & 75.4 & 72.9 & 70.4 & 67.9 & 65.3 & 62.8 & 60.3 & 57.8 & 55.2 & 52.7 & 50.2 & 47.7 \\
\hline & 60 & 74.1 & 71.6 & 69.1 & 66.6 & 64.1 & 61.5 & 59.0 & 56.5 & 54.0 & 51.4 & 48.9 & 46.4 & 43.9 \\
\hline & 50 & 70.6 & 68.1 & 65.6 & 63.1 & 60.5 & 58.0 & 55.5 & 53.0 & 50.4 & 47.9 & 45.4 & 42.9 & 40.4 \\
\hline & 40 & 67.1 & 64.6 & 62.1 & 59.5 & 57.0 & 54.5 & 52.0 & 49.4 & 46.9 & 44.4 & 41.9 & 39.4 & 36.8 \\
\hline & 30 & 63.3 & 60.8 & 58.2 & 55.7 & 53.2 & 50.7 & 48.2 & 45.6 & 43.1 & 40.6 & 38.1 & 35.5 & 33.0 \\
\hline & 20 & 58.8 & 56.3 & 53.7 & 51.2 & 48.7 & 46.2 & 43.6 & 41.1 & 38.6 & 36.1 & 33.6 & 31.0 & 28.5 \\
\hline & 15 & 56.0 & 53.4 & 50.9 & 48.4 & 45.9 & 43.3 & 40.8 & 38.3 & 35.8 & 33.3 & 30.7 & 28.2 & 25.7 \\
\hline & 10 & 52.6 & 50.1 & 47.5 & 45.0 & 42.5 & 40.0 & 37.4 & 34.9 & 32.4 & 29.9 & 27.4 & 24.8 & 22.3 \\
\hline & 5 & 47.5 & 45.0 & 42.5 & 39.9 & 37.4 & 34.9 & 32.4 & 29.8 & 27.3 & 24.8 & 22.3 & 19.8 & 17.2 \\
\hline \multirow{13}{*}{ 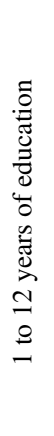 } & 95 & 85.5 & 83.0 & 80.5 & 77.9 & 75.4 & 72.9 & 70.4 & 67.9 & 65.3 & 62.8 & 60.3 & 57.8 & 55.2 \\
\hline & 90 & 80.4 & 77.9 & 75.4 & 72.9 & 70.3 & 67.8 & 65.3 & 62.8 & 60.3 & 57.7 & 55.2 & 52.7 & 50.2 \\
\hline & 85 & 77.1 & 74.5 & 72.0 & 69.5 & 67.0 & 64.4 & 61.9 & 59.4 & 56.9 & 54.4 & 51.8 & 49.3 & 46.8 \\
\hline & 80 & 74.2 & 71.7 & 69.2 & 66.7 & 64.1 & 61.6 & 59.1 & 56.6 & 54.1 & 51.5 & 49.0 & 46.5 & 44.0 \\
\hline & 70 & 69.7 & 67.2 & 64.7 & 62.2 & 59.6 & 57.1 & 54.6 & 52.1 & 49.5 & 47.0 & 44.5 & 42.0 & 39.5 \\
\hline & 60 & 65.9 & 63.4 & 60.9 & 58.4 & 55.8 & 53.3 & 50.8 & 48.3 & 45.7 & 43.2 & 40.7 & 38.2 & 35.7 \\
\hline & 50 & 62.4 & 59.9 & 57.4 & 54.8 & 52.3 & 49.8 & 47.3 & 44.7 & 42.2 & 39.7 & 37.2 & 34.7 & 32.1 \\
\hline & 40 & 58.9 & 56.3 & 53.8 & 51.3 & 48.8 & 46.3 & 43.7 & 41.2 & 38.7 & 36.2 & 33.6 & 31.1 & 28.6 \\
\hline & 30 & 55.1 & 52.5 & 50.0 & 47.5 & 45.0 & 42.5 & 39.9 & 37.4 & 34.9 & 32.4 & 29.8 & 27.3 & 24.8 \\
\hline & 20 & 50.6 & 48.0 & 45.5 & 43.0 & 40.5 & 37.9 & 35.4 & 32.9 & 30.4 & 27.9 & 25.3 & 22.8 & 20.3 \\
\hline & 15 & 47.7 & 45.2 & 42.7 & 40.2 & 37.6 & 35.1 & 32.6 & 30.1 & 27.6 & 25.0 & 22.5 & 20.0 & 17.5 \\
\hline & 10 & 44.4 & 41.8 & 39.3 & 36.8 & 34.3 & 31.7 & 29.2 & 26.7 & 24.2 & 21.7 & 19.1 & 16.6 & 14.1 \\
\hline & 5 & 39.3 & 36.8 & 34.2 & 31.7 & 29.2 & 26.7 & 24.1 & 21.6 & 19.1 & 16.6 & 14.1 & 11.5 & 9.0 \\
\hline
\end{tabular}


Table A19

Normative data for the Stroop-Color stratified by age and education levels for MEXICO

\begin{tabular}{|c|c|c|c|c|c|c|c|c|c|c|c|c|c|c|}
\hline & \multirow[b]{2}{*}{ Percentile } & \multicolumn{13}{|c|}{ Age (Years) } \\
\hline & & $18-22$ & $23-27$ & $28-32$ & $33-37$ & $38-42$ & $43-47$ & $48-52$ & $53-57$ & $58-62$ & $63-67$ & $68-72$ & $73-77$ & $>77$ \\
\hline \multirow{13}{*}{ 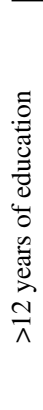 } & 95 & 104.0 & 101.8 & 99.6 & 97.4 & 95.1 & 92.9 & 90.7 & 88.5 & 86.3 & 84.0 & 81.8 & 79.6 & 77.4 \\
\hline & 90 & 98.8 & 96.6 & 94.3 & 92.1 & 89.9 & 87.7 & 85.5 & 83.2 & 81.0 & 78.8 & 76.6 & 74.3 & 72.1 \\
\hline & 85 & 95.3 & 93.1 & 90.8 & 88.6 & 86.4 & 84.2 & 82.0 & 79.7 & 77.5 & 75.3 & 73.1 & 70.8 & 68.6 \\
\hline & 80 & 92.4 & 90.1 & 87.9 & 85.7 & 83.5 & 81.3 & 79.0 & 76.8 & 74.6 & 72.4 & 70.2 & 67.9 & 65.7 \\
\hline & 70 & 87.7 & 85.5 & 83.3 & 81.0 & 78.8 & 76.6 & 74.4 & 72.2 & 69.9 & 67.7 & 65.5 & 63.3 & 61.0 \\
\hline & 60 & 83.8 & 81.6 & 79.3 & 77.1 & 74.9 & 72.7 & 70.4 & 68.2 & 66.0 & 63.8 & 61.6 & 59.3 & 57.1 \\
\hline & 50 & 80.1 & 77.9 & 75.7 & 73.5 & 71.2 & 69.0 & 66.8 & 64.6 & 62.4 & 60.1 & 57.9 & 55.7 & 53.5 \\
\hline & 40 & 76.5 & 74.3 & 72.0 & 69.8 & 67.6 & 65.4 & 63.2 & 60.9 & 58.7 & 56.5 & 54.3 & 52.0 & 49.8 \\
\hline & 30 & 72.6 & 70.3 & 68.1 & 65.9 & 63.7 & 61.4 & 59.2 & 57.0 & 54.8 & 52.6 & 50.3 & 48.1 & 45.9 \\
\hline & 20 & 67.9 & 65.7 & 63.4 & 61.2 & 59.0 & 56.8 & 54.6 & 52.3 & 50.1 & 47.9 & 45.7 & 43.4 & 41.2 \\
\hline & 15 & 65.0 & 62.8 & 60.5 & 58.3 & 56.1 & 53.9 & 51.6 & 49.4 & 47.2 & 45.0 & 42.8 & 40.5 & 38.3 \\
\hline & 10 & 61.5 & 59.3 & 57.0 & 54.8 & 52.6 & 50.4 & 48.1 & 45.9 & 43.7 & 41.5 & 39.3 & 37.0 & 34.8 \\
\hline & 5 & 56.2 & 54.0 & 51.8 & 49.6 & 47.3 & 45.1 & 42.9 & 40.7 & 38.5 & 36.2 & 34.0 & 31.8 & 29.6 \\
\hline \multirow{13}{*}{ 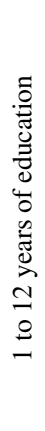 } & 95 & 98.7 & 96.4 & 94.2 & 92.0 & 89.8 & 87.6 & 85.3 & 83.1 & 80.9 & 78.7 & 76.5 & 74.2 & 72.0 \\
\hline & 90 & 93.4 & 91.2 & 89.0 & 86.8 & 84.5 & 82.3 & 80.1 & 77.9 & 75.6 & 73.4 & 71.2 & 69.0 & 66.8 \\
\hline & 85 & 89.9 & 87.7 & 85.5 & 83.3 & 81.0 & 78.8 & 76.6 & 74.4 & 72.2 & 69.9 & 67.7 & 65.5 & 63.3 \\
\hline & 80 & 87.0 & 84.8 & 82.6 & 80.3 & 78.1 & 75.9 & 73.7 & 71.5 & 69.2 & 67.0 & 64.8 & 62.6 & 60.4 \\
\hline & 70 & 82.3 & 80.1 & 77.9 & 75.7 & 73.5 & 71.2 & 69.0 & 66.8 & 64.6 & 62.4 & 60.1 & 57.9 & 55.7 \\
\hline & 60 & 78.4 & 76.2 & 74.0 & 71.7 & 69.5 & 67.3 & 65.1 & 62.9 & 60.6 & 58.4 & 56.2 & 54.0 & 51.8 \\
\hline & 50 & 74.8 & 72.5 & 70.3 & 68.1 & 65.9 & 63.7 & 61.4 & 59.2 & 57.0 & 54.8 & 52.6 & 50.3 & 48.1 \\
\hline & 40 & 71.1 & 68.9 & 66.7 & 64.5 & 62.2 & 60.0 & 57.8 & 55.6 & 53.4 & 51.1 & 48.9 & 46.7 & 44.5 \\
\hline & 30 & 67.2 & 65.0 & 62.7 & 60.5 & 58.3 & 56.1 & 53.9 & 51.6 & 49.4 & 47.2 & 45.0 & 42.8 & 40.5 \\
\hline & 20 & 62.5 & 60.3 & 58.1 & 55.9 & 53.6 & 51.4 & 49.2 & 47.0 & 44.8 & 42.5 & 40.3 & 38.1 & 35.9 \\
\hline & 15 & 59.6 & 57.4 & 55.2 & 52.9 & 50.7 & 48.5 & 46.3 & 44.1 & 41.8 & 39.6 & 37.4 & 35.2 & 33.0 \\
\hline & 10 & 56.1 & 53.9 & 51.7 & 49.5 & 47.2 & 45.0 & 42.8 & 40.6 & 38.3 & 36.1 & 33.9 & 31.7 & 29.5 \\
\hline & 5 & 50.9 & 48.6 & 46.4 & 44.2 & 42.0 & 39.8 & 37.5 & 35.3 & 33.1 & 30.9 & 28.7 & 26.4 & 24.2 \\
\hline
\end{tabular}

Table A20

Normative data for the Stroop-Color stratified by age and education levels for PARAGUAY

\begin{tabular}{|c|c|c|c|c|c|c|c|c|c|c|c|c|c|c|}
\hline & \multirow[b]{2}{*}{ Percentile } & \multicolumn{13}{|c|}{ Age (Years) } \\
\hline & & $18-22$ & $23-27$ & $28-32$ & $33-37$ & $38-42$ & $43-47$ & $48-52$ & $53-57$ & $58-62$ & $63-67$ & $68-72$ & $73-77$ & $>77$ \\
\hline \multirow{13}{*}{ 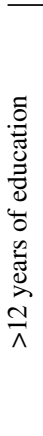 } & 95 & 96.4 & 95.4 & 94.5 & 93.5 & 92.5 & 91.5 & 90.6 & 89.6 & 88.6 & 87.6 & 86.7 & 85.7 & 84.7 \\
\hline & 90 & 92.5 & 91.5 & 90.5 & 89.5 & 88.6 & 87.6 & 86.6 & 85.6 & 84.7 & 83.7 & 82.7 & 81.7 & 80.8 \\
\hline & 85 & 89.8 & 88.9 & 87.9 & 86.9 & 85.9 & 85.0 & 84.0 & 83.0 & 82.0 & 81.1 & 80.1 & 79.1 & 78.1 \\
\hline & 80 & 87.6 & 86.7 & 85.7 & 84.7 & 83.7 & 82.8 & 81.8 & 80.8 & 79.8 & 78.9 & 77.9 & 76.9 & 75.9 \\
\hline & 70 & 84.1 & 83.2 & 82.2 & 81.2 & 80.2 & 79.3 & 78.3 & 77.3 & 76.3 & 75.4 & 74.4 & 73.4 & 72.4 \\
\hline & 60 & 81.2 & 80.2 & 79.2 & 78.3 & 77.3 & 76.3 & 75.3 & 74.4 & 73.4 & 72.4 & 71.4 & 70.5 & 69.5 \\
\hline & 50 & 78.4 & 77.5 & 76.5 & 75.5 & 74.5 & 73.6 & 72.6 & 71.6 & 70.6 & 69.7 & 68.7 & 67.7 & 66.7 \\
\hline & 40 & 75.7 & 74.7 & 73.7 & 72.8 & 71.8 & 70.8 & 69.9 & 68.9 & 67.9 & 66.9 & 66.0 & 65.0 & 64.0 \\
\hline & 30 & 72.7 & 71.8 & 70.8 & 69.8 & 68.8 & 67.9 & 66.9 & 65.9 & 64.9 & 64.0 & 63.0 & 62.0 & 61.0 \\
\hline & 20 & 69.2 & 68.3 & 67.3 & 66.3 & 65.3 & 64.4 & 63.4 & 62.4 & 61.4 & 60.5 & 59.5 & 58.5 & 57.5 \\
\hline & 15 & 67.0 & 66.1 & 65.1 & 64.1 & 63.1 & 62.2 & 61.2 & 60.2 & 59.2 & 58.3 & 57.3 & 56.3 & 55.3 \\
\hline & 10 & 64.4 & 63.4 & 62.5 & 61.5 & 60.5 & 59.5 & 58.6 & 57.6 & 56.6 & 55.6 & 54.7 & 53.7 & 52.7 \\
\hline & 5 & 60.5 & 59.5 & 58.5 & 57.5 & 56.6 & 55.6 & 54.6 & 53.6 & 52.7 & 51.7 & 50.7 & 49.7 & 48.8 \\
\hline \multirow{13}{*}{ 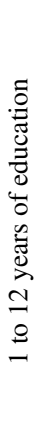 } & 95 & 84.3 & 83.3 & 82.3 & 81.3 & 80.4 & 79.4 & 78.4 & 77.4 & 76.5 & 75.5 & 74.5 & 73.5 & 72.6 \\
\hline & 90 & 80.3 & 79.3 & 78.4 & 77.4 & 76.4 & 75.4 & 74.5 & 73.5 & 72.5 & 71.5 & 70.6 & 69.6 & 68.6 \\
\hline & 85 & 77.7 & 76.7 & 75.7 & 74.8 & 73.8 & 72.8 & 71.8 & 70.9 & 69.9 & 68.9 & 67.9 & 67.0 & 66.0 \\
\hline & 80 & 75.5 & 74.5 & 73.5 & 72.6 & 71.6 & 70.6 & 69.6 & 68.7 & 67.7 & 66.7 & 65.7 & 64.8 & 63.8 \\
\hline & 70 & 72.0 & 71.0 & 70.0 & 69.1 & 68.1 & 67.1 & 66.1 & 65.2 & 64.2 & 63.2 & 62.2 & 61.3 & 60.3 \\
\hline & 60 & 69.0 & 68.0 & 67.1 & 66.1 & 65.1 & 64.1 & 63.2 & 62.2 & 61.2 & 60.3 & 59.3 & 58.3 & 57.3 \\
\hline & 50 & 66.3 & 65.3 & 64.3 & 63.4 & 62.4 & 61.4 & 60.4 & 59.5 & 58.5 & 57.5 & 56.5 & 55.6 & 54.6 \\
\hline & 40 & 63.5 & 62.6 & 61.6 & 60.6 & 59.6 & 58.7 & 57.7 & 56.7 & 55.7 & 54.8 & 53.8 & 52.8 & 51.8 \\
\hline & 30 & 60.6 & 59.6 & 58.6 & 57.7 & 56.7 & 55.7 & 54.7 & 53.8 & 52.8 & 51.8 & 50.8 & 49.9 & 48.9 \\
\hline & 20 & 57.1 & 56.1 & 55.1 & 54.2 & 53.2 & 52.2 & 51.2 & 50.3 & 49.3 & 48.3 & 47.3 & 46.4 & 45.4 \\
\hline & 15 & 54.9 & 53.9 & 52.9 & 52.0 & 51.0 & 50.0 & 49.0 & 48.1 & 47.1 & 46.1 & 45.1 & 44.2 & 43.2 \\
\hline & 10 & 52.3 & 51.3 & 50.3 & 49.3 & 48.4 & 47.4 & 46.4 & 45.4 & 44.5 & 43.5 & 42.5 & 41.5 & 40.6 \\
\hline & 5 & 48.3 & 47.3 & 46.4 & 45.4 & 44.4 & 43.4 & 42.5 & 41.5 & 40.5 & 39.5 & 38.6 & 37.6 & 36.6 \\
\hline
\end{tabular}


Table A21

Normative data for the Stroop-Color stratified by age for PERU

\begin{tabular}{lccccccccccccc}
\hline & \multicolumn{10}{c}{ Age (Years) } \\
\cline { 2 - 21 } Percentile & $18-22$ & $23-27$ & $28-32$ & $33-37$ & $38-42$ & $43-47$ & $48-52$ & $53-57$ & $58-62$ & $63-67$ & $68-72$ & $73-77$ & $>77$ \\
\hline 95 & 100.6 & 98.9 & 97.3 & 95.6 & 94.0 & 92.3 & 90.7 & 89.0 & 87.4 & 85.7 & 84.1 & 82.5 & 80.8 \\
90 & 95.4 & 93.8 & 92.1 & 90.5 & 88.8 & 87.2 & 85.5 & 83.9 & 82.3 & 80.6 & 79.0 & 77.3 & 75.7 \\
85 & 92.0 & 90.4 & 88.7 & 87.1 & 85.4 & 83.8 & 82.1 & 80.5 & 78.8 & 77.2 & 75.5 & 73.9 & 72.2 \\
80 & 89.1 & 87.5 & 85.9 & 84.2 & 82.6 & 80.9 & 79.3 & 77.6 & 76.0 & 74.3 & 72.7 & 71.0 & 69.4 \\
70 & 84.6 & 82.9 & 81.3 & 79.6 & 78.0 & 76.3 & 74.7 & 73.1 & 71.4 & 69.8 & 68.1 & 66.5 & 64.8 \\
60 & 80.7 & 79.1 & 77.4 & 75.8 & 74.1 & 72.5 & 70.9 & 69.2 & 67.6 & 65.9 & 64.3 & 62.6 & 61.0 \\
50 & 77.2 & 75.5 & 73.9 & 72.2 & 70.6 & 68.9 & 67.3 & 65.6 & 64.0 & 62.3 & 60.7 & 59.1 & 57.4 \\
40 & 73.6 & 71.9 & 70.3 & 68.7 & 67.0 & 65.4 & 63.7 & 62.1 & 60.4 & 58.8 & 57.1 & 55.5 & 53.8 \\
30 & 69.7 & 68.1 & 66.5 & 64.8 & 63.2 & 61.5 & 59.9 & 58.2 & 56.6 & 54.9 & 53.3 & 51.6 & 50.0 \\
20 & 65.2 & 63.5 & 61.9 & 60.2 & 58.6 & 56.9 & 55.3 & 53.7 & 52.0 & 50.4 & 48.7 & 47.1 & 45.4 \\
15 & 62.3 & 60.7 & 59.0 & 57.4 & 55.7 & 54.1 & 52.4 & 50.8 & 49.2 & 47.5 & 45.9 & 44.2 & 42.6 \\
10 & 58.9 & 57.3 & 55.6 & 54.0 & 52.3 & 50.7 & 49.0 & 47.4 & 45.7 & 44.1 & 42.4 & 40.8 & 39.1 \\
5 & 53.8 & 52.1 & 50.5 & 48.8 & 47.2 & 45.5 & 43.9 & 42.2 & 40.6 & 39.0 & 37.3 & 35.7 & 34.0 \\
\hline
\end{tabular}

Table A22

Normative data for the Stroop-Color stratified by age and education levels for PUERTO RICO

\begin{tabular}{|c|c|c|c|c|c|c|c|c|c|c|c|c|c|c|}
\hline & \multirow[b]{2}{*}{ Percentile } & \multicolumn{13}{|c|}{ Age (Years) } \\
\hline & & $18-22$ & $23-27$ & $28-32$ & $33-37$ & $38-42$ & $43-47$ & $48-52$ & $53-57$ & $58-62$ & $63-67$ & $68-72$ & $73-77$ & $>77$ \\
\hline \multirow{13}{*}{ 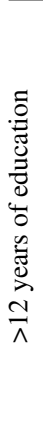 } & 95 & 99.5 & 97.2 & 95.0 & 92.8 & 90.5 & 88.3 & 86.1 & 83.9 & 81.6 & 79.4 & 77.2 & 74.9 & 72.7 \\
\hline & 90 & 95.0 & 92.8 & 90.5 & 88.3 & 86.1 & 83.8 & 81.6 & 79.4 & 77.1 & 74.9 & 72.7 & 70.4 & 68.2 \\
\hline & 85 & 92.0 & 89.8 & 87.5 & 85.3 & 83.1 & 80.8 & 78.6 & 76.4 & 74.2 & 71.9 & 69.7 & 67.5 & 65.2 \\
\hline & 80 & 89.5 & 87.3 & 85.1 & 82.8 & 80.6 & 78.4 & 76.1 & 73.9 & 71.7 & 69.4 & 67.2 & 65.0 & 62.7 \\
\hline & 70 & 85.5 & 83.3 & 81.1 & 78.8 & 76.6 & 74.4 & 72.1 & 69.9 & 67.7 & 65.4 & 63.2 & 61.0 & 58.8 \\
\hline & 60 & 82.2 & 79.9 & 77.7 & 75.5 & 73.3 & 71.0 & 68.8 & 66.6 & 64.3 & 62.1 & 59.9 & 57.6 & 55.4 \\
\hline & 50 & 79.1 & 76.8 & 74.6 & 72.4 & 70.1 & 67.9 & 65.7 & 63.4 & 61.2 & 59.0 & 56.7 & 54.5 & 52.3 \\
\hline & 40 & 76.0 & 73.7 & 71.5 & 69.3 & 67.0 & 64.8 & 62.6 & 60.3 & 58.1 & 55.9 & 53.6 & 51.4 & 49.2 \\
\hline & 30 & 72.6 & 70.4 & 68.1 & 65.9 & 63.7 & 61.4 & 59.2 & 57.0 & 54.7 & 52.5 & 50.3 & 48.0 & 45.8 \\
\hline & 20 & 68.6 & 66.4 & 64.2 & 61.9 & 59.7 & 57.5 & 55.2 & 53.0 & 50.8 & 48.5 & 46.3 & 44.1 & 41.8 \\
\hline & 15 & 66.1 & 63.9 & 61.7 & 59.4 & 57.2 & 55.0 & 52.7 & 50.5 & 48.3 & 46.0 & 43.8 & 41.6 & 39.3 \\
\hline & 10 & 63.1 & 60.9 & 58.7 & 56.4 & 54.2 & 52.0 & 49.7 & 47.5 & 45.3 & 43.0 & 40.8 & 38.6 & 36.4 \\
\hline & 5 & 58.7 & 56.4 & 54.2 & 52.0 & 49.7 & 47.5 & 45.3 & 43.0 & 40.8 & 38.6 & 36.3 & 34.1 & 31.9 \\
\hline \multirow{13}{*}{ 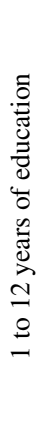 } & 95 & 95.0 & 92.7 & 90.5 & 88.3 & 86.0 & 83.8 & 81.6 & 79.3 & 77.1 & 74.9 & 72.7 & 70.4 & 68.2 \\
\hline & 90 & 90.5 & 88.3 & 86.0 & 83.8 & 81.6 & 79.3 & 77.1 & 74.9 & 72.6 & 70.4 & 68.2 & 65.9 & 63.7 \\
\hline & 85 & 87.5 & 85.3 & 83.0 & 80.8 & 78.6 & 76.3 & 74.1 & 71.9 & 69.7 & 67.4 & 65.2 & 63.0 & 60.7 \\
\hline & 80 & 85.0 & 82.8 & 80.6 & 78.3 & 76.1 & 73.9 & 71.6 & 69.4 & 67.2 & 64.9 & 62.7 & 60.5 & 58.2 \\
\hline & 70 & 81.0 & 78.8 & 76.6 & 74.3 & 72.1 & 69.9 & 67.6 & 65.4 & 63.2 & 60.9 & 58.7 & 56.5 & 54.3 \\
\hline & 60 & 77.7 & 75.4 & 73.2 & 71.0 & 68.7 & 66.5 & 64.3 & 62.1 & 59.8 & 57.6 & 55.4 & 53.1 & 50.9 \\
\hline & 50 & 74.6 & 72.3 & 70.1 & 67.9 & 65.6 & 63.4 & 61.2 & 58.9 & 56.7 & 54.5 & 52.2 & 50.0 & 47.8 \\
\hline & 40 & 71.5 & 69.2 & 67.0 & 64.8 & 62.5 & 60.3 & 58.1 & 55.8 & 53.6 & 51.4 & 49.1 & 46.9 & 44.7 \\
\hline & 30 & 68.1 & 65.9 & 63.6 & 61.4 & 59.2 & 56.9 & 54.7 & 52.5 & 50.2 & 48.0 & 45.8 & 43.5 & 41.3 \\
\hline & 20 & 64.1 & 61.9 & 59.7 & 57.4 & 55.2 & 53.0 & 50.7 & 48.5 & 46.3 & 44.0 & 41.8 & 39.6 & 37.3 \\
\hline & 15 & 61.6 & 59.4 & 57.2 & 54.9 & 52.7 & 50.5 & 48.2 & 46.0 & 43.8 & 41.5 & 39.3 & 37.1 & 34.8 \\
\hline & 10 & 58.6 & 56.4 & 54.2 & 51.9 & 49.7 & 47.5 & 45.2 & 43.0 & 40.8 & 38.5 & 36.3 & 34.1 & 31.9 \\
\hline & 5 & 54.2 & 51.9 & 49.7 & 47.5 & 45.2 & 43.0 & 40.8 & 38.5 & 36.3 & 34.1 & 31.8 & 29.6 & 27.4 \\
\hline
\end{tabular}


Table A23

Normative data for the Stroop Word-Color stratified by age and education levels for ARGENTINA

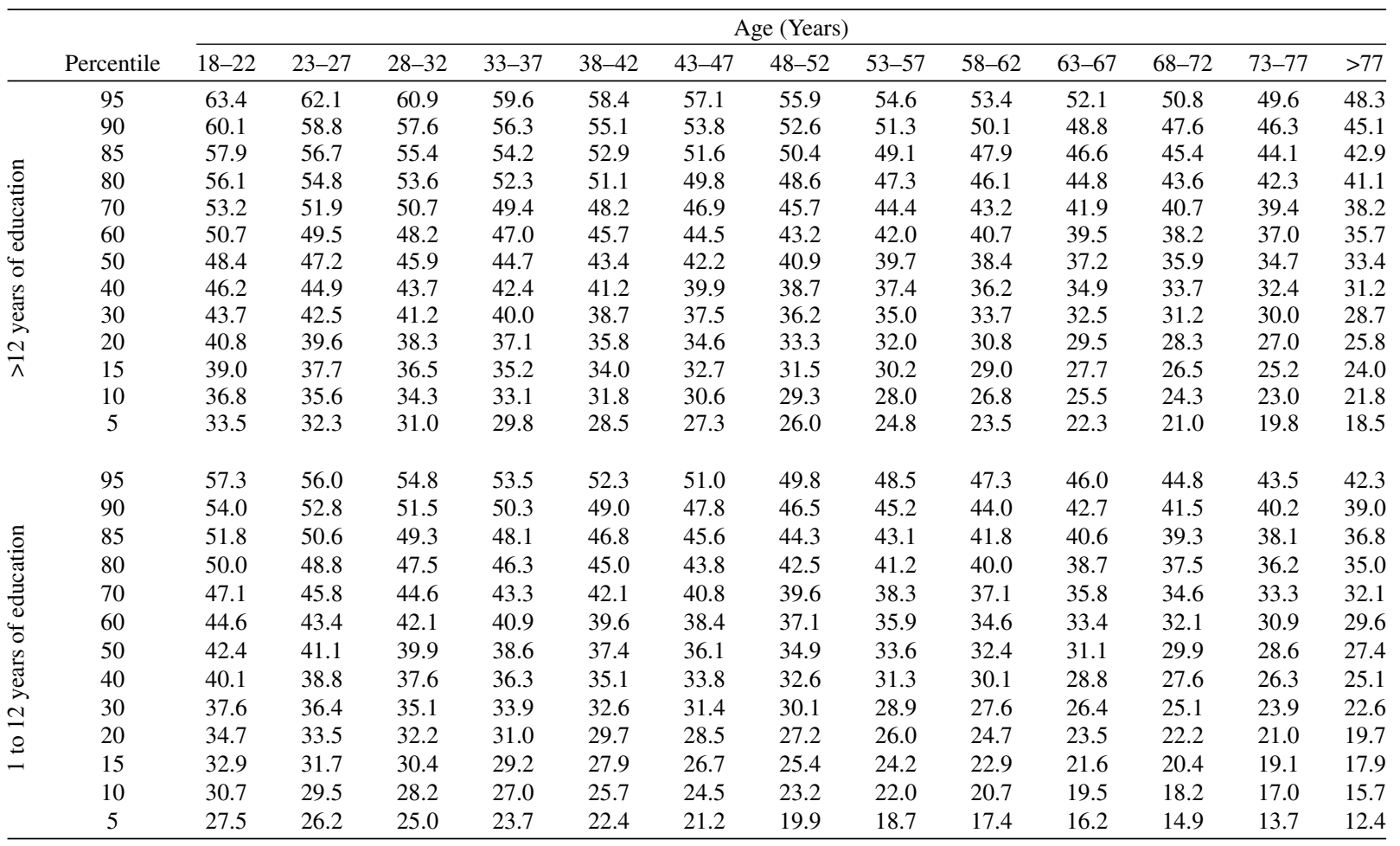

Table A24

Normative data for the Stroop Word-Color stratified by age and education levels for BOLIVIA

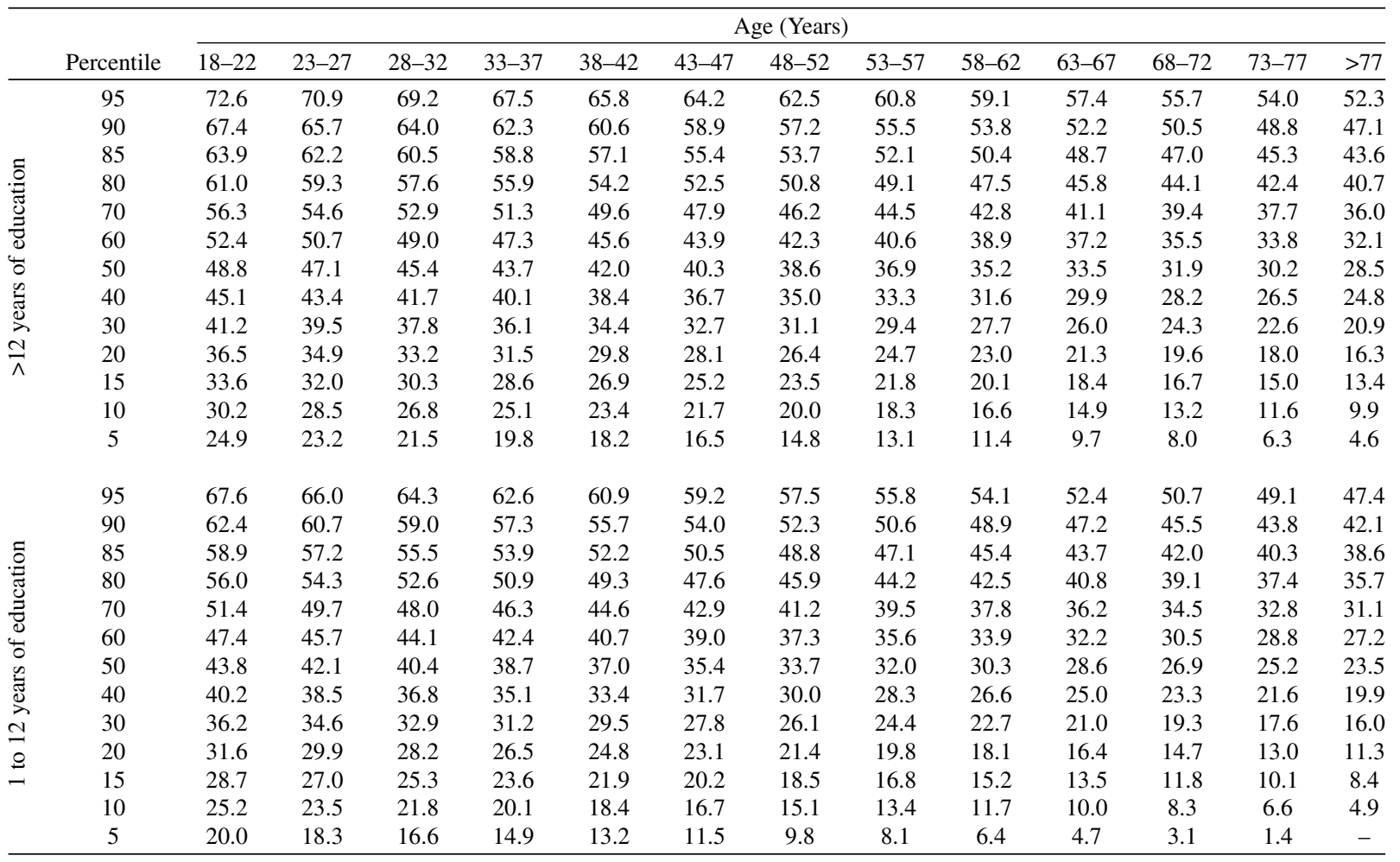


Table A25

Normative data for the Stroop Word-Color stratified by age and education levels for CHILE

\begin{tabular}{|c|c|c|c|c|c|c|c|c|c|c|c|c|c|c|}
\hline & \multirow[b]{2}{*}{ Percentile } & \multicolumn{13}{|c|}{ Age (Years) } \\
\hline & & $18-22$ & $23-27$ & $28-32$ & $33-37$ & $38-42$ & $43-47$ & $48-52$ & $53-57$ & $58-62$ & $63-67$ & $68-72$ & $73-77$ & $>77$ \\
\hline \multirow{13}{*}{ 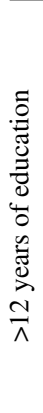 } & 95 & 73.5 & 71.7 & 69.9 & 68.1 & 66.3 & 64.6 & 62.8 & 61.0 & 59.2 & 57.4 & 55.6 & 53.8 & $\overline{52.1}$ \\
\hline & 90 & 69.4 & 67.6 & 65.8 & 64.0 & 62.2 & 60.4 & 58.7 & 56.9 & 55.1 & 53.3 & 51.5 & 49.7 & 47.9 \\
\hline & 85 & 66.6 & 64.8 & 63.1 & 61.3 & 59.5 & 57.7 & 55.9 & 54.1 & 52.3 & 50.6 & 48.8 & 47.0 & 45.2 \\
\hline & 80 & 64.3 & 62.6 & 60.8 & 59.0 & 57.2 & 55.4 & 53.6 & 51.8 & 50.1 & 48.3 & 46.5 & 44.7 & 42.9 \\
\hline & 70 & 60.7 & 58.9 & 57.1 & 55.3 & 53.5 & 51.8 & 50.0 & 48.2 & 46.4 & 44.6 & 42.8 & 41.0 & 39.3 \\
\hline & 60 & 57.6 & 55.8 & 54.0 & 52.2 & 50.5 & 48.7 & 46.9 & 45.1 & 43.3 & 41.5 & 39.7 & 38.0 & 36.2 \\
\hline & 50 & 54.7 & 53.0 & 51.2 & 49.4 & 47.6 & 45.8 & 44.0 & 42.2 & 40.5 & 38.7 & 36.9 & 35.1 & 33.3 \\
\hline & 40 & 51.9 & 50.1 & 48.3 & 46.5 & 44.7 & 43.0 & 41.2 & 39.4 & 37.6 & 35.8 & 34.0 & 32.2 & 30.5 \\
\hline & 30 & 48.8 & 47.0 & 45.2 & 43.4 & 41.7 & 39.9 & 38.1 & 36.3 & 34.5 & 32.7 & 30.9 & 29.2 & 27.4 \\
\hline & 20 & 45.1 & 43.4 & 41.6 & 39.8 & 38.0 & 36.2 & 34.4 & 32.6 & 30.9 & 29.1 & 27.3 & 25.5 & 23.7 \\
\hline & 15 & 42.9 & 41.1 & 39.3 & 37.5 & 35.7 & 33.9 & 32.1 & 30.4 & 28.6 & 26.8 & 25.0 & 23.2 & 21.4 \\
\hline & 10 & 40.1 & 38.3 & 36.5 & 34.8 & 33.0 & 31.2 & 29.4 & 27.6 & 25.8 & 24.0 & 22.3 & 20.5 & 18.7 \\
\hline & 5 & 36.0 & 34.2 & 32.4 & 30.6 & 28.9 & 27.1 & 25.3 & 23.5 & 21.7 & 19.9 & 18.1 & 16.4 & 14.6 \\
\hline \multirow{13}{*}{ 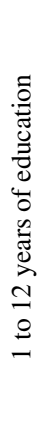 } & 95 & 61.4 & 59.6 & 57.8 & 56.0 & 54.2 & 52.5 & 50.7 & 48.9 & 47.1 & 45.3 & 43.5 & 41.7 & 40.0 \\
\hline & 90 & 57.3 & 55.5 & 53.7 & 51.9 & 50.1 & 48.3 & 46.6 & 44.8 & 43.0 & 41.2 & 39.4 & 37.6 & 35.8 \\
\hline & 85 & 54.5 & 52.7 & 51.0 & 49.2 & 47.4 & 45.6 & 43.8 & 42.0 & 40.2 & 38.5 & 36.7 & 34.9 & 33.1 \\
\hline & 80 & 52.2 & 50.5 & 48.7 & 46.9 & 45.1 & 43.3 & 41.5 & 39.7 & 38.0 & 36.2 & 34.4 & 32.6 & 30.8 \\
\hline & 70 & 48.6 & 46.8 & 45.0 & 43.2 & 41.4 & 39.7 & 37.9 & 36.1 & 34.3 & 32.5 & 30.7 & 28.9 & 27.2 \\
\hline & 60 & 45.5 & 43.7 & 41.9 & 40.1 & 38.4 & 36.6 & 34.8 & 33.0 & 31.2 & 29.4 & 27.6 & 25.9 & 24.1 \\
\hline & 50 & 42.6 & 40.9 & 39.1 & 37.3 & 35.5 & 33.7 & 31.9 & 30.1 & 28.4 & 26.6 & 24.8 & 23.0 & 21.2 \\
\hline & 40 & 39.8 & 38.0 & 36.2 & 34.4 & 32.6 & 30.9 & 29.1 & 27.3 & 25.5 & 23.7 & 21.9 & 20.1 & 18.4 \\
\hline & 30 & 36.7 & 34.9 & 33.1 & 31.3 & 29.6 & 27.8 & 26.0 & 24.2 & 22.4 & 20.6 & 18.8 & 17.1 & 15.3 \\
\hline & 20 & 33.0 & 31.3 & 29.5 & 27.7 & 25.9 & 24.1 & 22.3 & 20.5 & 18.8 & 17.0 & 15.2 & 13.4 & 11.6 \\
\hline & 15 & 30.8 & 29.0 & 27.2 & 25.4 & 23.6 & 21.8 & 20.0 & 18.3 & 16.5 & 14.7 & 12.9 & 11.1 & 9.3 \\
\hline & 10 & 28.0 & 26.2 & 24.4 & 22.7 & 20.9 & 19.1 & 17.3 & 15.5 & 13.7 & 11.9 & 10.2 & 8.4 & 6.6 \\
\hline & 5 & 23.9 & 22.1 & 20.3 & 18.5 & 16.8 & 15.0 & 13.2 & 11.4 & 9.6 & 7.8 & 6.0 & 4.3 & 2.5 \\
\hline
\end{tabular}

Table A26

Normative data for the Stroop Word-Color stratified by age and education levels for CUBA

\begin{tabular}{|c|c|c|c|c|c|c|c|c|c|c|c|c|c|c|}
\hline & \multirow[b]{2}{*}{ Percentile } & \multicolumn{13}{|c|}{ Age (Years) } \\
\hline & & $18-22$ & $23-27$ & $28-32$ & $33-37$ & $38-42$ & $43-47$ & $48-52$ & $53-57$ & $58-62$ & $63-67$ & $68-72$ & $73-77$ & $>77$ \\
\hline \multirow{13}{*}{ 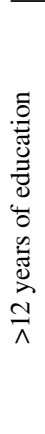 } & 95 & 69.8 & 68.4 & 66.9 & 65.4 & 64.0 & 62.5 & 61.0 & 59.6 & 58.1 & 56.6 & 55.2 & 53.7 & 52.2 \\
\hline & 90 & 65.0 & 63.6 & 62.1 & 60.6 & 59.2 & 57.7 & 56.2 & 54.8 & 53.3 & 51.8 & 50.4 & 48.9 & 47.4 \\
\hline & 85 & 61.8 & 60.4 & 58.9 & 57.4 & 56.0 & 54.5 & 53.0 & 51.6 & 50.1 & 48.6 & 47.2 & 45.7 & 44.2 \\
\hline & 80 & 59.2 & 57.7 & 56.2 & 54.8 & 53.3 & 51.8 & 50.4 & 48.9 & 47.4 & 46.0 & 44.5 & 43.0 & 41.6 \\
\hline & 70 & 54.9 & 53.4 & 52.0 & 50.5 & 49.0 & 47.6 & 46.1 & 44.6 & 43.2 & 41.7 & 40.2 & 38.8 & 37.3 \\
\hline & 60 & 51.3 & 49.8 & 48.4 & 46.9 & 45.4 & 44.0 & 42.5 & 41.0 & 39.6 & 38.1 & 36.6 & 35.2 & 33.7 \\
\hline & 50 & 48.0 & 46.5 & 45.0 & 43.6 & 42.1 & 40.6 & 39.2 & 37.7 & 36.2 & 34.8 & 33.3 & 31.8 & 30.4 \\
\hline & 40 & 44.6 & 43.2 & 41.7 & 40.2 & 38.8 & 37.3 & 35.8 & 34.4 & 32.9 & 31.5 & 30.0 & 28.5 & 27.1 \\
\hline & 30 & 41.1 & 39.6 & 38.1 & 36.7 & 35.2 & 33.7 & 32.3 & 30.8 & 29.3 & 27.9 & 26.4 & 24.9 & 23.5 \\
\hline & 20 & 36.8 & 35.3 & 33.9 & 32.4 & 30.9 & 29.5 & 28.0 & 26.5 & 25.1 & 23.6 & 22.1 & 20.7 & 19.2 \\
\hline & 15 & 34.1 & 32.7 & 31.2 & 29.7 & 28.3 & 26.8 & 25.3 & 23.9 & 22.4 & 20.9 & 19.5 & 18.0 & 16.5 \\
\hline & 10 & 30.9 & 29.5 & 28.0 & 26.5 & 25.1 & 23.6 & 22.1 & 20.7 & 19.2 & 17.7 & 16.3 & 14.8 & 13.3 \\
\hline & 5 & 26.1 & 24.7 & 23.2 & 21.7 & 20.3 & 18.8 & 17.3 & 15.9 & 14.4 & 12.9 & 11.5 & 10.0 & 8.5 \\
\hline \multirow{13}{*}{ 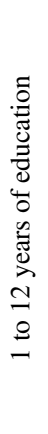 } & 95 & 66.1 & 64.6 & 63.1 & 61.7 & 60.2 & 58.7 & 57.3 & 55.8 & 54.3 & 52.9 & 51.4 & 49.9 & 48.5 \\
\hline & 90 & 61.3 & 59.8 & 58.3 & 56.9 & 55.4 & 53.9 & 52.5 & 51.0 & 49.5 & 48.1 & 46.6 & 45.1 & 43.7 \\
\hline & 85 & 58.1 & 56.6 & 55.1 & 53.7 & 52.2 & 50.7 & 49.3 & 47.8 & 46.3 & 44.9 & 43.4 & 41.9 & 40.5 \\
\hline & 80 & 55.4 & 53.9 & 52.5 & 51.0 & 49.5 & 48.1 & 46.6 & 45.1 & 43.7 & 42.2 & 40.8 & 39.3 & 37.8 \\
\hline & 70 & 51.1 & 49.7 & 48.2 & 46.8 & 45.3 & 43.8 & 42.4 & 40.9 & 39.4 & 38.0 & 36.5 & 35.0 & 33.6 \\
\hline & 60 & 47.6 & 46.1 & 44.6 & 43.2 & 41.7 & 40.2 & 38.8 & 37.3 & 35.8 & 34.4 & 32.9 & 31.4 & 30.0 \\
\hline & 50 & 44.2 & 42.8 & 41.3 & 39.8 & 38.4 & 36.9 & 35.4 & 34.0 & 32.5 & 31.0 & 29.6 & 28.1 & 26.6 \\
\hline & 40 & 40.9 & 39.4 & 38.0 & 36.5 & 35.0 & 33.6 & 32.1 & 30.6 & 29.2 & 27.7 & 26.2 & 24.8 & 23.3 \\
\hline & 30 & 37.3 & 35.8 & 34.4 & 32.9 & 31.4 & 30.0 & 28.5 & 27.0 & 25.6 & 24.1 & 22.6 & 21.2 & 19.7 \\
\hline & 20 & 33.0 & 31.6 & 30.1 & 28.6 & 27.2 & 25.7 & 24.2 & 22.8 & 21.3 & 19.8 & 18.4 & 16.9 & 15.4 \\
\hline & 15 & 30.4 & 28.9 & 27.4 & 26.0 & 24.5 & 23.0 & 21.6 & 20.1 & 18.6 & 17.2 & 15.7 & 14.2 & 12.8 \\
\hline & 10 & 27.2 & 25.7 & 24.2 & 22.8 & 21.3 & 19.8 & 18.4 & 16.9 & 15.4 & 14.0 & 12.5 & 11.0 & 9.6 \\
\hline & 5 & 22.4 & 20.9 & 19.4 & 18.0 & 16.5 & 15.0 & 13.6 & 12.1 & 10.7 & 9.2 & 7.7 & 6.3 & 4.8 \\
\hline
\end{tabular}


Table A27

Normative data for the Stroop Word-Color stratified by age and education levels for EL SALVADOR

\begin{tabular}{|c|c|c|c|c|c|c|c|c|c|c|c|c|c|c|}
\hline & \multirow[b]{2}{*}{ Percentile } & \multicolumn{13}{|c|}{ Age (Years) } \\
\hline & & $18-22$ & $23-27$ & $28-32$ & $33-37$ & $38-42$ & $43-47$ & $48-52$ & $53-57$ & $58-62$ & $63-67$ & $68-72$ & $73-77$ & $>77$ \\
\hline \multirow{13}{*}{ 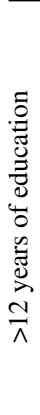 } & 95 & 61.7 & 60.7 & 59.7 & 58.7 & 57.7 & 56.7 & 55.7 & 54.7 & 53.7 & 52.7 & 51.7 & 50.7 & 49.7 \\
\hline & 90 & 57.9 & 56.9 & 55.9 & 54.9 & 53.8 & 52.8 & 51.8 & 50.8 & 49.8 & 48.8 & 47.8 & 46.8 & 45.8 \\
\hline & 85 & 55.3 & 54.3 & 53.3 & 52.3 & 51.3 & 50.3 & 49.3 & 48.3 & 47.3 & 46.3 & 45.3 & 44.3 & 43.3 \\
\hline & 80 & 53.2 & 52.2 & 51.2 & 50.2 & 49.2 & 48.2 & 47.2 & 46.2 & 45.2 & 44.2 & 43.2 & 42.2 & 41.1 \\
\hline & 70 & 49.8 & 48.8 & 47.8 & 46.8 & 45.8 & 44.8 & 43.8 & 42.8 & 41.8 & 40.8 & 39.7 & 38.7 & 37.7 \\
\hline & 60 & 46.9 & 45.9 & 44.9 & 43.9 & 42.9 & 41.9 & 40.9 & 39.9 & 38.9 & 37.9 & 36.9 & 35.9 & 34.9 \\
\hline & 50 & 44.2 & 43.2 & 42.2 & 41.2 & 40.2 & 39.2 & 38.2 & 37.2 & 36.2 & 35.2 & 34.2 & 33.2 & 32.2 \\
\hline & 40 & 41.6 & 40.6 & 39.6 & 38.6 & 37.6 & 36.6 & 35.6 & 34.6 & 33.6 & 32.6 & 31.6 & 30.6 & 29.6 \\
\hline & 30 & 38.7 & 37.7 & 36.7 & 35.7 & 34.7 & 33.7 & 32.7 & 31.7 & 30.7 & 29.7 & 28.7 & 27.7 & 26.7 \\
\hline & 20 & 35.3 & 34.3 & 33.3 & 32.3 & 31.3 & 30.3 & 29.3 & 28.3 & 27.3 & 26.3 & 25.3 & 24.3 & 23.3 \\
\hline & 15 & 33.2 & 32.2 & 31.2 & 30.2 & 29.2 & 28.2 & 27.2 & 26.2 & 25.2 & 24.2 & 23.1 & 22.1 & 21.1 \\
\hline & 10 & 30.6 & 29.6 & 28.6 & 27.6 & 26.6 & 25.6 & 24.6 & 23.6 & 22.6 & 21.6 & 20.6 & 19.6 & 18.6 \\
\hline & 5 & 26.8 & 25.8 & 24.8 & 23.8 & 22.8 & 21.8 & 20.8 & 19.8 & 18.8 & 17.8 & 16.8 & 15.8 & 14.8 \\
\hline \multirow{13}{*}{ 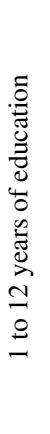 } & 95 & 51.5 & 50.5 & 49.5 & 48.5 & 47.5 & 46.5 & 45.5 & 44.5 & 43.5 & 42.5 & 41.5 & 40.5 & 39.5 \\
\hline & 90 & 47.7 & 46.7 & 45.7 & 44.7 & 43.7 & 42.7 & 41.6 & 40.6 & 39.6 & 38.6 & 37.6 & 36.6 & 35.6 \\
\hline & 85 & 45.1 & 44.1 & 43.1 & 42.1 & 41.1 & 40.1 & 39.1 & 38.1 & 37.1 & 36.1 & 35.1 & 34.1 & 33.1 \\
\hline & 80 & 43.0 & 42.0 & 41.0 & 40.0 & 39.0 & 38.0 & 37.0 & 36.0 & 35.0 & 34.0 & 33.0 & 32.0 & 31.0 \\
\hline & 70 & 39.6 & 38.6 & 37.6 & 36.6 & 35.6 & 34.6 & 33.6 & 32.6 & 31.6 & 30.6 & 29.6 & 28.5 & 27.5 \\
\hline & 60 & 36.7 & 35.7 & 34.7 & 33.7 & 32.7 & 31.7 & 30.7 & 29.7 & 28.7 & 27.7 & 26.7 & 25.7 & 24.7 \\
\hline & 50 & 34.0 & 33.0 & 32.0 & 31.0 & 30.0 & 29.0 & 28.0 & 27.0 & 26.0 & 25.0 & 24.0 & 23.0 & 22.0 \\
\hline & 40 & 31.4 & 30.4 & 29.4 & 28.4 & 27.4 & 26.4 & 25.4 & 24.4 & 23.4 & 22.4 & 21.4 & 20.4 & 19.4 \\
\hline & 30 & 28.5 & 27.5 & 26.5 & 25.5 & 24.5 & 23.5 & 22.5 & 21.5 & 20.5 & 19.5 & 18.5 & 17.5 & 16.5 \\
\hline & 20 & 25.1 & 24.1 & 23.1 & 22.1 & 21.1 & 20.1 & 19.1 & 18.1 & 17.1 & 16.1 & 15.1 & 14.1 & 13.1 \\
\hline & 15 & 23.0 & 22.0 & 21.0 & 20.0 & 19.0 & 18.0 & 17.0 & 16.0 & 15.0 & 14.0 & 13.0 & 11.9 & 10.9 \\
\hline & 10 & 20.4 & 19.4 & 18.4 & 17.4 & 16.4 & 15.4 & 14.4 & 13.4 & 12.4 & 11.4 & 10.4 & 9.4 & 8.4 \\
\hline & 5 & 16.6 & 15.6 & 14.6 & 13.6 & 12.6 & 11.6 & 10.6 & 9.6 & 8.6 & 7.6 & 6.6 & 5.6 & 4.6 \\
\hline
\end{tabular}

Table A28

Normative data for the Stroop Word-Color stratified by age and education levels for GUATEMALA

\begin{tabular}{|c|c|c|c|c|c|c|c|c|c|c|c|c|c|c|}
\hline & \multirow[b]{2}{*}{ Percentile } & \multicolumn{13}{|c|}{ Age (Years) } \\
\hline & & $18-22$ & $23-27$ & $28-32$ & $33-37$ & $38-42$ & $43-47$ & $48-52$ & $53-57$ & $58-62$ & $63-67$ & $68-72$ & $73-77$ & $>77$ \\
\hline \multirow{13}{*}{ 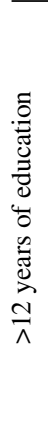 } & 95 & 63.7 & 62.5 & 61.3 & 60.1 & 58.9 & 57.7 & 56.5 & 55.3 & 54.1 & 52.9 & 51.7 & 50.5 & 49.3 \\
\hline & 90 & 59.5 & 58.3 & 57.1 & 55.9 & 54.7 & 53.5 & 52.3 & 51.1 & 49.9 & 48.7 & 47.5 & 46.4 & 45.2 \\
\hline & 85 & 56.7 & 55.5 & 54.3 & 53.1 & 51.9 & 50.7 & 49.5 & 48.3 & 47.1 & 46.0 & 44.8 & 43.6 & 42.4 \\
\hline & 80 & 54.4 & 53.2 & 52.0 & 50.8 & 49.6 & 48.4 & 47.2 & 46.0 & 44.8 & 43.6 & 42.4 & 41.2 & 40.1 \\
\hline & 70 & 50.7 & 49.5 & 48.3 & 47.1 & 45.9 & 44.7 & 43.5 & 42.3 & 41.1 & 39.9 & 38.7 & 37.5 & 36.3 \\
\hline & 60 & 47.5 & 46.3 & 45.1 & 43.9 & 42.7 & 41.6 & 40.4 & 39.2 & 38.0 & 36.8 & 35.6 & 34.4 & 33.2 \\
\hline & 50 & 44.6 & 43.4 & 42.2 & 41.0 & 39.8 & 38.7 & 37.5 & 36.3 & 35.1 & 33.9 & 32.7 & 31.5 & 30.3 \\
\hline & 40 & 41.7 & 40.5 & 39.3 & 38.1 & 36.9 & 35.7 & 34.6 & 33.4 & 32.2 & 31.0 & 29.8 & 28.6 & 27.4 \\
\hline & 30 & 38.6 & 37.4 & 36.2 & 35.0 & 33.8 & 32.6 & 31.4 & 30.2 & 29.0 & 27.8 & 26.6 & 25.5 & 24.3 \\
\hline & 20 & 34.9 & 33.7 & 32.5 & 31.3 & 30.1 & 28.9 & 27.7 & 26.5 & 25.3 & 24.1 & 22.9 & 21.7 & 20.5 \\
\hline & 15 & 32.5 & 31.3 & 30.2 & 29.0 & 27.8 & 26.6 & 25.4 & 24.2 & 23.0 & 21.8 & 20.6 & 19.4 & 18.2 \\
\hline & 10 & 29.8 & 28.6 & 27.4 & 26.2 & 25.0 & 23.8 & 22.6 & 21.4 & 20.2 & 19.0 & 17.8 & 16.6 & 15.4 \\
\hline & 5 & 25.6 & 24.4 & 23.2 & 22.0 & 20.8 & 19.6 & 18.4 & 17.2 & 16.0 & 14.8 & 13.6 & 12.4 & 11.3 \\
\hline \multirow{13}{*}{ 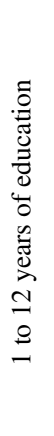 } & 95 & 57.6 & 56.4 & 55.2 & 54.0 & 52.8 & 51.7 & 50.5 & 49.3 & 48.1 & 46.9 & 45.7 & 44.5 & 43.3 \\
\hline & 90 & 53.4 & 52.2 & 51.1 & 49.9 & 48.7 & 47.5 & 46.3 & 45.1 & 43.9 & 42.7 & 41.5 & 40.3 & 39.1 \\
\hline & 85 & 50.7 & 49.5 & 48.3 & 47.1 & 45.9 & 44.7 & 43.5 & 42.3 & 41.1 & 39.9 & 38.7 & 37.5 & 36.3 \\
\hline & 80 & 48.3 & 47.1 & 45.9 & 44.7 & 43.6 & 42.4 & 41.2 & 40.0 & 38.8 & 37.6 & 36.4 & 35.2 & 34.0 \\
\hline & 70 & 44.6 & 43.4 & 42.2 & 41.0 & 39.8 & 38.6 & 37.5 & 36.3 & 35.1 & 33.9 & 32.7 & 31.5 & 30.3 \\
\hline & 60 & 41.5 & 40.3 & 39.1 & 37.9 & 36.7 & 35.5 & 34.3 & 33.1 & 31.9 & 30.7 & 29.5 & 28.4 & 27.2 \\
\hline & 50 & 38.6 & 37.4 & 36.2 & 35.0 & 33.8 & 32.6 & 31.4 & 30.2 & 29.0 & 27.8 & 26.6 & 25.5 & 24.3 \\
\hline & 40 & 35.7 & 34.5 & 33.3 & 32.1 & 30.9 & 29.7 & 28.5 & 27.3 & 26.1 & 24.9 & 23.7 & 22.5 & 21.4 \\
\hline & 30 & 32.5 & 31.3 & 30.2 & 29.0 & 27.8 & 26.6 & 25.4 & 24.2 & 23.0 & 21.8 & 20.6 & 19.4 & 18.2 \\
\hline & 20 & 28.8 & 27.6 & 26.4 & 25.2 & 24.0 & 22.9 & 21.7 & 20.5 & 19.3 & 18.1 & 16.9 & 15.7 & 14.5 \\
\hline & 15 & 26.5 & 25.3 & 24.1 & 22.9 & 21.7 & 20.5 & 19.3 & 18.1 & 17.0 & 15.8 & 14.6 & 13.4 & 12.2 \\
\hline & 10 & 23.7 & 22.5 & 21.3 & 20.1 & 18.9 & 17.7 & 16.6 & 15.4 & 14.2 & 13.0 & 11.8 & 10.6 & 9.4 \\
\hline & 5 & 19.5 & 18.3 & 17.1 & 16.0 & 14.8 & 13.6 & 12.4 & 11.2 & 10.0 & 8.8 & 7.6 & 6.4 & 5.2 \\
\hline
\end{tabular}


Table A29

Normative data for the Stroop Word-Color stratified by age and education levels for HONDURAS

\begin{tabular}{|c|c|c|c|c|c|c|c|c|c|c|c|c|c|c|}
\hline & \multirow[b]{2}{*}{ Percentile } & \multicolumn{13}{|c|}{ Age (Years) } \\
\hline & & $18-22$ & $23-27$ & $28-32$ & $33-37$ & $38-42$ & $43-47$ & $48-52$ & $53-57$ & $58-62$ & $63-67$ & $68-72$ & $73-77$ & $>77$ \\
\hline \multirow{13}{*}{ 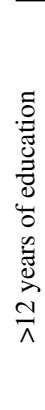 } & 95 & 56.3 & 55.2 & 54.1 & 53.1 & 52.0 & 51.0 & 49.9 & 48.9 & 47.8 & 46.7 & 45.7 & 44.6 & 43.6 \\
\hline & 90 & 52.9 & 51.8 & 50.8 & 49.7 & 48.6 & 47.6 & 46.5 & 45.5 & 44.4 & 43.3 & 42.3 & 41.2 & 40.2 \\
\hline & 85 & 50.6 & 49.5 & 48.5 & 47.4 & 46.4 & 45.3 & 44.3 & 43.2 & 42.1 & 41.1 & 40.0 & 39.0 & 37.9 \\
\hline & 80 & 48.7 & 47.7 & 46.6 & 45.5 & 44.5 & 43.4 & 42.4 & 41.3 & 40.3 & 39.2 & 38.1 & 37.1 & 36.0 \\
\hline & 70 & 45.7 & 44.6 & 43.6 & 42.5 & 41.5 & 40.4 & 39.4 & 38.3 & 37.2 & 36.2 & 35.1 & 34.1 & 33.0 \\
\hline & 60 & 43.2 & 42.1 & 41.0 & 40.0 & 38.9 & 37.9 & 36.8 & 35.7 & 34.7 & 33.6 & 32.6 & 31.5 & 30.5 \\
\hline & 50 & 40.8 & 39.7 & 38.7 & 37.6 & 36.6 & 35.5 & 34.4 & 33.4 & 32.3 & 31.3 & 30.2 & 29.2 & 28.1 \\
\hline & 40 & 38.4 & 37.4 & 36.3 & 35.3 & 34.2 & 33.1 & 32.1 & 31.0 & 30.0 & 28.9 & 27.9 & 26.8 & 25.7 \\
\hline & 30 & 35.9 & 34.8 & 33.8 & 32.7 & 31.7 & 30.6 & 29.5 & 28.5 & 27.4 & 26.4 & 25.3 & 24.3 & 23.2 \\
\hline & 20 & 32.9 & 31.8 & 30.8 & 29.7 & 28.6 & 27.6 & 26.5 & 25.5 & 24.4 & 23.3 & 22.3 & 21.2 & 20.2 \\
\hline & 15 & 31.0 & 29.9 & 28.9 & 27.8 & 26.8 & 25.7 & 24.6 & 23.6 & 22.5 & 21.5 & 20.4 & 19.3 & 18.3 \\
\hline & 10 & 28.7 & 27.7 & 26.6 & 25.6 & 24.5 & 23.4 & 22.4 & 21.3 & 20.3 & 19.2 & 18.1 & 17.1 & 16.0 \\
\hline & 5 & 25.3 & 24.3 & 23.2 & 22.2 & 21.1 & 20.0 & 19.0 & 17.9 & 16.9 & 15.8 & 14.7 & 13.7 & 12.6 \\
\hline \multirow{13}{*}{ 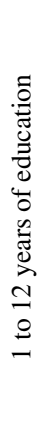 } & 95 & 50.3 & 49.2 & 48.2 & 47.1 & 46.1 & 45.0 & 43.9 & 42.9 & 41.8 & 40.8 & 39.7 & 38.7 & 37.6 \\
\hline & 90 & 46.9 & 45.8 & 44.8 & 43.7 & 42.7 & 41.6 & 40.5 & 39.5 & 38.4 & 37.4 & 36.3 & 35.3 & 34.2 \\
\hline & 85 & 44.6 & 43.6 & 42.5 & 41.5 & 40.4 & 39.3 & 38.3 & 37.2 & 36.2 & 35.1 & 34.1 & 33.0 & 31.9 \\
\hline & 80 & 42.8 & 41.7 & 40.6 & 39.6 & 38.5 & 37.5 & 36.4 & 35.3 & 34.3 & 33.2 & 32.2 & 31.1 & 30.0 \\
\hline & 70 & 39.7 & 38.7 & 37.6 & 36.6 & 35.5 & 34.4 & 33.4 & 32.3 & 31.3 & 30.2 & 29.1 & 28.1 & 27.0 \\
\hline & 60 & 37.2 & 36.1 & 35.1 & 34.0 & 33.0 & 31.9 & 30.8 & 29.8 & 28.7 & 27.7 & 26.6 & 25.5 & 24.5 \\
\hline & 50 & 34.8 & 33.8 & 32.7 & 31.7 & 30.6 & 29.5 & 28.5 & 27.4 & 26.4 & 25.3 & 24.2 & 23.2 & 22.1 \\
\hline & 40 & 32.5 & 31.4 & 30.4 & 29.3 & 28.2 & 27.2 & 26.1 & 25.1 & 24.0 & 22.9 & 21.9 & 20.8 & 19.8 \\
\hline & 30 & 29.9 & 28.9 & 27.8 & 26.7 & 25.7 & 24.6 & 23.6 & 22.5 & 21.5 & 20.4 & 19.3 & 18.3 & 17.2 \\
\hline & 20 & 26.9 & 25.8 & 24.8 & 23.7 & 22.7 & 21.6 & 20.6 & 19.5 & 18.4 & 17.4 & 16.3 & 15.3 & 14.2 \\
\hline & 15 & 25.0 & 24.0 & 22.9 & 21.8 & 20.8 & 19.7 & 18.7 & 17.6 & 16.6 & 15.5 & 14.4 & 13.4 & 12.3 \\
\hline & 10 & 22.8 & 21.7 & 20.6 & 19.6 & 18.5 & 17.5 & 16.4 & 15.3 & 14.3 & 13.2 & 12.2 & 11.1 & 10.1 \\
\hline & 5 & 19.4 & 18.3 & 17.2 & 16.2 & 15.1 & 14.1 & 13.0 & 12.0 & 10.9 & 9.8 & 8.8 & 7.7 & 6.7 \\
\hline
\end{tabular}

Table A30

Normative data for the Stroop Word-Color stratified by age and education levels for MEXICO

\begin{tabular}{|c|c|c|c|c|c|c|c|c|c|c|c|c|c|c|}
\hline & \multirow[b]{2}{*}{ Percentile } & \multicolumn{13}{|c|}{ Age (Years) } \\
\hline & & $18-22$ & $23-27$ & $28-32$ & $33-37$ & $38-42$ & $43-47$ & $48-52$ & $53-57$ & $58-62$ & $63-67$ & $68-72$ & $73-77$ & $>77$ \\
\hline \multirow{13}{*}{ 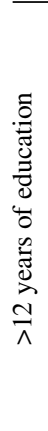 } & 95 & 72.6 & 70.8 & 69.0 & 67.2 & 65.4 & 63.6 & 61.8 & 60.0 & 58.2 & 56.4 & 54.6 & 52.8 & 51.0 \\
\hline & 90 & 68.3 & 66.5 & 64.7 & 62.8 & 61.0 & 59.2 & 57.4 & 55.6 & 53.8 & 52.0 & 50.2 & 48.4 & 46.6 \\
\hline & 85 & 65.4 & 63.5 & 61.7 & 59.9 & 58.1 & 56.3 & 54.5 & 52.7 & 50.9 & 49.1 & 47.3 & 45.5 & 43.7 \\
\hline & 80 & 62.9 & 61.1 & 59.3 & 57.5 & 55.7 & 53.9 & 52.1 & 50.3 & 48.5 & 46.7 & 44.9 & 43.1 & 41.2 \\
\hline & 70 & 59.0 & 57.2 & 55.4 & 53.6 & 51.8 & 50.0 & 48.2 & 46.4 & 44.6 & 42.8 & 41.0 & 39.2 & 37.4 \\
\hline & 60 & 55.8 & 54.0 & 52.1 & 50.3 & 48.5 & 46.7 & 44.9 & 43.1 & 41.3 & 39.5 & 37.7 & 35.9 & 34.1 \\
\hline & 50 & 52.7 & 50.9 & 49.1 & 47.3 & 45.5 & 43.7 & 41.9 & 40.1 & 38.3 & 36.5 & 34.7 & 32.9 & 31.0 \\
\hline & 40 & 49.7 & 47.9 & 46.1 & 44.3 & 42.5 & 40.7 & 38.9 & 37.0 & 35.2 & 33.4 & 31.6 & 29.8 & 28.0 \\
\hline & 30 & 46.4 & 44.6 & 42.8 & 41.0 & 39.2 & 37.4 & 35.6 & 33.8 & 32.0 & 30.2 & 28.3 & 26.5 & 24.7 \\
\hline & 20 & 42.5 & 40.7 & 38.9 & 37.1 & 35.3 & 33.5 & 31.7 & 29.9 & 28.1 & 26.3 & 24.5 & 22.7 & 20.8 \\
\hline & 15 & 40.1 & 38.3 & 36.5 & 34.7 & 32.9 & 31.1 & 29.3 & 27.5 & 25.6 & 23.8 & 22.0 & 20.2 & 18.4 \\
\hline & 10 & 37.2 & 35.4 & 33.6 & 31.8 & 30.0 & 28.1 & 26.3 & 24.5 & 22.7 & 20.9 & 19.1 & 17.3 & 15.5 \\
\hline & 5 & 32.8 & 31.0 & 29.2 & 27.4 & 25.6 & 23.8 & 22.0 & 20.2 & 18.4 & 16.6 & 14.7 & 12.9 & 11.1 \\
\hline \multirow{13}{*}{ 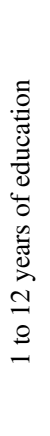 } & 95 & 67.1 & 65.3 & 63.5 & 61.7 & 59.9 & 58.1 & 56.3 & 54.5 & 52.7 & 50.9 & 49.1 & 47.3 & 45.5 \\
\hline & 90 & 62.8 & 61.0 & 59.2 & 57.4 & 55.6 & 53.7 & 51.9 & 50.1 & 48.3 & 46.5 & 44.7 & 42.9 & 41.1 \\
\hline & 85 & 59.9 & 58.1 & 56.3 & 54.4 & 52.6 & 50.8 & 49.0 & 47.2 & 45.4 & 43.6 & 41.8 & 40.0 & 38.2 \\
\hline & 80 & 57.4 & 55.6 & 53.8 & 52.0 & 50.2 & 48.4 & 46.6 & 44.8 & 43.0 & 41.2 & 39.4 & 37.6 & 35.8 \\
\hline & 70 & 53.5 & 51.7 & 49.9 & 48.1 & 46.3 & 44.5 & 42.7 & 40.9 & 39.1 & 37.3 & 35.5 & 33.7 & 31.9 \\
\hline & 60 & 50.3 & 48.5 & 46.7 & 44.9 & 43.0 & 41.2 & 39.4 & 37.6 & 35.8 & 34.0 & 32.2 & 30.4 & 28.6 \\
\hline & 50 & 47.2 & 45.4 & 43.6 & 41.8 & 40.0 & 38.2 & 36.4 & 34.6 & 32.8 & 31.0 & 29.2 & 27.4 & 25.6 \\
\hline & 40 & 44.2 & 42.4 & 40.6 & 38.8 & 37.0 & 35.2 & 33.4 & 31.6 & 29.7 & 27.9 & 26.1 & 24.3 & 22.5 \\
\hline & 30 & 40.9 & 39.1 & 37.3 & 35.5 & 33.7 & 31.9 & 30.1 & 28.3 & 26.5 & 24.7 & 22.9 & 21.1 & 19.2 \\
\hline & 20 & 37.0 & 35.2 & 33.4 & 31.6 & 29.8 & 28.0 & 26.2 & 24.4 & 22.6 & 20.8 & 19.0 & 17.2 & 15.4 \\
\hline & 15 & 34.6 & 32.8 & 31.0 & 29.2 & 27.4 & 25.6 & 23.8 & 22.0 & 20.2 & 18.3 & 16.5 & 14.7 & 12.9 \\
\hline & 10 & 31.7 & 29.9 & 28.1 & 26.3 & 24.5 & 22.7 & 20.9 & 19.0 & 17.2 & 15.4 & 13.6 & 11.8 & 10.0 \\
\hline & 5 & 27.3 & 25.5 & 23.7 & 21.9 & 20.1 & 18.3 & 16.5 & 14.7 & 12.9 & 11.1 & 9.3 & 7.5 & 5.6 \\
\hline
\end{tabular}


Table A31

Normative data for the Stroop Word-Color stratified by age and education levels for PARAGUAY

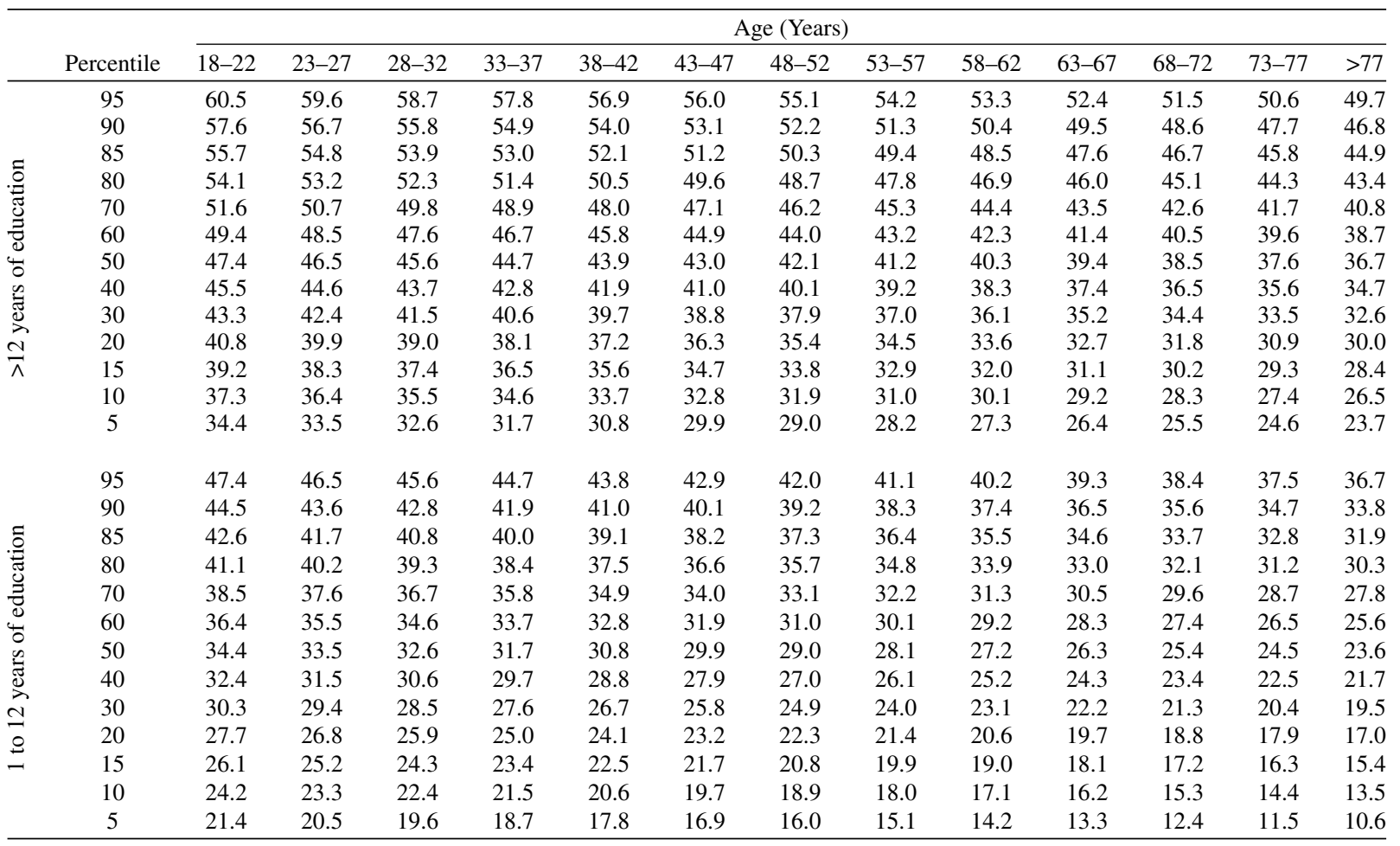

Table A32

Normative data for the Stroop Word-Color stratified by age and education levels for PERU

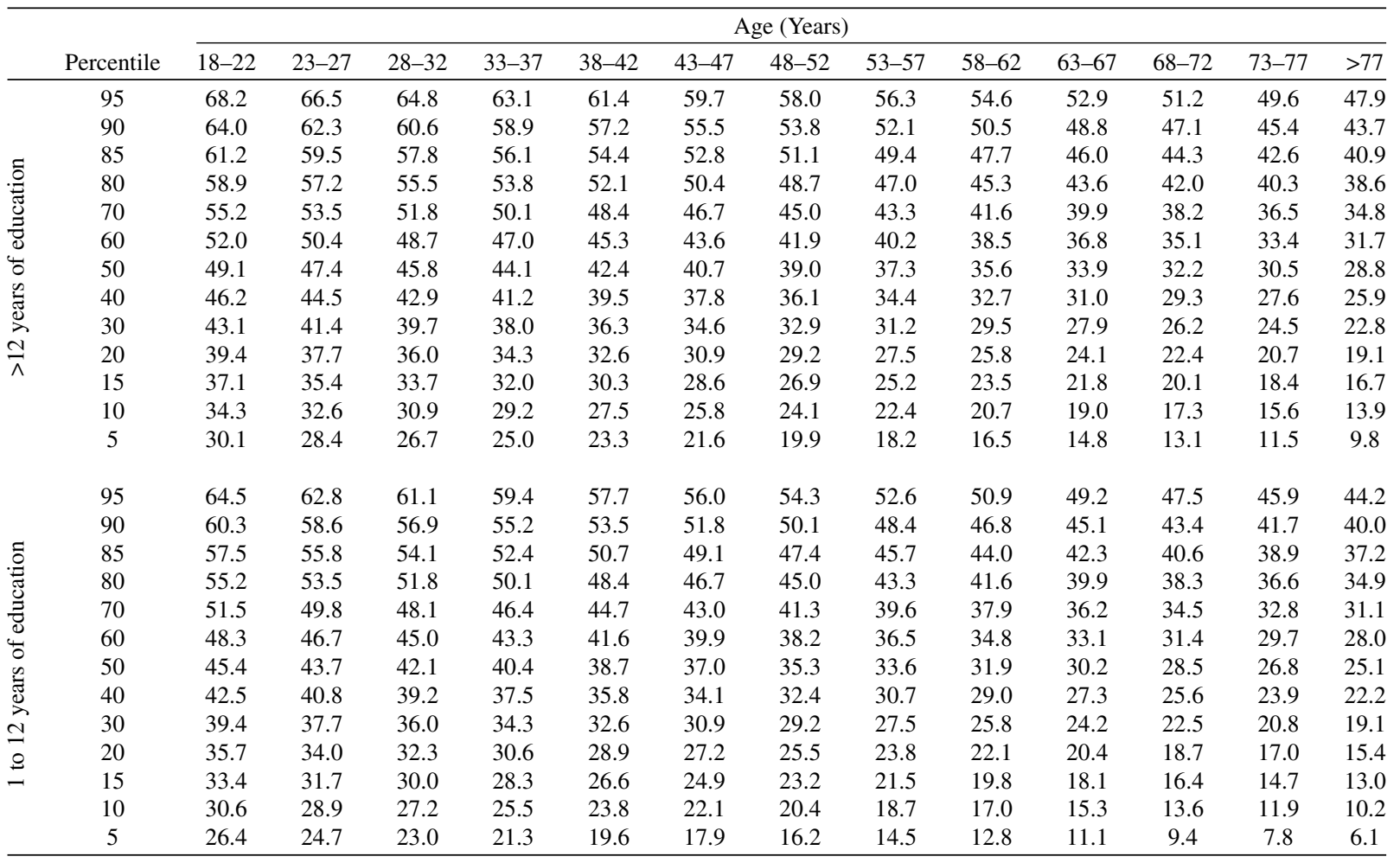


Table A33

Normative data for the Stroop Word-Color stratified by age and education levels for PUERTO RICO

\begin{tabular}{|c|c|c|c|c|c|c|c|c|c|c|c|c|c|c|}
\hline & \multirow[b]{2}{*}{ Percentile } & \multicolumn{13}{|c|}{ Age (Years) } \\
\hline & & $18-22$ & $23-27$ & $28-32$ & $33-37$ & $38-42$ & $43-47$ & $48-52$ & $53-57$ & $58-62$ & $63-67$ & $68-72$ & $73-77$ & $>77$ \\
\hline \multirow{13}{*}{ 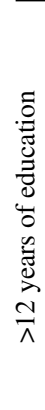 } & 95 & 72.1 & 69.8 & 67.5 & 65.2 & 63.0 & 60.7 & 58.4 & 56.1 & 53.8 & 51.5 & 49.2 & 46.9 & 44.6 \\
\hline & 90 & 68.2 & 65.9 & 63.6 & 61.3 & 59.0 & 56.7 & 54.4 & 52.1 & 49.8 & 47.5 & 45.3 & 43.0 & 40.7 \\
\hline & 85 & 65.6 & 63.3 & 61.0 & 58.7 & 56.4 & 54.1 & 51.8 & 49.5 & 47.2 & 44.9 & 42.6 & 40.3 & 38.0 \\
\hline & 80 & 63.4 & 61.1 & 58.8 & 56.5 & 54.2 & 51.9 & 49.6 & 47.3 & 45.0 & 42.7 & 40.4 & 38.1 & 35.8 \\
\hline & 70 & 59.9 & 57.6 & 55.3 & 53.0 & 50.7 & 48.4 & 46.1 & 43.8 & 41.5 & 39.2 & 36.9 & 34.6 & 32.3 \\
\hline & 60 & 56.9 & 54.6 & 52.3 & 50.0 & 47.7 & 45.4 & 43.2 & 40.9 & 38.6 & 36.3 & 34.0 & 31.7 & 29.4 \\
\hline & 50 & 54.2 & 51.9 & 49.6 & 47.3 & 45.0 & 42.7 & 40.4 & 38.1 & 35.8 & 33.5 & 31.2 & 29.0 & 26.7 \\
\hline & 40 & 51.4 & 49.2 & 46.9 & 44.6 & 42.3 & 40.0 & 37.7 & 35.4 & 33.1 & 30.8 & 28.5 & 26.2 & 23.9 \\
\hline & 30 & 48.5 & 46.2 & 43.9 & 41.6 & 39.3 & 37.0 & 34.7 & 32.4 & 30.1 & 27.8 & 25.6 & 23.3 & 21.0 \\
\hline & 20 & 45.0 & 42.7 & 40.4 & 38.1 & 35.8 & 33.5 & 31.2 & 28.9 & 26.6 & 24.3 & 22.1 & 19.8 & 17.5 \\
\hline & 15 & 42.8 & 40.5 & 38.2 & 35.9 & 33.6 & 31.3 & 29.0 & 26.7 & 24.5 & 22.2 & 19.9 & 17.6 & 15.3 \\
\hline & 10 & 40.2 & 37.9 & 35.6 & 33.3 & 31.0 & 28.7 & 26.4 & 24.1 & 21.8 & 19.5 & 17.2 & 14.9 & 12.6 \\
\hline & 5 & 36.2 & 33.9 & 31.6 & 29.4 & 27.1 & 24.8 & 22.5 & 20.2 & 17.9 & 15.6 & 13.3 & 11.0 & 8.7 \\
\hline \multirow{13}{*}{ 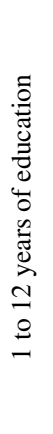 } & 95 & 68.6 & 66.3 & 64.0 & 61.7 & 59.4 & 57.1 & 54.8 & 52.5 & 50.2 & 47.9 & 45.6 & 43.3 & 41.0 \\
\hline & 90 & 64.6 & 62.3 & 60.0 & 57.7 & 55.4 & 53.1 & 50.8 & 48.6 & 46.3 & 44.0 & 41.7 & 39.4 & 37.1 \\
\hline & 85 & 62.0 & 59.7 & 57.4 & 55.1 & 52.8 & 50.5 & 48.2 & 45.9 & 43.6 & 41.3 & 39.0 & 36.8 & 34.5 \\
\hline & 80 & 59.8 & 57.5 & 55.2 & 52.9 & 50.6 & 48.3 & 46.0 & 43.7 & 41.4 & 39.2 & 36.9 & 34.6 & 32.3 \\
\hline & 70 & 56.3 & 54.0 & 51.7 & 49.4 & 47.1 & 44.8 & 42.5 & 40.2 & 37.9 & 35.6 & 33.4 & 31.1 & 28.8 \\
\hline & 60 & 53.3 & 51.0 & 48.8 & 46.5 & 44.2 & 41.9 & 39.6 & 37.3 & 35.0 & 32.7 & 30.4 & 28.1 & 25.8 \\
\hline & 50 & 50.6 & 48.3 & 46.0 & 43.7 & 41.4 & 39.1 & 36.8 & 34.5 & 32.3 & 30.0 & 27.7 & 25.4 & 23.1 \\
\hline & 40 & 47.9 & 45.6 & 43.3 & 41.0 & 38.7 & 36.4 & 34.1 & 31.8 & 29.5 & 27.2 & 24.9 & 22.6 & 20.3 \\
\hline & 30 & 44.9 & 42.6 & 40.3 & 38.0 & 35.7 & 33.4 & 31.1 & 28.9 & 26.6 & 24.3 & 22.0 & 19.7 & 17.4 \\
\hline & 20 & 41.4 & 39.1 & 36.8 & 34.5 & 32.2 & 29.9 & 27.6 & 25.4 & 23.1 & 20.8 & 18.5 & 16.2 & 13.9 \\
\hline & 15 & 39.2 & 36.9 & 34.6 & 32.3 & 30.0 & 27.8 & 25.5 & 23.2 & 20.9 & 18.6 & 16.3 & 14.0 & 11.7 \\
\hline & 10 & 36.6 & 34.3 & 32.0 & 29.7 & 27.4 & 25.1 & 22.8 & 20.5 & 18.2 & 16.0 & 13.7 & 11.4 & 9.1 \\
\hline & 5 & 32.7 & 30.4 & 28.1 & 25.8 & 23.5 & 21.2 & 18.9 & 16.6 & 14.3 & 12.0 & 9.7 & 7.4 & 5.1 \\
\hline
\end{tabular}

Table A34

Normative data for the Stroop Interference stratified by age and education levels for ARGENTINA

\begin{tabular}{|c|c|c|c|c|c|c|c|c|c|c|c|c|c|c|}
\hline & \multirow[b]{2}{*}{ Percentile } & \multicolumn{13}{|c|}{ Age (Years) } \\
\hline & & $18-22$ & $23-27$ & $28-32$ & $33-37$ & $38-42$ & $43-47$ & $48-52$ & $53-57$ & $58-62$ & $63-67$ & $68-72$ & $73-77$ & $>77$ \\
\hline \multirow{13}{*}{ 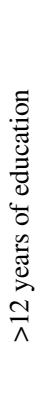 } & 95 & 16.1 & 15.5 & 14.9 & 14.3 & 13.7 & 13.1 & 12.5 & 11.9 & 11.3 & 10.6 & 10.0 & 9.4 & 8.8 \\
\hline & 90 & 13.5 & 12.9 & 12.3 & 11.7 & 11.1 & 10.5 & 9.9 & 9.3 & 8.7 & 8.1 & 7.5 & 6.8 & 6.2 \\
\hline & 85 & 11.8 & 11.2 & 10.6 & 10.0 & 9.4 & 8.8 & 8.2 & 7.5 & 6.9 & 6.3 & 5.7 & 5.1 & 4.5 \\
\hline & 80 & 10.4 & 9.7 & 9.1 & 8.5 & 7.9 & 7.3 & 6.7 & 6.1 & 5.5 & 4.9 & 4.3 & 3.7 & 3.1 \\
\hline & 70 & 8.1 & 7.4 & 6.8 & 6.2 & 5.6 & 5.0 & 4.4 & 3.8 & 3.2 & 2.6 & 2.0 & 1.4 & 0.8 \\
\hline & 60 & 6.1 & 5.5 & 4.9 & 4.3 & 3.7 & 3.1 & 2.5 & 1.9 & 1.3 & 0.7 & 0.0 & -0.6 & -1.2 \\
\hline & 50 & 4.3 & 3.7 & 3.1 & 2.5 & 1.9 & 1.3 & 0.7 & 0.1 & -0.5 & -1.1 & -1.8 & -2.4 & -3.0 \\
\hline & 40 & 2.5 & 1.9 & 1.3 & 0.7 & 0.1 & -0.5 & -1.1 & -1.7 & -2.3 & -2.9 & -3.6 & -4.2 & -4.8 \\
\hline & 30 & 0.6 & 0.0 & -0.6 & -1.2 & -1.9 & -2.5 & -3.1 & -3.7 & -4.3 & -4.9 & -5.5 & -6.1 & -6.7 \\
\hline & 20 & -1.7 & -2.3 & -2.9 & -3.5 & -4.2 & -4.8 & -5.4 & -6.0 & -6.6 & -7.2 & -7.8 & -8.4 & -9.0 \\
\hline & 15 & -3.2 & -3.8 & -4.4 & -5.0 & -5.6 & -6.2 & -6.8 & -7.4 & -8.0 & -8.6 & -9.2 & -9.8 & -10.4 \\
\hline & 10 & -4.9 & -5.5 & -6.1 & -6.7 & -7.3 & -7.9 & -8.5 & -9.1 & -9.7 & -10.4 & -11.0 & -11.6 & -12.2 \\
\hline & 5 & -7.5 & -8.1 & -8.7 & -9.3 & -9.9 & -10.5 & -11.1 & -11.7 & -12.3 & -12.9 & -13.5 & -14.2 & -14.8 \\
\hline \multirow{13}{*}{ 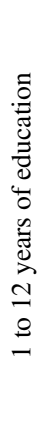 } & 95 & 13.4 & 12.8 & 12.2 & 11.6 & 11.0 & 10.4 & 9.8 & 9.2 & 8.6 & 8.0 & 7.4 & 6.7 & 6.1 \\
\hline & 90 & 10.8 & 10.2 & 9.6 & 9.0 & 8.4 & 7.8 & 7.2 & 6.6 & 6.0 & 5.4 & 4.8 & 4.2 & 3.6 \\
\hline & 85 & 9.1 & 8.5 & 7.9 & 7.3 & 6.7 & 6.1 & 5.5 & 4.9 & 4.3 & 3.6 & 3.0 & 2.4 & 1.8 \\
\hline & 80 & 7.7 & 7.1 & 6.5 & 5.8 & 5.2 & 4.6 & 4.0 & 3.4 & 2.8 & 2.2 & 1.6 & 1.0 & 0.4 \\
\hline & 70 & 5.4 & 4.8 & 4.2 & 3.5 & 2.9 & 2.3 & 1.7 & 1.1 & 0.5 & -0.1 & -0.7 & -1.3 & -1.9 \\
\hline & 60 & 3.4 & 2.8 & 2.2 & 1.6 & 1.0 & 0.4 & -0.2 & -0.8 & -1.4 & -2.0 & -2.6 & -3.2 & -3.9 \\
\hline & 50 & 1.6 & 1.0 & 0.4 & -0.2 & -0.8 & -1.4 & -2.0 & -2.6 & -3.2 & -3.8 & -4.4 & -5.0 & -5.7 \\
\hline & 40 & -0.2 & -0.8 & -1.4 & -2.0 & -2.6 & -3.2 & -3.8 & -4.4 & -5.0 & -5.6 & -6.2 & -6.8 & -7.5 \\
\hline & 30 & -2.1 & -2.7 & -3.3 & -3.9 & -4.5 & -5.1 & -5.8 & -6.4 & -7.0 & -7.6 & -8.2 & -8.8 & -9.4 \\
\hline & 20 & -4.4 & -5.0 & -5.6 & -6.2 & -6.8 & -7.4 & -8.1 & -8.7 & -9.3 & -9.9 & -10.5 & -11.1 & -11.7 \\
\hline & 15 & -5.9 & -6.5 & -7.1 & -7.7 & -8.3 & -8.9 & -9.5 & -10.1 & -10.7 & -11.3 & -11.9 & -12.5 & -13.1 \\
\hline & 10 & -7.6 & -8.2 & -8.8 & -9.4 & -10.0 & -10.6 & -11.2 & -11.8 & -12.4 & -13.0 & -13.6 & -14.3 & -14.9 \\
\hline & 5 & -10.2 & -10.8 & -11.4 & -12.0 & -12.6 & -13.2 & -13.8 & -14.4 & -15.0 & -15.6 & -16.2 & -16.8 & -17.4 \\
\hline
\end{tabular}


Table A35

Normative data for the Stroop Interference for BOLIVIA

\begin{tabular}{lc}
\hline Percentile & Raw Score \\
\hline 95 & 23.9 \\
90 & 18.5 \\
85 & 14.0 \\
80 & 12.1 \\
70 & 8.2 \\
60 & 5.1 \\
50 & 2.4 \\
40 & 0.0 \\
30 & -3.8 \\
20 & -7.2 \\
15 & -9.0 \\
10 & -10.6 \\
5 & -16.9 \\
\hline
\end{tabular}

Table A36

Normative data for the Stroop Interference stratified by age and education levels for CHILE

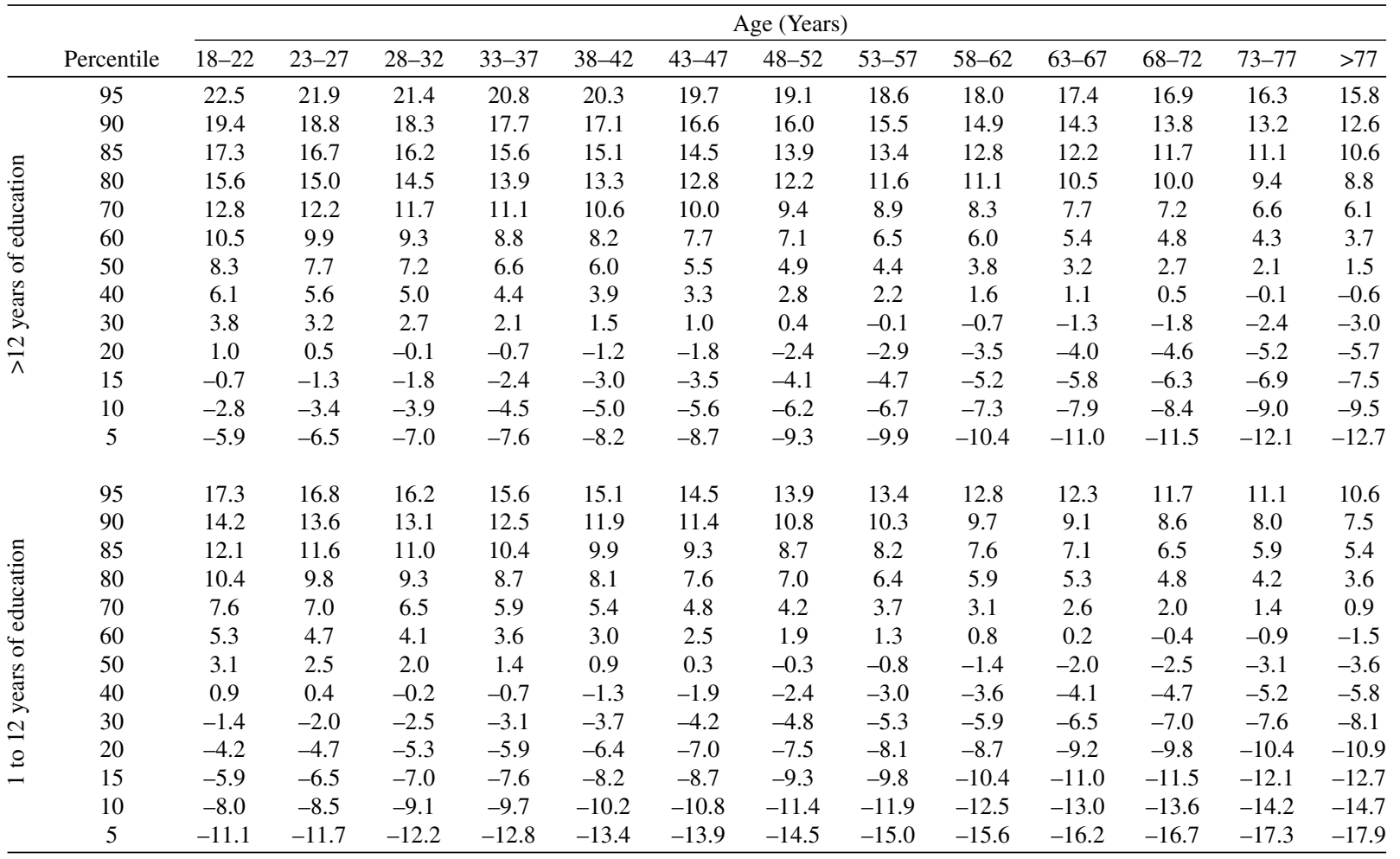


Table A37

Normative data for the Stroop Interference for CUBA

\begin{tabular}{lc}
\hline Percentile & Raw Score \\
\hline 95 & 18.6 \\
90 & 12.2 \\
85 & 9.2 \\
80 & 6.9 \\
70 & 4.2 \\
60 & 1.8 \\
50 & -0.1 \\
40 & -1.8 \\
30 & -4.3 \\
20 & -7.0 \\
15 & -9.1 \\
10 & -11.2 \\
5 & -14.9 \\
\hline
\end{tabular}

Table A38

Normative data for the Stroop Interference stratified by age for EL SALVADOR

\begin{tabular}{lccccccccccccc}
\hline & \multicolumn{10}{c}{ Age (Years) } \\
\cline { 2 - 26 } Percentile & $18-22$ & $23-27$ & $28-32$ & $33-37$ & $38-42$ & $43-47$ & $48-52$ & $53-57$ & $58-62$ & $63-67$ & $68-72$ & $73-77$ & $>77$ \\
\hline 95 & 17.0 & 16.6 & 16.2 & 15.9 & 15.5 & 15.1 & 14.7 & 14.3 & 13.9 & 13.5 & 13.1 & 12.8 & 12.4 \\
90 & 13.9 & 13.5 & 13.2 & 12.8 & 12.4 & 12.0 & 11.6 & 11.2 & 10.8 & 10.4 & 10.1 & 9.7 & 9.3 \\
85 & 11.9 & 11.5 & 11.1 & 10.7 & 10.3 & 9.9 & 9.5 & 9.2 & 8.8 & 8.4 & 8.0 & 7.6 & 7.2 \\
80 & 10.2 & 9.8 & 9.4 & 9.0 & 8.6 & 8.2 & 7.8 & 7.4 & 7.1 & 6.7 & 6.3 & 5.9 & 5.5 \\
70 & 7.4 & 7.0 & 6.6 & 6.3 & 5.9 & 5.5 & 5.1 & 4.7 & 4.3 & 3.9 & 3.5 & 3.2 & 2.8 \\
60 & 5.1 & 4.7 & 4.3 & 3.9 & 3.6 & 3.2 & 2.8 & 2.4 & 2.0 & 1.6 & 1.2 & 0.8 & 0.5 \\
50 & 3.0 & 2.6 & 2.2 & 1.8 & 1.4 & 1.0 & 0.6 & 0.2 & -0.1 & -0.5 & -0.9 & -1.3 & -1.7 \\
40 & 0.8 & 0.4 & 0.0 & -0.3 & -0.7 & -1.1 & -1.5 & -1.9 & -2.3 & -2.7 & -3.1 & -3.4 & -3.8 \\
30 & -1.5 & -1.9 & -2.3 & -2.7 & -3.0 & -3.4 & -3.8 & -4.2 & -4.6 & -5.0 & -5.4 & -5.8 & -6.1 \\
20 & -4.2 & -4.6 & -5.0 & -5.4 & -5.8 & -6.2 & -6.6 & -7.0 & -7.3 & -7.7 & -8.1 & -8.5 & -8.9 \\
15 & -6.0 & -6.3 & -6.7 & -7.1 & -7.5 & -7.9 & -8.3 & -8.7 & -9.1 & -9.4 & -9.8 & -10.2 & -10.6 \\
10 & -8.0 & -8.4 & -8.8 & -9.2 & -9.6 & -10.0 & -10.3 & -10.7 & -11.1 & -11.5 & -11.9 & -12.3 & -12.7 \\
5 & -11.1 & -11.5 & -11.9 & -12.3 & -12.6 & -13.0 & -13.4 & -13.8 & -14.2 & -14.6 & -15.0 & -15.4 & -15.7 \\
\hline
\end{tabular}

Table A39

Normative data for the Stroop Interference for GUATEMALA

\begin{tabular}{lc}
\hline Percentile & Raw Score \\
\hline 95 & 15.5 \\
90 & 11.8 \\
85 & 7.5 \\
80 & 5.8 \\
70 & 2.7 \\
60 & 0.8 \\
50 & -1.3 \\
40 & -3.4 \\
30 & -5.4 \\
20 & -7.3 \\
15 & -9.3 \\
10 & -12.1 \\
5 & -16.3 \\
\hline
\end{tabular}


Table A40

Normative data for the Stroop Interference for HONDURAS

\begin{tabular}{lc}
\hline Percentile & Raw Score \\
\hline 95 & 12.2 \\
90 & 9.5 \\
85 & 8.2 \\
80 & 6.5 \\
70 & 4.6 \\
60 & 3.5 \\
50 & 2.0 \\
40 & 1.1 \\
30 & -0.9 \\
20 & -2.4 \\
15 & -4.8 \\
10 & -5.4 \\
5 & -7.3 \\
\hline
\end{tabular}

Table A41

Normative data for the Stroop Interference stratified by age and education levels for MEXICO

\begin{tabular}{|c|c|c|c|c|c|c|c|c|c|c|c|c|c|c|}
\hline \multirow{2}{*}{\multicolumn{2}{|c|}{ rcentile }} & \multicolumn{13}{|c|}{ Age (Years) } \\
\hline & & $18-22$ & $23-27$ & $28-32$ & $33-37$ & $38-42$ & $43-47$ & $48-52$ & $53-57$ & $58-62$ & $63-67$ & $68-72$ & $73-77$ & $>77$ \\
\hline \multirow{13}{*}{ 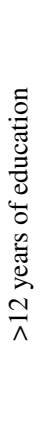 } & 95 & 23.8 & 23.2 & 22.6 & 21.9 & 21.3 & 20.7 & 20.0 & 19.4 & 18.8 & 18.2 & 17.5 & 16.9 & 16.3 \\
\hline & 90 & 20.2 & 19.5 & 18.9 & 18.3 & 17.7 & 17.0 & 16.4 & 15.8 & 15.2 & 14.5 & 13.9 & 13.3 & 12.7 \\
\hline & 85 & 17.8 & 17.1 & 16.5 & 15.9 & 15.2 & 14.6 & 14.0 & 13.4 & 12.7 & 12.1 & 11.5 & 10.9 & 10.2 \\
\hline & 80 & 15.7 & 15.1 & 14.5 & 13.9 & 13.2 & 12.6 & 12.0 & 11.3 & 10.7 & 10.1 & 9.5 & 8.8 & 8.2 \\
\hline & 70 & 12.5 & 11.9 & 11.2 & 10.6 & 10.0 & 9.4 & 8.7 & 8.1 & 7.5 & 6.9 & 6.2 & 5.6 & 5.0 \\
\hline & 60 & 9.8 & 9.1 & 8.5 & 7.9 & 7.3 & 6.6 & 6.0 & 5.4 & 4.8 & 4.1 & 3.5 & 2.9 & 2.3 \\
\hline & 50 & 7.3 & 6.6 & 6.0 & 5.4 & 4.7 & 4.1 & 3.5 & 2.9 & 2.2 & 1.6 & 1.0 & 0.4 & -0.3 \\
\hline & 40 & 4.7 & 4.1 & 3.5 & 2.8 & 2.2 & 1.6 & 1.0 & 0.3 & -0.3 & -0.9 & -1.5 & -2.2 & -2.8 \\
\hline & 30 & 2.0 & 1.4 & 0.7 & 0.1 & -0.5 & -1.1 & -1.8 & -2.4 & -3.0 & -3.6 & -4.3 & -4.9 & -5.5 \\
\hline & 20 & -1.2 & -1.9 & -2.5 & -3.1 & -3.7 & -4.4 & -5.0 & -5.6 & -6.2 & -6.9 & -7.5 & -8.1 & -8.7 \\
\hline & 15 & -3.2 & -3.9 & -4.5 & -5.1 & -5.8 & -6.4 & -7.0 & -7.6 & -8.3 & -8.9 & -9.5 & -10.1 & -10.8 \\
\hline & 10 & -5.7 & -6.3 & -6.9 & -7.6 & -8.2 & -8.8 & -9.4 & -10.1 & -10.7 & -11.3 & -11.9 & -12.6 & -13.2 \\
\hline & 5 & -9.3 & -9.9 & -10.6 & -11.2 & -11.8 & -12.4 & -13.1 & -13.7 & -14.3 & -14.9 & -15.6 & -16.2 & -16.8 \\
\hline \multirow{13}{*}{ 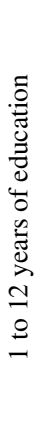 } & 95 & 21.8 & 21.2 & 20.5 & 19.9 & 19.3 & 18.7 & 18.0 & 17.4 & 16.8 & 16.1 & 15.5 & 14.9 & 14.3 \\
\hline & 90 & 18.2 & 17.5 & 16.9 & 16.3 & 15.6 & 15.0 & 14.4 & 13.8 & 13.1 & 12.5 & 11.9 & 11.3 & 10.6 \\
\hline & 85 & 15.7 & 15.1 & 14.5 & 13.8 & 13.2 & 12.6 & 12.0 & 11.3 & 10.7 & 10.1 & 9.5 & 8.8 & 8.2 \\
\hline & 80 & 13.7 & 13.1 & 12.5 & 11.8 & 11.2 & 10.6 & 10.0 & 9.3 & 8.7 & 8.1 & 7.4 & 6.8 & 6.2 \\
\hline & 70 & 10.5 & 9.9 & 9.2 & 8.6 & 8.0 & 7.3 & 6.7 & 6.1 & 5.5 & 4.8 & 4.2 & 3.6 & 3.0 \\
\hline & 60 & 7.8 & 7.1 & 6.5 & 5.9 & 5.2 & 4.6 & 4.0 & 3.4 & 2.7 & 2.1 & 1.5 & 0.9 & 0.2 \\
\hline & 50 & 5.2 & 4.6 & 4.0 & 3.3 & 2.7 & 2.1 & 1.5 & 0.8 & 0.2 & -0.4 & -1.0 & -1.7 & -2.3 \\
\hline & 40 & 2.7 & 2.1 & 1.5 & 0.8 & 0.2 & -0.4 & -1.1 & -1.7 & -2.3 & -2.9 & -3.6 & -4.2 & -4.8 \\
\hline & 30 & 0.0 & -0.6 & -1.3 & -1.9 & -2.5 & -3.2 & -3.8 & -4.4 & -5.0 & -5.7 & -6.3 & -6.9 & -7.5 \\
\hline & 20 & -3.3 & -3.9 & -4.5 & -5.1 & -5.8 & -6.4 & -7.0 & -7.6 & -8.3 & -8.9 & -9.5 & -10.1 & -10.8 \\
\hline & 15 & -5.3 & -5.9 & -6.5 & -7.1 & -7.8 & -8.4 & -9.0 & -9.7 & -10.3 & -10.9 & -11.5 & -12.2 & -12.8 \\
\hline & 10 & -7.7 & -8.3 & -8.9 & -9.6 & -10.2 & -10.8 & -11.5 & -12.1 & -12.7 & -13.3 & -14.0 & -14.6 & -15.2 \\
\hline & 5 & -11.3 & -12.0 & -12.6 & -13.2 & -13.8 & -14.5 & -15.1 & -15.7 & -16.3 & -17.0 & -17.6 & -18.2 & -18.8 \\
\hline
\end{tabular}


Table A42

Normative data for the Stroop Interference stratified by age and education levels for PARAGUAY

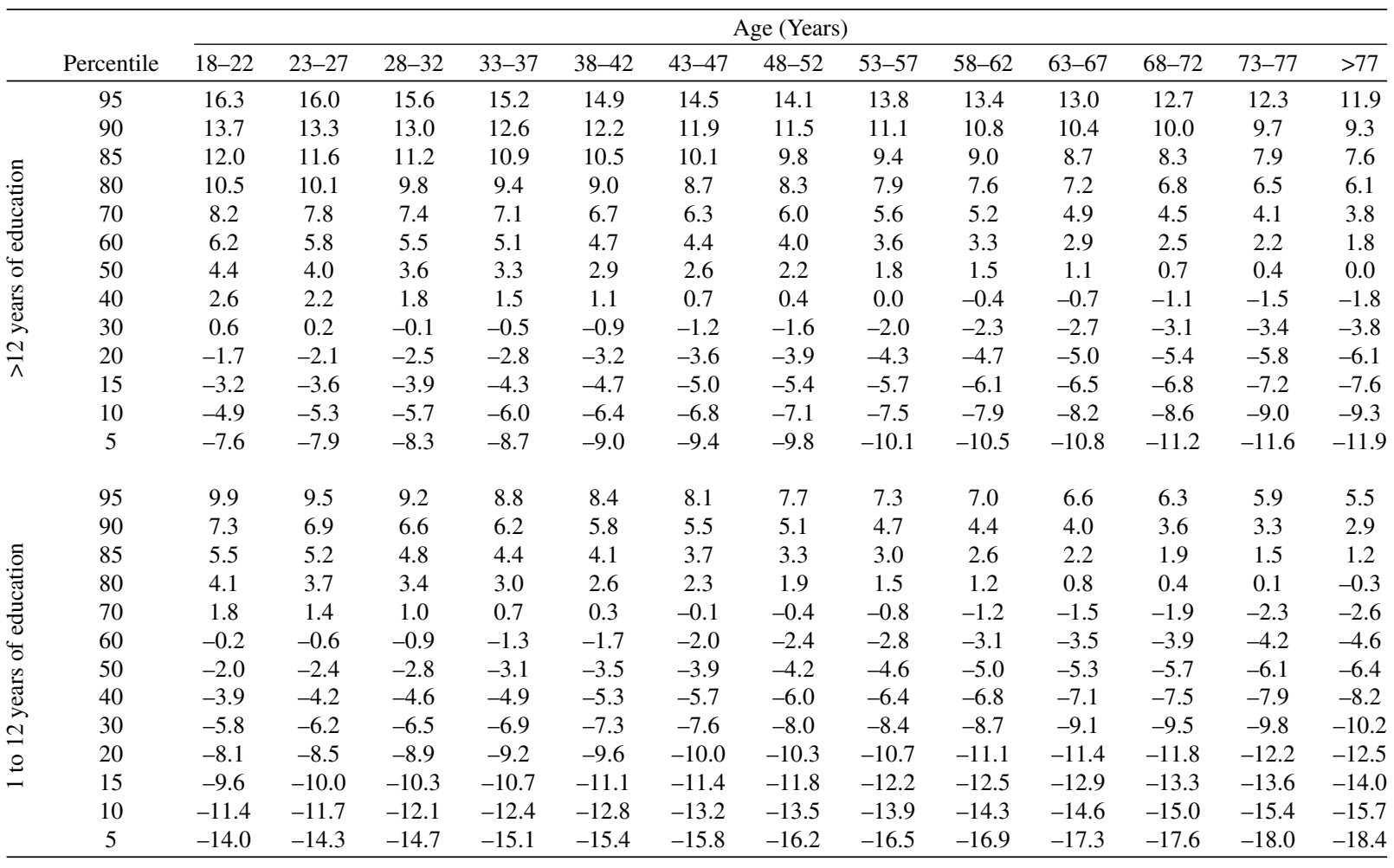

Table A43

Normative data for the Stroop Interference stratified by age for PERU

\begin{tabular}{lccccccccccccc}
\hline & \multicolumn{10}{c}{ Age (Years) } \\
\cline { 2 - 13 } Percentile & $18-22$ & $23-27$ & $28-32$ & $33-37$ & $38-42$ & $43-47$ & $48-52$ & $53-57$ & $58-62$ & $63-67$ & $68-72$ & $73-77$ & $>77$ \\
\hline 95 & 19.9 & 19.1 & 18.3 & 17.5 & 16.6 & 15.8 & 15.0 & 14.2 & 13.4 & 12.6 & 11.8 & 11.0 & 10.2 \\
90 & 16.5 & 15.7 & 14.9 & 14.1 & 13.2 & 12.4 & 11.6 & 10.8 & 10.0 & 9.2 & 8.4 & 7.6 & 6.7 \\
85 & 14.2 & 13.4 & 12.6 & 11.8 & 11.0 & 10.2 & 9.3 & 8.5 & 7.7 & 6.9 & 6.1 & 5.3 & 4.5 \\
80 & 12.3 & 11.5 & 10.7 & 9.9 & 9.1 & 8.3 & 7.5 & 6.6 & 5.8 & 5.0 & 4.2 & 3.4 & 2.6 \\
70 & 9.3 & 8.5 & 7.7 & 6.9 & 6.0 & 5.2 & 4.4 & 3.6 & 2.8 & 2.0 & 1.2 & 0.4 & -0.4 \\
60 & 6.7 & 5.9 & 5.1 & 4.3 & 3.5 & 2.7 & 1.9 & 1.1 & 0.2 & -0.6 & -1.4 & -2.2 & -3.0 \\
50 & 4.4 & 3.6 & 2.8 & 1.9 & 1.1 & 0.3 & -0.5 & -1.3 & -2.1 & -2.9 & -3.7 & -4.6 & -5.4 \\
40 & 2.0 & 1.2 & 0.4 & -0.4 & -1.2 & -2.1 & -2.9 & -3.7 & -4.5 & -5.3 & -6.1 & -6.9 & -7.7 \\
30 & -0.5 & -1.4 & -2.2 & -3.0 & -3.8 & -4.6 & -5.4 & -6.2 & -7.0 & -7.9 & -8.7 & -9.5 & -10.3 \\
20 & -3.6 & -4.4 & -5.2 & -6.0 & -6.8 & -7.6 & -8.4 & -9.3 & -10.1 & -10.9 & -11.7 & -12.5 & -13.3 \\
15 & -5.5 & -6.3 & -7.1 & -7.9 & -8.7 & -9.5 & -10.3 & -11.2 & -12.0 & -12.8 & -13.6 & -14.4 & -15.2 \\
10 & -7.7 & -8.6 & -9.4 & -10.2 & -11.0 & -11.8 & -12.6 & -13.4 & -14.2 & -15.0 & -15.9 & -16.7 & -17.5 \\
5 & -11.1 & -12.0 & -12.8 & -13.6 & -14.4 & -15.2 & -16.0 & -16.8 & -17.6 & -18.5 & -19.3 & -20.1 & -20.9 \\
\hline
\end{tabular}


Table A44

Normative data for the Stroop Interference stratified by age for PUERTO RICO

\begin{tabular}{lcccccccccccccc}
\hline & \multicolumn{10}{c}{ Age (Years) } \\
\cline { 2 - 12 } Percentile & $18-22$ & $23-27$ & $28-32$ & $33-37$ & $38-42$ & $43-47$ & $48-52$ & $53-57$ & $58-62$ & $63-67$ & $68-72$ & $73-77$ & $>77$ \\
\hline 95 & 25.3 & 24.1 & 23.0 & 21.9 & 20.7 & 19.6 & 18.4 & 17.3 & 16.2 & 15.0 & 13.9 & 12.8 & 11.6 \\
90 & 21.7 & 20.5 & 19.4 & 18.3 & 17.1 & 16.0 & 14.8 & 13.7 & 12.6 & 11.4 & 10.3 & 9.2 & 8.0 \\
85 & 19.3 & 18.1 & 17.0 & 15.9 & 14.7 & 13.6 & 12.4 & 11.3 & 10.2 & 9.0 & 7.9 & 6.8 & 5.6 \\
80 & 17.3 & 16.1 & 15.0 & 13.9 & 12.7 & 11.6 & 10.4 & 9.3 & 8.2 & 7.0 & 5.9 & 4.8 & 3.6 \\
70 & 14.1 & 12.9 & 11.8 & 10.7 & 9.5 & 8.4 & 7.2 & 6.1 & 5.0 & 3.8 & 2.7 & 1.6 & 0.4 \\
60 & 11.4 & 10.2 & 9.1 & 8.0 & 6.8 & 5.7 & 4.5 & 3.4 & 2.3 & 1.1 & 0.0 & -1.1 & -2.3 \\
50 & 8.9 & 7.7 & 6.6 & 5.5 & 4.3 & 3.2 & 2.0 & 0.9 & -0.2 & -1.4 & -2.5 & -3.6 & -4.8 \\
40 & 5.4 & 5.2 & 4.1 & 3.0 & 1.8 & 0.7 & -0.5 & -1.6 & -2.7 & -3.9 & -5.0 & -6.1 & -7.3 \\
30 & 3.7 & 2.5 & 1.4 & 0.3 & -0.9 & -2.0 & -3.2 & -4.3 & -5.4 & -6.6 & -7.7 & -8.8 & -10.0 \\
20 & 0.5 & -0.7 & -1.8 & -2.9 & -4.1 & -5.2 & -6.4 & -7.5 & -8.6 & -9.8 & -10.9 & -12.0 & -13.2 \\
15 & -1.5 & -2.7 & -3.8 & -4.9 & -6.1 & -7.2 & -8.3 & -9.5 & -10.6 & -11.8 & -12.9 & -14.0 & -15.2 \\
10 & -3.9 & -5.1 & -6.2 & -7.3 & -8.5 & -9.6 & -10.7 & -11.9 & -13.0 & -14.2 & -15.3 & -16.4 & -17.6 \\
5 & -7.5 & -8.7 & -9.8 & -10.9 & -12.1 & -13.2 & -14.3 & -15.5 & -16.6 & -17.8 & -18.9 & -20.0 & -21.2 \\
\hline
\end{tabular}

